\title{
PROJECT
}

\section{THE LEGAL PROBLEMS OF THE RURAL POOR*}

\begin{abstract}
"Providing equal justice for poor and rich, weak and powerful alike is an age-old problem. People have never ceased to hope and strive to move closer to that goal." Griffin v. Illinois, 351 U.S. 12, 16 (1956). The Duke Law Journal presents this report of its survey study of the legal problems of the rural poor. It is an attempt initially to lend some insight into the kinds of problems, the methods of resolution, the utilization of services, and the perception of legal or other remedies common to the rural poverty group. The second phase of the study is devoted to assessing the ability of various community leadership figures and service agencies to assist in problem solving by either their own efforts or appropriate referrals. Finally, the activity of the local bar in serving the needs of the poor was evaluated, and suggestions are offered for the problem areas most in need of attention.
\end{abstract}

\section{INTRODUCTION}

$T$ he need for legal services to provide equal justice for the

American poor has been a subject of sporadic interest since the 1924 publication of Reginald Heber Smith's study Justice and the Poor.' American Bar Association field studies of legal assistance in 1938 and 1947 led to the production of E.A. Brownell's Legal Aid in the United States, ${ }^{2}$ an urban-centered report based on extensive field studies which has become the primary work in the field. Since that time a number of more limited studies have been conducted, ${ }^{3}$ primarily in the Eastern urban areas. The advent of the

\footnotetext{
* This study was conducted by the staff of the Duke Law Journal under a grant from the American Bar Foundation, to which the Journal expresses its sincere appreciation. Reprints of the study are available through the Foundation or from the Duke Law Journal.

'R. Smith, Justice AND the POOR (1924).

2 E. Brownell, Legal. Aid in the United States (1951, Supp. 1961).

3See, e.g., B. Seligman, Poverty as a Public Issue (1965).
} 
Office of Economic Opportunity legal services programs has sparked renewed interest in extensive field studies on the legal problems of the poor, the most significant recent example being the urban-oriented Peoria Study conducted by the American Bar Foundation in Peoria, lllinois in 1966.5 Thus far, however, surprisingly little attention has been directed toward the unique legal assistance problems in the rural or small-town setting. ${ }^{6}$

Plans for the extension of the OEO legal services into rural and small town communities have created a pressing need for field studies probing the legal problems and needs of the rural poor, especially in the southeast section of the United States where the rural poor population is high. The uniqueness of this region-with its tenant farming system, its large numbers of small farm operators, its lingering racial problems, and its substantial population below the federal poverty level ${ }^{7}$ necessitates a specialized study of its legal problems. Moreover, the essentially rural social conditions found in the southeast and the general absence of urban centers from which services and information might emanate are characteristics common to any rural area in the United States. Analysis of the impact of such features upon effective legal assistance should therefore be helpful to efforts in rural communities throughout the nation. ${ }^{8}$ With that in mind, the Duke

' Economic Opportunity Act of 1964, 42 U.S.C. $\$ \$ 2781-2791$ (1964). These sections provide for the establishment of neighborhood law offices in low-income areas. In conjunction with community education programs, legal services are furnished for indigent clients who cannot afford the advice and representation of a private attorney.

${ }^{3}$ American Bar Foundation. Peoria General Community Survey (1966) thereinafter cited as Peoria Study] (copy on file with Duke Law Journal; additional copies should be obtained from the American Bar Foundation).

- But see Symposium: The War on Poverty, Legal Services, and the Rural Poor, 15 Kan. L. Rev. 401 (1967); cf.. e.g., Beatty \& Wilkinson, Survey on Defense of Indigent Accused Persons in Alabama, 17 ALA. L. Rev. 43 (1964); S!mposium: A Legal Services Program for West Virginia, 70 W. VA. L. REv. 277 (1968).

' For information on the percent of rural poor in the South, or other such information, contact: Office of Economic Opportunity, 19th St. Office, Information Center, Washington, D.C. Current data will be given if the contact is by phone.

For additional information contact Miss Linda Riley, O.E.O. Office, Durham, North Carolina.

* It should be noted that the area here studied differs significantly from the Appalachian areas in the rural poverty belt. While counties in the Appalachian areas are the least populated and among the poorest in North Carolina, they are not representative of the southern agricultural community. Farming operations are not extensive in Appalachia nor is the tenant farmer relationship prevalent. Unemployment is generally higher. The 
Law Journal with the assistance of the American Bar Foundation, undertook during the summer and fall of 1968 a detailed field study of the legal problems of the rural poor in an eastern North Carolina county ${ }^{9}$ typical of the rural poverty belt.

The primary purposes of this study were (1) to determine the types of legal problems confronting the rural poor person (2) to ascertain whether he perceived those problems as "legal" (3) to discover the typical methods and institutional sources employed in solving these problems (4) to assess the effectiveness of sources utilized, (5) to identify the factors operative in increasing legal perception and problem-solving ability, and (6) to suggest direction for resolution of the particular problems revealed by the study. To achieve this last end knowledge of existing community services was tested to determine the degree to which a failure in communications between the poor and service agencies impeded problem resolution. An assessment of the ability of service and "community leadership" personnel to recognize problems, legal and otherwise, and to make referrals to appropriate problem-solving sources was considered crucial to an accurate evaluation of the services effectively available and of the channels of communication which can be utilized to create an awareness of legal remedies as a problem solving method. Testing the proficiency of the community leadership group in recognizing and referring legal and other problems was thus an important part of the study. Finally the activity of the local bar in servicing poverty-level clients and the low-income group's general willingness to seek legal assistance were surveyed. By way of analysis, an attempt was made to determine why some individuals possessed awareness of the legal aspects of their problems and were willing to take affirmative action, legal or otherwise, toward problem resolution, while other persons neither effectively perceived nor attempted to solve similar problems.

Appalachian areas are almost entirely white while the vast portion of the rural South has a significant Negro population. Because of these differences, many of the conclusions suggested by the instant study may not hold true for the Appalachian areas where the plight of the rural poor appears worse than in the more productive agricultural areas. See M. Brooks, The Dimensions of Poverty in North Carolina (1964) [hereinafter cited as Brooks].

- Since much of the information reported in the study was obtained in confidence the name of the sample county will not be revealed. Because of the smallness of service operations in the county, the mere naming of the agency would reveal the personnel interviewed. Where exact statistical figures would also result in recognition of the county, approximations are utilized in their place. Citation to authority is also omitted when it would reveal the sample county. 


\section{Selection of the Sample County}

The eastern North Carolina county selected as representative of the rural situation in the South has a low population density, a large percentage of its acreage devoted to agricultural uses, and a correspondingly low incidence of metropolitan development. North Carolina Fund ${ }^{10}$ figures indicate that the sample county is about $50 \%$ rural farm and 50\% rural non-farm land with no metropolitan areas. Within its 460 square miles lives a population of about 11,000 . The largest concentrations of population exist in three small communities each about 10 miles apart along the main road through the county. The population of these communities are about 400,450 and 900 respectively." The remainder of the population is dispersed throughout the county with some concentration along the county highways. Around 40 miles outside the sample county are two larger towns with populations of approximately $25,000.12$ The primary occupation of residents of the county is in agriculture, 46 percent of the working force engaged in farm-related tasks, while only 9 percent are engaged in industry ${ }^{13}$ and 16 percent in white collar or community service occupations." Although the unemployment percentage is quite low, around 6 percent, more than 46 percent of the work force is employed for less than 40 weeks during the year. There are 974 farms operated in the county, with an average gross income of $\$ 9,200$ per farm.

1" The North Carolina Fund was a non-profit, charitable corporation incorporated in 1963 to study the problems involved in improving the education, economic opportunities and living environment in North Carolina. The Fund undertook several research projects concerning the poor in North Carolina and established agenciés such as Manpower, Incorporated, a job finding service, which are now operating independently. The Fund's five-year program expired in 1968. The Duke Law Journal is indebted to the staff of the North Carolina Fund for assistance and advice in the preparation of this study.

"No interviews of the poverty group were conducted within the municipal limits of any of these towns. The population of the towns was for the most part white middle-income families.

12 A substantial number of county residents, over $10 \%$, commute to employment in towns outside the county. However, few of the lower income group are in this category. See North Carolina Mental. Health Planning Staff, Baseline Maps for mental Health Planning in North Carolina 8 (1965) thereinafter cited as Mental. Health].

13 Pulp wood harvesting is the only industry having significant operations in the county. Smaller portions of the population are involved in construction work or are owners or employees of small business establishments.

"The figures reported are approximations of those provided in Brooks. supra note 8, or in U.S. Bureau of Census, 1960 Census of Population: Charactertstics of population pt. 35 (1960) [hereinafter cited as 1960 Census]. 
The sample county's agriculture, and, concommitantly, a large part of its economic prosperity are dependent upon a fluctuating tobacco market. A large proportion of those in the under $\$ 3,000$ income bracket work in tobacco, some on small tenant operations, but a much larger number work as hourly employees, receiving between $\$ .90$ and $\$ 1.20$ per hour for their labor. The recent establishment of a federal minimum wage of $\$ 1.30$ per hour ${ }^{15}$ for agricultural employees has resulted in a reduction in the number of tenant operations and, consequently, the number of day hands hired, at least among those employers who have complied with the minimum wage. The landlord-tenant relationship in general appears to be rapidly passing from the scene. The smaller tenants do not have the capital available before harvest to acquire sufficient labor to operate more than a family-sized holding, and it appears more profitable for the large land owners to rent the land outright or to farm it themselves with a hired crew..$^{16}$

The old tenant houses continue to dot the landscape of the farming areas and are often occupied at little or no rent ${ }^{17}$ by those whom the landowner intends to employ as tobacco hands. Most of these tenant houses, along with some rental housing and small single dwellings on individually owned lots, ${ }^{18}$ make up the 70 percent of housing in the county classified as unsound or having inadequate plumbing facilities. ${ }^{19}$

\footnotetext{
${ }^{15}$ Fair Labor Standards Áct of 1938, as amended, 29 U.S.C. $\$ \$ 201-02$ (Supp. 1968). Effective February 1, 1969, a minimum wage of $\$ 1.30$ an hour must be paid to every worker who is employed in certain prescribed agricultural work by an employer who used more than 500 man-days of farm labor in any calendar quarter of the preceding calendar year.

"The U.S. Department of Agriculture agent in the county reported the growth of a practice known as "contract" farming. Crews of migrant workers are brought onto the land to perform various seasonal operations, and the land owner pays the crew leader a flat fee for the service rather than paying the individual workers. In this fashion the farmer can avoid concerning himself with whether the minimum wage is in fact being met. The crews generally work the farm circuit from Florida up through the Southeast, some going as far as New Jersey or Connecticut.

${ }^{17}$ The land owners will often provide housing for little or no rent in order to have field hands available for seasonal agricultural employment. They pay the employees. by the day as they are needed rather tban entering into a profit-sharing tenant farmer relationship with them. People living in this situation will be referred to as "quasi-tenants" throughout the study. Sce note 154 infra and accompanying text.

1" The Farmers Home Administration agent, who is involved in providing home construction and improvement loans, reported that home lots along roads in the county can generally be acquired for as low as $\$ 100$.

1" Brooks, supra note 8 , at 41 .
} 
The median family income for the county is approximately $\$ 2,300$ per year with over 1400 families, or 60 percent of the population, below the $\$ 3,000$ level. ${ }^{20}$ The racial breakdown of families below the poverty line is 52 percent white, 48 percent Negro. The population per household of Negro families, however, was somewhat higher than that for white households. ${ }^{21}$ Most of the remainder of the population fell within the $\$ 3,000-6,000$ income range. Although all of the more substantial farm operators handled many times this amount in the course of a year's business, several reported a net return within this bracket.

As is the case in urban and rural communities in both the North and South, race relations is considered one of the most significant social issues facing the community. Racial integration in the county schools is a fairly recent phenomenon. When the decision was made to consolidate the county high schools in 1950, two identical facilities were built, each an equal distance from the center of the county seat. Until 1965 these high schools as well as the grade schools were operated on a segregated basis. Then a freedom of choice plan was instituted under the impetus of a federal court order. Twenty-five. Negro students entered the "integrated" high school, the remainder continuing to attend the separate facility. With the rejection of freedom of choice by the Justice Department and the courts, ${ }^{22}$ the county school board again found itself under desegregation orders from the federal court. A local association of school teachers filed suit against the school board to enjoin the implementation of the board's plan for 1968 on the ground that it also fell short of the federal guidelines. Their primary concern was that the school program not be deprived of federal funds.

A local lunchroom and pool hall was desegregated by federal court order in early 1968. Other public accommodations were available on an integrated basis, although for the most part they did not appear to be so used. Social and economic pressure against

\footnotetext{
$201 d$. at 7.

${ }^{21} 1960$ Census, supra note 15, pt. 35, at 126, 280, 295.

2 See Green v. County School Bd., 39 I U.S. 430 (1968); United States v. Jefferson County Bd. of Educ., 372 F.2d 836 (5th Cir. 1966), aff'd en banc, 380 F.2d 385 (5th Cir. 1967), cert. denied, 389 U.S. 840 (1967); see 81 HaRv. L. REv. 474 (1967); 21 VaND. L. Rfv. 1093 (1968). But see Avins, Toward freedom of (hoice in Education, 45 J. URBAN L. 23, 106 (1967).
} 
integration no doubt still remains high. Although the local chapter of NAACP has been active in desegregation efforts, it has mainly relied upon legal action rather than demonstration and a substantial part of the black population has shown some hesitancy to become involved in NAACP activity. ${ }^{23}$ in the summer of 1968 , however, a Negro demonstration against the elimination of welfare benefits during the tobacco season was held without incident in the county seat. Although feelings surrounding racial issues certainly run strong among the white community, and an increasingly more militant attitude is apparent among some of the black leaders, no incidents of organized violence have yet been traceable to racial conflict within the county. Since the vast majority of jobs for individuals in the $\$ 3,000$ income bracket are found in agricultural labor, little racial discrimination in employment exists for the poverty classes. ${ }^{24}$ Jobs are unskilled and highly seasonal, and during peaks of the agricultural season, labor is in great demand. Aside from agriculture, the state and federal governments are the largest employers and for the most part evidence no discrimination. ${ }^{25}$

The level of education in the sample county is nearly average for North Carolina rural areas, the median years of schooling for adults over 25 being eight years. ${ }^{26}$ More than 18 percent of the population over 25 , however, attended school for less than five years. The number of high school dropouts both in the sample and

None of the sample group reported being NAACP members. The NAACP membership in the county is primarily made up of middle income Negroes such as school teachers and OEO workers.

"Although most of the landlords and agricultural employers demonstrated some racial bias in areas such as welfare, they all reported that they had both black and white employees and did not find one race or the other in the low income level to be more capable or harder working. Compare how North Carolina -Whites aNd Blacks VIEW: Each other. Governient ANd Police, Housing. Poverty. EduCation aNi) linjployment (Summaty of a 1968 Opinion Poll conducted by Oliver Quayle \& Company for the North Carolina Fund.) Furthermore, they did not report paying different wages on the basis of race. Employers apparently found it very difficult to obtain satisfactory labor, and when they found a good worker of either race they reportedly went to some extremes to keep him in their employment. See textual paragraph following note 199 infra. But see text accompanying note 199 infra.

$\approx$ The post office, extension service, department of agriculture, health department and highway department all had some Negro employees. While the welfare department secretarial staff was integrated, each of the five caseworkers was white.

${ }^{38}$ This figure is somewhat deceptive since until after 1945 the Negro high school was not a significant operation and did not offer an educational program beyond the tenth grade. Interview with school board official. 
surrounding rural counties is lower than that in many of the more urban and industrialized North Carolina counties. ${ }^{27}$ The lack of employment opportunity for the population in general during the winter months probably has a direct bearing on this factor. There are no colleges or technical institutions within the county, although adjoining counties have a community college and a technical school. A public library in each of the three towns and a bookmobile serve the county. The state and federal agencies operating in the county, including the state Agricultural Extension Service, the U.S. Department of Agriculture, the county welfare department, the county health department, the county sheriff's office and the OEO, have offices only in the county seat. Since the county is a large geographic area, transportation to the county seat is itself one of the greatest problems in the utilization of services. ${ }^{28}$ One full-time general prảctitioner and one part-time county health department doctor in the county, seat provide the entire medical service within the county: The county bar has three actively practicing members also located in the county seat. No dentists and no Negro medical doctors or lawyers are presently working in the county.

The OEO operates or has operated Neighborhood Youth Corps, ${ }^{29}$. Project Headstart, ${ }^{30}$ summer recreation, ${ }^{31}$ community worker ${ }^{32}$ and sanitation programs $\mathrm{s}^{33}$-the latter two providing a mobile service reaching the more remote areas of the county. The

${ }^{27}$ See Brooks, supra note 8, at 20.

2" See Peoria Study'at 64.

2 Economic Opportunity Act of 1964, 42 U.S.C. \$ $\$ 2731-2736$ (1964). The Youth Corps is a three-part program for high school age children from low income families. The inschool, summer and out-of-school programs provide encouragement to gain additional education, summer jobs, part-time employment and on-the-job training.

${ }^{30}$ Economic Opportunity Act of 1964, 42 U.S.C. $\$ \$ 2781-2791$ (1964). Head Start is a child development program which offers the economically disadvantaged pre-school child varying learning experiences, medical and dental examinations and in some cases, treatment and proper nutrition. The purpose is to enable the child of a poverty family to begin his school career on more equal terms with his more fortunate classmates.

" Economic Opportunity Act of 1964, 42 U.S.C. $\$ \$ 2781-2791$ (1964). Community action programs mobilize community resources to help families combat the problems of poverty. These programs cncourage the participation of the poor in planning, policy-making and operation of the program's special projects.

* See text accompanying note 188 infra.

is The sanitation program operates under the authorization for community-action activities. See 42 U.S.C. $\$ \S \cdot 2781-2791$ (1964). 
state Agricultural Extension Service also conducts a visiting homemaker program..$^{34}$ Churches often serve as a focal point of group activities in the local areas isolated from the county seat. ${ }^{35} \mathrm{~A}$ private country club with golf course and swimming pool built with the aid of federal agriculture loan funds ${ }^{36}$ provides a center of activities for the more well-to-do citizenry.

The county has a commission form of government with five elected commissioners, each of whom has other full-time employment. The commissioners are charged with thc administration on the county level of state agencies such as the health and welfare departments and the county court system, as well as the organization of local governmental programs authorized by North Carolina state statute. The clerk of the court, sheriff, justice of the peace, county attorney and the school board make up the balance of the elected officials. ${ }^{37}$

The county's crime rate is among the lowest in the state for white males and falls in the second lowest category for non-white males, based upon figures for the number of convictions. ${ }^{38}$ The county reported no juvenile delinquency cases for the period covered by the 1960 census, ranking lowest among the 24 rural counties reporting the lowest levels of delinquency.

s The visiting homemaker program of the Agricultural Extension Service seeks to bring a variety of home economics and other information to housewives in rural areas. Home demonstration clubs are organized and cooking and domestic arts as well as sanitation and home repair are among the subjects discussed.

is While the incidence of church membership was high among the sample group, church related activities other than attendance at religious services were very limited. The local ministers reported that most church group participation was from the middle and higher income groups.

* Consolidated Farmers Home Administration Act of 1961, 7 U.S.C. \$\$ 1921-1928 (1964). Among other things, this program provides loans for recreational enterprises to farmers and ranchers who personally manage and operate not larger than family farms, so that they may develop enterprises that will supplement their farm incomes.

"See J. Sanders, Selection of North Carolina State Governmental Officials (1964).

3x See Mental Health, supra note 12, at 65-68. See also textual paragraph infra accompanying note 77 . Of course these figures do not include unreported crimes or cases where there was an acquittal or decision not to prosecute. The prosecutor's discretion might also, to some extent, account for the difference in convictions betwecn white and Negro defendants-about four blacks are convicted for every white conviction. Although figures were not available for the total number of crimes reported, the sheriff indicated a belief that the number was very' low in comparison to more densely populated counties. On the other hand, he did recognize that many crimes went unreported. Interview with sheriff. 
Economic prospects for the future of the county are not particularly bright. The net out-migration of young adults $\mathrm{s}^{39}$ is high, close to 40 percent for the period 1950 to 1960 . The enrollment in the county high school is decreasing and the average age of county residents is continuously rising. With the decrease in the number of farms operating and the scope of farming operations, in addition to the use of migrant crew farm labor, employment opportunity for county residents continuously lessens. Unemployment-in absolute terms-increased by over 10 percent for the years $1950-1960 .^{10}$ The number of residents commuting a long distance to work outside the county, and the number being permanently relocated in employment outside the county by the North Carolina Fund's Manpower Employment Service," are other figures that should be considered as part of the employment decline. Groups within the county are concerned with the outward migration of the young, and recognize its direct relation to employment opportunity. Attempts have been made to attract industry, but the lack of a.centralized work force, a general resistance to change among certain of the county leaders, and the absence of any industrial skills among the vast majority of the available personnel have been a severe impediment to efforts thus far..$^{22}$

\section{The Survey Method}

The survey study of the sample county was conducted on two levels, the first consisting of a questionnaire ${ }^{3}$ administered to a sample group of residents in the $\$ 3,000$ income bracket, $\$ 4$ in selected areas of the county. Information garnered from this survey was in turn utilized in unstructured interviews with the "community leadership" group in an attempt to ascertain the leaders' perception of problems facing the poor and the methods of

\footnotetext{
33 This figure is computed on the basis of percentage of change in persons aged 5-19 in 1950 who were 15-29 in 1960. See Mental Health supra note 12, at 3-5.

Id. at 13.

"Id. at 7.

12 The primary group involved in this area is the Technical Action Panel (TAP) discussed at text immediately preceding note 187 infra and accompanying text.

t5 The questionnaire is reproduced in Appendix B. The Duke Law Journal is indebted to the American Bar Foundation for the basic outline of the questionnaire, which was utilized in the Foundation's Peoria Study, supra note 5. Assistance in the preparation of the questionnaire from the North Carolina Fund, the departments of sociology at Duke University and North Carolina College, and the Research Triangle Institute was also helpful.

"The following values are used by the $O E O$ as revised $O E O$ income poverty guidelines:
} 
resolution the leaders would provide or recommend by way of referral. lmportant to this probe was a test of knowledge concerning the available assistance and service programs. Special attention was also given to the leaders' understanding of a problem as "legal" and their willingness to suggest a legal solution to persons in the low income bracket.

\section{The Sample Group for "Questionnaire" Interviews}

Seven areas of somewhat concentrated poor population were selected within the county. These areas were distributed throughout the county, and each region in which there was a significant concentration of population was represented by an area. Within each area a random sample was selected by identifying dwellings on a map prepared from aerial photographs showing every dwelling in the county. ${ }^{45}$ Sample dwellings were selected by choosing every third or every fourth one within an area, depending upon the area's size. Before an interview was commenced it was determined whether a sample dwelling was being occupied by a Negro or white family, and an interviewer of the same race as the subject was utilized..$^{48}$ An effort was made, in determining the sample area, to provide for a number of white and Negro dwellings within the area somewhat in proportion to the racial breakdown of the county's poor. ${ }^{47}$ In two

\begin{tabular}{ccc}
\hline Family Size & Non-Farm & Farm \\
\cline { 2 - 3 } 3 & $\$ 2,500$ & $\$ 1,700$ \\
4 & 3,200 & 2,200 \\
5 & 3,800 & 2,600 \\
6 & 4,200 & 3,000 \\
7 & 4,700 & 3,300 \\
8 & 5,300 & 3,700 \\
9 & 5,800 & 4,000 \\
10 & 6,300 & 4,400 \\
11 & 6,800 & 4,700 \\
12 & 7,300 & 5,100 \\
13 & 7,800 & 5,400
\end{tabular}

O.E.O. Instruction \# 6004-1 (Dec. 27, 1968). See also M. HaRrington. The OTher AMERICA app. 171-86 (1967).

is The Duke Law Journal is especially grateful to the Research Triangle Institute for the use of this map.

so Because of racial tensions, sociologists advised that freer responses could be elicited from respondents by interviewers of their own race.

$"$ Figures from the 1960 Census indicated that 680 non-white families and 730 white 
areas of population this was impossible since they were almost entirely white or Negro. In sampling these two areas an attempt was made in determining the number to be sampled to maintain a ratio of black to white interviews in proportion to the racial breakdown of the county poor. The final result was that the racial breakdown of the interviews obtained approximated the racial composition of the county poor ${ }^{48}$

A team of seven interviewers consisting of students from North Carolina College and Duke University law schools administered the questionnaires over a two-week period. All of the interviewers were indigenous to the eastern North Carolina area. A brief training session for the interviewers was conducted with the assistance of personnel from the North Carolina Fund and the Research Triangle Institute, both of which have conducted extensive questionnaire studies with the same type of sample group. After the training session a "pilot run" of the questionnaire was undertaken by each of the seven interviewers in rural areas surrounding Durham, North Carolina. As a result of this test certain linguistic adjustments and other refinements were made in the questionnaire.

The questionnaire itself was patterned after one utilized by the American Bar Foundation in its Peoria Study.9 The questionnaire proceeded by first ascertaining the family income of the subject being interviewed.$^{50}$ If the subject's family income was below $\$ 3,000$ the questionnaire was administered or an appointment was made for a later interview session. If the subject was a married female, an attempt was made to arrange an interview with her husband. If she was reluctant to do so, the questionnaire was administered to her. The questionnaire was divided into four sections. The first section posed a series of hypothetical problems covering social security, landlord-tenant, child custody, consumer protection, debtor-

families in the county fell below the $\$ 3000$ income level. For purposes of racial balance in the sample group, therefore, efforts were made to obtain $48 \%$ of the interviews from non-white families.

is Of the 198 interviews obtained, 94 were with Negroes and 104 were with whites. Because of the relatively small sample some caution should be exercised in drawing general conclusions, although it is believed that the manner in which the sample was selected lends considerably to the representative value of findings.

"Sec note 5 supra.

so The interviewers informed the subjects that they were from Duke University and were conducting a study in problem solving. No mention of the law school or legal problems was made in order to avoid orienting the subjects toward legal responses. 
creditor, agricultural lien, will and estate, and criminal problems. The subject was asked what if anything he would do if confronted with these problems. The second questionnaire section probed the subject's knowledge of resources available for problem solving and his experience in utilizing these resources. Knowledge about the availability of legal services through private counsel ${ }^{51}$ was tested along with the level of information concerning various service programs such as welfare, surplus food, ${ }^{52}$ birth control, public housing, home improvement and construction loans, ${ }^{53}$ the health department, and the agricultural extension service. In this section the subject was asked if he knew of a particular service; he was asked to choose from several possibilities the function which that service performed; and he was asked about any personal experiences he had had with the service. Part three of the questionnaire inquired into actual problems with which the subject previously had been confronted.5 What the subject did about the problem, from whom he sought advice, or alternatively, why he did nothing about the problem, were the answers sought through a series of questions.

Part four was directed toward eliciting background information about the subject including education, family relations, voting,

81 There are no organized legal service programs operating in the county. The Committee on Indigent Legal Services of the North Carolina Bar Association had no formal operations in the county, see text following note 117 infra, and indeed members of the local bar had no knowledge of its existence. Primarily, the work of the North Carolina Bar Committee on Indigent Legal Services has been to attempt to arrange legal services for any indigent persons who have asked the Bar Association for assistance. To do this, members of the Legal Aid Committee are appointed each year by the President of the North Carolina Bar Association in each of the state's judicial districts. When a request for legal assistance is reeeived by the North Carolina Bar Association, it is forwarded by the Chairman to one of the associate members of the Legal Aid Committee in the judicial district from which the request originated. The associate members of the Legal Aid Committee have a responsibility for seeing that the indigent receives the services requested, although the associate member will normally refer the matter to some other lawyer in the area. Although services are provided all over the state, the need is greatest in the rural areas, and the Committee is primarily concerned with requests for assistance coming from the rural or less populated areas. Letter from David M. Clark, Chairman, Legal Aid Committee, N.C. Bar Ass'n, to the Duke Law Journal, April 29, 1969.

S2. See note 98 infra.

See note 106 infra and App. A.

H The areas probed included workman's compensation, wage collection, social security and unemployment denials, welfare cuts and terminations, consumer frauds and overcharges, loan and credit problems, housing repair and rental difficulties, child custody and divorce, and criminal and juvenile delinquency problems. 
church and club or organization activity. Although the questionnaire was quite long and took about one hour to administer, the interviewers found the poor population to be extremely cooperative, ${ }^{55}$ the refusal or termination ratio being less than 3 percent. A total of 198 usable interviews were conducted.

\section{The Community Leader Interviews}

The interviews of "community leaders"'56 including federal and state agency employees, county governmental officials, OEO personnel, school authorities, ministers, businessmen, agricultural landlords, employers and the local bar were conducted by two members of the Duke Law Journal staff. Appointments and introductions were arranged through personal contacts within the county.

The community leader interviews were unstructured.57 The subjects, except for the local attorneys, whose approval of the study was obtained beforehand, were informed that the interviewers were conducting a study in "problem solving" for Duke University. Anything relating the interview with law or lawyers was avoided at the beginning of the interview. ${ }^{58}$ In conversation the subjects were presented with a variety of hypothetical problems and asked what advice they would give to a poor person coming to them with such a problem. The hypothetical areas covered were the same as those utilized in the first section of the questionnaire. If the subject, when confronted with a problem having legal overtones, responded that he would suggest a lawyer, he was asked whether he would actually send a poor person to a lawyer, how often he had done so, and if not, why not? If the subject indicated that knowledge of the expense of legal services would prevent him from recommending a lawyer,

\footnotetext{
${ }^{3 s}$ Only one white interviewer reported being subjected to any hostility. He was ordered off certain property for being a "damned integrationer."

st Persons to whom the sample group resorted for advice, as well as others who might be expected to be sources of assistance or information, were included in the leadership group. The leaders interviewed are enumerated in Part 11 of the Study.

$s \pi$ The interviews were approached in a conversational fashion. A basic outline of problems to be included was relied upon, but for the most part the subjects were encouraged to volunteer information and to discuss their own views and experiences in regard to particular problems rather than respond to a list of questions which might suggest some particular response.

sx See note 57 supra and accompanying text.
} 
he was questioned about the availability of free services, and contingent fee or time payment arrangements. the subjects were also interrogated about their knowledge of existing assistance programs, both state and federal, with which they might be expected to have some relation. Attention here was directed toward knowledge of programs provided by other agencies as well as their own and the ability to make appropriate referrals. Subjects were then asked about their personal knowledge of specific problems which confronted the poor of the county. They were asked about the ultimate resolution of the particular problems they mentioned and about what advice or assistance they did or would provide.

The community leader interviews averaged around two hours, although some involved more than one two-hour session. The cooperation received from all parties interviewed was excellent, and although it was sometimes difficult to schedule a convenient time, no one flatly refused an interview. Since the interviewing did take place over a two-week period, however, the interviewers suspected that as time passed, many of the subjects became aware of the nature of the questioning before their interview, and were substantially more inclined to give a legally-oriented response. ${ }^{59}$ Since this was to some degree expected in so small a community, efforts were made to compensate for this factor by interviewing parties expected to be most familiar with legal implications later in the two-week period.

\section{PART I:}

\section{The Questionnaire STUdY}

\section{The Hypothetical Problems}

The questionnaire began with a series of nine hypothetical problems through which the subject was asked what he would do if confronted with a similar situation. These hypotheticals were generally utilized to test perception of a problem as legal, ${ }^{60}$

\footnotetext{
ss The clerk of the court, for instance, ended his interview by saying that he knew the interviewers were there to demonstrate that the government should provide free legal services, and asked how long it would be before a program was initiated.

${ }^{B 0} \mathrm{~A}$ number of the questions (one, three, four, six, seven, eight and nine) were designed to present the extreme case, where alternatives other than legal help were already exhausted or not feasible. Questions 2 and 5 involving a rental housing problem and the inability to pay
} 
knowledge of legal and other problem-solving means, and willingness to take action. They were also aimed at determining the correlation, if any, between environmental factors-education, employment, and actual problem experience-and the ability to recognize and utilize an effective problem solving means, legal or otherwise.

Question one involved an unjustified denial of social security benefits. Only 15 of the 198 subjects indicated they would pursue the matter with the social security office. A slightly larger number, 19 , chose the county welfare department for help. Surprisingly, four of the 19 were not and had never been welfare clients; apparently, however, the welfare department has been quite active in seeking social security benefits and ironing out difficulties for applicants, and on occasion, has assisted non-welfare recipients with these problems as well. ${ }^{61}$

The great majority responded that they would either do nothing or that they did not know what they should do. The group opting to "do nothing" about this problem was significantly larger than for any other problem posed. The absence of a social security office within the county may well account for the unfamiliarity with remedies and procedures available. Indeed, although those actually receiving social security benefits (48) showed greater willingness to appeal to the social security office or consult the welfare department ${ }^{62}$ than the sample group in general, a substantial portion of the social security group(18) was unable to suggest any remedy. This figure

off a loan were directed more toward determining means of resolution other than presenting a problem for which only a lawyer could be of assistance. (A lawyer could not be of much assistance with the rental housing problem, because most of the housing in the county was not covered by any housing code. See N.C. GEN. STAT. $\S$ 143-138 (1964)). Moreover, use of a "lawyer" would not necessarily be the only appropriate or effective means of solving any of the problems. For example, stopping payment on defective consumer items might be just as effective as seeking legal help. Attention was given, therefore, not only to the ability to perceive problems as legal and suggest legal resolutions, but also to knowledge of other effective problem solving means.

"I Information about service agency activities not reported in the questionnaire, such as the welfare department's assistance with social security matters, was obtained through interviews with the individual agencies. A discussion of these interviews is the subject of Part 11 of the study.

2 Either continuing to appeal to the social security office or enlisting the aid of the welfare department would be a step toward some resolution. If the welfare department could not successfully resolve the problem, its personnel would probably have referred the subject to a lawyer. See text following note 169 infra. 
suggests that experience with the social security office did not always result in a greater ability to deal with social security problems. The persons most able to suggest some means for handling the social security problem were welfare recipients who could resort to the welfare department for aid. Only five subjects responded that they would seek legal advice, and all five of these were in the "legal activist"'63 category, suggesting legal assistance for at least five of the nine hypothetical problems. A slightly greater number of white respondents thought in terms of seeking aid from the social security office, while a slightly larger number of Negroes relied upon the welfare department for advice. A substantial number of those suggesting these two latter remedies were also in the activist or semi-activist group..$^{64}$

The second hypothetical question involved a landlord's refusal to make repairs to a rented house. The most common resolution suggested was for the tenant to undertake repairs himself, while two other responses frequently noted were to move out or stop paying rent. Study of actual landlord-tenant conflicts that occurred in this area demonstrated that this latter means of self help was effective with "true rental property." 65 The difficulty in rent withholding for the rural tenant farmer is that a signficant number of persons pay

a For purposes of comparing legal perception to a variety of other factors probed, the term "legal activist" will be used. Those classified as legal activists gave legally oriented responses to at least five of the nine hypothetical problems. The usual pattern was a legal response to questions three, six, seven and nine, and either four or eight. For purposes of determining activism, an indication that the subject would make a will was considered a "legal" response to question seven. Attention was given throughout the study to the background, special characteristics and experiences of the activist group, as well as their success in handling actual problems. The responses of those suggesting viable non-legal methods of problem resolution were also compared to a number of factors such as past experience with actual problems, but no clearly definable group giving this type of response emerged. Most often it was the activist or semi-activist, see note 64 infra, who suggested some viable non-legal alternatives for some of the questions, particularly questions two and four.

* The denomination "semi-activist" will be utilized in a fashion similar to that discussed for the "activist" term in note 63 supra. The semi-activists gave legal responses for three or four hypothetical problems. The most common pattern consisted of legal responses to questions three, six and seven, and occasionally to eight or nine.

ss See text infra accompanying notes 154-158 for the discussion of actual housing problems.

For purposes of this study the term "true rental property" refers to a situation where the tenant is making a significant monetary contribution for rent. Often a farmer will permit persons to live on his land for little or no rent in order to have agricultural day labor readily available, and many of the dwellings with which repair problems are experienced are those in 
very little or no rent. ${ }^{66}$ Their refusal to pay is therefore a very minor economic incentive to make repairs to a landlord whose prime interest in making the houses available is not connected with rental income at all but rather with having day labor readily available for work during the farming seasons. A refusal on the part of a tenant to work unless repairs were made might be viewed as the equivalent of a rent stoppage, ${ }^{67}$ but since it involves great hardship in the loss of income to the tenant during the limited season when work is available, few if any would resort to it. ${ }^{68}$

A fairly substantial number (20) indicated that they would take the housing repair problem to the health department. Activity of the health department in the area of sanitation, ${ }^{69}$ including enforcement of the state sanitation laws against those maintaining improper toilet facilities, is probably the main factor motivating resort to this source. ${ }^{70}$ Outside the sanitation area, however, neither the health department nor any other county or state agency could force repairs by a landlord since no building codes are in effect outside the narrow city limits of the county's three towns. Over onefourth of the interviewees responded that they would do nothing or did not know what to do about the problem, and only four persons suggested the aid of a lawyer. Again all of these fell within the "legal activist" classification. A significantly greater number of Negro subjects chose rent stoppage or complaint to the health department while a greater number of white subjects elected to

whieh the landlord has little interest in aetually renting for profit. It is apparently more or less assumed that the tenants will be responsible for repairs.

The landlords for tenant farmers demonstrated slightly different attitudes concerning repairs. The tenant farmer, of course, works for a share of the crop rather than for a farm laborer's daily wages and generally lives on the landlord's property. Although the sharecroppers were expected to be primarily responsible for most of their own repairs, landlords demonstrated more willingness to assist than for the mere farm laborer tenant.

"A total of 58 persons reported living in the tenant or "quasi-tenant" relation, paying a rent of zero to ten dollars per month. See note 17 supra and accompanying text.

"See Note, Rent Withholding and the Improventent of Substandard Housing, 53 CaLlf.

L. Rev. 304 (1965): Tenant Rent Strikes. 3 Colu.M. J. of L. \& Social. Prob. 1 (1967).

a Of the very few instances of eviction that were reported, most resulted from a refusal or inability to work. See textual paragraph preceding note 157 infra.

"See note 189 infra and accompanying text.

70 The sanitation laws of North Carolina arc enforced against "any person owning or controlling any residence, place of business or place of public assembly . . . N.C. GEN. STAT. $\$ 130-128(17)$ (Supp. 1967). See generally N.C. GeN. STAT. $\$ \$ 130-203$ to $130-205$ (1964). 
make their own repairs. This difference may have resulted somewhat from the fact that more Negroes involved in true rentals reported actual experience with housing problems than did white renters. The black population also showed a greater willingness to take advantage of other health department services than did the whites.

Question number three presented a child custody problem wherein one parent had unjustifiably taken the child from the other. Of the nine hypotheticals, only the question involving the commission of a crime by the interviewer's child was more frequently viewed as a legal problem. Almost half of the respondents indicated that they would seek the aid of a lawyer (60) or the court (26) in this custody situation. ${ }^{71}$ While 50 indicated that they did not know what to do, only six stated that they would do nothing. Sixteen reported that they would seek the aid of the welfare department which has often been involved in such disputes; as might be expected all of these were welfare clients. All of the "legal activists" recognized child custody as a legal problem. Although this was the problem with the highest number of "legal" responses, the number of people who chose this question as the only one out of nine for which they suggested a legal remedy was very low. The other question having a high number of legal responses (question six) had a substantial number of respondents that recommended a lawyer's aid only for that one question out of the nine. As one might expect, that question was in the criminal area. A conclusion suggested by this difference is that those inclined to view lawyers and the law as a means of protection or assistance will tend to do so in a broader area than those thinking in terms of the lawyer's function in criminal defense.

The fairly substantial number (26) who indicated that they would seek the aid of the "court" perhaps results from considerable activity by the clerk of the county court as a judicial officer for juvenile proceedings when the court is not in session. ${ }^{72}$

\footnotetext{
"Of course seeking the aid of a lawyer would not be the only means of resolving the child custody problem. Both the welfare department and the clerk of the court, who has the power of a juvenile judicial officer when the court is not in session, see note 72 infra, may also be helpful. The welfare department indicated that it investigates such matters and recommends action to the court. School authorities reported that they refer such problems to the sheriff's office immediately.

72 N.C. GeN. Stat. $§ 110-22$ (1966): "The clerk of the superior court of each county in
} 
Use of the clerk in "getting out a warrant" is a common method of bringing pressure to get voluntary compliance from one's opponent in custody or support matters. ${ }^{73} \mathrm{~A}$ slightly larger portion of the white sample gave a legal response to the custody question while the number of self help responses was slightly higher among the Negroes. Although the child custody problem was one which evoked a high number of legal responses, study into the existence of problems in that area among the sample group revealed not a single actual problem. While experience with actual problems appeared to be somewhat of an educational factor in other problem areas, the lack of an actual experience here did not inhibit the sample group's ability to think in legal terms.

Question four involved the installment purchase of a refrigerator which malfunctioned. Well over half of the sample group indicated that they would stop paying for the item. In the study of actual consumer problems this was indeed the most common method utilized, and it was fairly effective, resulting in very few repossessions. ${ }^{74}$ The number of Negroes suggesting this method was almost twice as great as the number of whites although this was the most common response for both racial groups. A greater number of Negroes also reported having experienced actual problems in this area. A significant number of whites indicated that they would return the item or negotiate with the seller while few Negroes gave this response. The study of actual problems indeed indicated that negotiation with the seller was successful far more frequently for white than for Negro purchasers. Negotiation coupled with a cessation of payments, however, resulted in additional success in the Negro cases. A number of whites (21) indicated that they would attempt to repair the item themselves while only one Negro gave this response. The number of those willing to do nothing or not knowing what to do with this problem (I6) was quite small. Of the thirteen subjects who indicated that

the State shall serve ex officio as judge of the juvenile court in the hearing of cases . . . ." However, a county or municipality may appoint or have elected some other competent and qualified individual.

73 The clerk reported that many women are willing to swear out a warrant for non-support to coerce their husband's cooperation, but few are willing to prosecute beyond the warrant stage. The warrant reportedly is also used in a "quasi-civil" fashion to compel payment for damaged property and dishonored checks. Interview with clerk of court.

"See text infra generally accompanying notes 148-149 for a discussion of actual consumer problems: 
they would seek the aid of a lawyer, ten were Negro whereas only three were white, suggesting some greater suspicion on the part of the Negro population that individual negotiation with the sellers would be unproductive. Again, most of those who suggested seeking the aid of a lawyer were within the activist group. Although no one indicated that they would seek the aid of the welfare department, the caseworkers reported being consulted by clients on consumer difficulties and often negotiating with the seller on behalf of the client.

Question five involved the inability to pay off an overdue loan. The great majority of both black and white respondents indicated that they would seek an extension or work out some alternative payment plan through direct negotiation with the lender. The study of actual problems in this area demonstrated that some variation of this method was utilized in practically every case. ${ }^{i 5}$ Surprisingly, few court actions or foreclosures seem to have resulted. Most subjects indicated that they would deal directly with the lenders rather than seek external advice or assistance. ${ }^{76}$ The three subjects who reported that they would consult a lawyer gave legally-oriented responses in only one or two of the other hypotheticals and were not members of the "legal activist"' group. All three, however, had actually. been involved in serious installment purchase credit problems, perhaps suggesting that their experience made them aware of the value of legal assistance. A surprisingly small number of respondents (24) indicated that they did not know what to do or would ${ }^{*}$ do nothing in the overdue debt situation.

Question six, which involved the arrest of the subject's child for riding in a stolen car, evinced the largest number of "lawyer" responses. ${ }^{77}$ Of the 73 subjects who suggested the aid of a lawyer, however, 54 were Negro and 19 were white. Thirty-two white

\footnotetext{
${ }^{73}$ See text infra accompanying notes $150-153$ for a discussion of actual loan and credit problems.

${ }^{76}$ The welfare department reported considerable activity on behalf of welfare clients in arranging payment extensions. None of the welfare recipients in the sample group, however, indicated that they would take the debt problem to the welfare department or that they had had such help.

THut see responses to question seven concerning the drafting of testamentary conveyances. Rather than giving direet "lawyer" respones to that question, many just said they would draft a will or have one drafted. If "will" and "lawyer" responses are considered equivalents, question seven had the largest total of legally-oriented answers.
} 
respondents indicated that they would attempt to help their child by interceding with the sheriff or the court, while only eight Negroes gave this response. A substantial number of whites also volunteered that they would abide by the court's decision, whereas no such general sentiment was expressed by the Negro group. These figures certainly suggest a greater feeling on the part of the Negro population that professional legal assistance would be needed in a criminal matter, while the whites seemed significantly more confident that some benefit could be gained through informal intersession with the court or police authority.

Another interesting observation concerning hypothetical number six is the fact that a signficant number of subjects who gave a "lawyer" response here gave a legally-oriented response for no other question. This was not the case with any of the other hypotheticals-the common situation being a legal oriented response for at least two of the nine questions if any legal response was given at all. One might conclude from this that those who think of lawyers in terms of defense to criminal action are much less likely to view the law as a problem-solving resource. Indeed, the study of actual problems indicated that those involved in criminal prosecutions, including those having the services of a lawyer, were less inclined to think of legal assistance for handling other types of problems than was the sample group in general..$^{78}$ Of course, the likelihood that at least a substantial part of this group had by hypothesis already demonstrated some antisocial acitivity or unwillingness to follow established norms of conduct provides a ready explanation for the group's apparent failure to think in terms of "legal" resolution. It may nevertheless be observed that going through the procedures of criminal justice apparently did not serve to heighten the subjects' sensitivity to the law as a problem solving device, whereas other problem experiences apparently often had this effect. ${ }^{79}$

Question seven, which involved the hypothetical desire on the part of the subject to see that a certain person received a particular piece of his property after his death, evoked a number of

\footnotetext{
${ }^{7 x}$ See text accompanying note 165 infra.

7" See text infra generally accompanying notes 124-160 indicating that problem experiences in the areas other than crime have generally increased awareness of the law as a problemsolving device.
} 
surprisingly accurate responses. Of the 135 persons who indicated they would make a will, 11 actually specified that it would be a holographic will. The only explanation available for the surprising level of knowledge regarding this technical term as well as wills in general is the educational program undertaken by the Agricultural Extension Service.

The extension service program, through pamphlets ${ }^{\mathrm{s} 0}$ and oral information distributed by the county agents and home demonstration agents, and through talks at various gatherings by members of the local bar, sought to make the population aware of the need for a will and the method by which one might be prepared by the testator himself. While the program encouraged use of a lawyer for all but the simplest bequests, it apparently inspired considerable self confidence in the sample group, as only 25 reported that they would resort to a lawyer for assistance. Nineteen of this group were Negro, perhaps reflecting the difference in educational levels ${ }^{81}$ or at least a difference in self confidence in an activity requiring writing ability. Less than half of the legal activists suggested a lawyer for this purpose, the remainder responding that they would make their own will.

A number of respondents indicated that they would consult the clerk of the court for assistance. Some of those so responding claimed, upon further investigation, that the clerk on occasion assisted with will drawing. The clerk, however, denied such activity, expressing the view that it would be unauthorized practice of law on his part. $^{82}$ The fact that the clerk's position is a sought-after political office, however, lends some credence to reports that the clerk sometimes provides the electorate with free advice or assistance in legal matters such as deeds, wills and child support.

Question eight involved a refusal by an employer to pay wages. ${ }^{83}$ About 25 percent of the sample group indicated that they would take up the problem with their employer. Another group of

\footnotetext{
worth Carolina Agricultural extension Service, have You Made Your Will? (undated).

"See textual paragraphs following note 120 infra.

2 The clerk of the superior court is not required to be an attorney, nor was he one in the sample county. See N.C. Gen. Stat. \& 2-2 (1953). J. Sanders, A Selection of North Carolina State Governmental Officials 28 (1964).

* This question does not relate to a garnishment situation as North Carolina is one of the few states that does not provide for a garnishment procedure.
} 
32 indicated that they would see a lawyer. A fairly substantial group reported that they would not know what to do or would do nothing. While the group consulting with their employer was about evenly divided racially, again a noticeably larger group of Negro respondents suggested legal assistance. These figures again seem to suggest some feeling or the part of the Negro group that the protection of a lawyer is necessary in dealing with authority figures. White respondents apparently are not so pessimistic or are not as likely to think in terms of a need for protection through legal assistance. Five respondents suggested that they would seek the aid of the clerk of the court in getting a warrant issued against the parties responsible for the loss of wages. Use of the warrant in such a quasi-civil fashion to compel payments of debts was reported in various situations. . $^{84}$ A number of the "legal activist" group suggested use of a lawyer in the wage problem situation, but it did not rate as high among the activists as did most of the other hypotheticals. Inquiry regarding actual problems in the wage area revealed few such problems in the sample group. The fact that seasonal employment is often irregular during the working week, resulting in employees being frequently paid on a day by day basis, and that the tenant farming relationship does not provide regular wages offers some explanation for the absence of these problems. Despite the lack of significant experience with this particular problem, as in the child custody question, the sample group demonstrated considerable ability in viewing the problem in legal terms.

Question nine involved the refusal by a landlord to allow his tenant farmer to sell the tenant's portion of the crop. A fairly large number of the sample group, over 25 percent, indicated that they would do nothing in this situation, probably because of the possible illegality of self help. ${ }^{85}$ Another 25 percent indicated that they did

* See note 73 supra and accompanying text.

xs "When lands are rented ... for agricultural purposes, or are eultivated by a cropper, . . . any and all crops raised on said lands shall be deemed and held to be vested in possession of the lessor or his assigns at all times, until the rents for said lands are paid ....

-This lien shall be preferred to all other liens, and the lessor or his assigns is entitled, against the lessee or cropper, or the assigns of either, who removes the crop or any part thereof from the lands without the consent of the lessor . . . N.C. GeN. STat. \$42-15 (1966); see Hall v. Odom, 240 N.C. 66, 81 S.E.2d 129 (1954). 
not know what to do. Only twenty respondents, six Negroes and 14 whites, indicated that they would sell on their own, and only seven suggested that they would pursue the matter with the landlord. Thirty-four respondents suggested the aid of a lawyer in this situation, and again the larger portion of this group was Negro; almost all of the respondents who suggested a lawyer were members of the activist group. A larger number of the white group was willing to undertake self help, despite the illegality of a sale without permission, perhaps indicating greater confidence in the fair application of the tenant law. Twenty-one indicated that they would consult the county extension service agent. However, resort to this source was not as great as might be expected in light of the fact that the extension service was the agency with which the greatest number of the sample group, over 70 percent, had some actual contact. The county agent did report some situations in which he sought to mediate landlord-tenant disputes, but felt that this was outside his official capacity as a technical agricultural expert.

Study of actual problems revealed no instance of a refusal to permit sale of crops by a landlord. The county agent and the local attorneys indicated that most landlord/tenant-farmer disputes arose concerning the accounting when the profits for a season's production are divided. Because the tenants rarely keep records of the amounts advanced to them, they must rely on the landlord's figures and are sometimes not satisfied. The county agents and local attorneys, however, did not believe these disputes to be particularly frequent.

\section{Summary of the Hypothetical Responses}

Although the results of the hypothetical problems will be utilized throughout the study for correlation with knowledge of resources, education and background, the handling of actual problems, and the effect of legal and non-legal experience, it would seem useful to present a brief summary here. Members of the sample group recommended the aid of a lawyer most frequently in the criminal and child custody areas. In both of these problems an additional number indicated that they would attempt some resolution by enlisting the aid of the court, sheriff, or clerk of the court, bringing the legally-oriented responses for both questions to over 50 percent. Although a substantial number responded that 
they did not know what to do about the criminal and custody problems, only a very few stated that they would do nothing, perhaps indicating that the areas in which the most urgency is felt are those in which people are most likely to seek legal assistance.

In the hypotheticals involving consumer or employer problems (questions four, eight, and nine), the sample group was much less inclined to think in terms of legal remedies. In the problems regarding the refusal to pay wages (question eight) and the refusal to allow sale of the tenant's crop (question nine), only about 35 subjects suggested the aid of a lawyer, and in the question involving the defective refrigerator (question four) only 13 recommended legal assistance. In questions eight and nine a fairly substantial number did not know what to do or would do nothing, whereas in question four, where the remedy of stopping payment was readily available, a large number of subjects suggested that action. In all three of these situations the number of Negroes suggesting the need of a lawyer was noticeably greater than the number of whites. This fact suggests two related conclusions. First, because of the activities of the NAACP in the county in suits to desegregate schools and public accommodations, the Negro population may be more aware of the positive use of legal help to solve problems. ${ }^{86}$ Secondly, because of past inequalities, the Negro may feel more in need of protection or representation when dealing with power figures such as landlords, merchants or employers.

Most of the respondents who recommended the aid of a lawyer in one of the above three situations did so in several other situations and therefore fell within the group classified as "legal activists." The common pattern for the activist group consisted of legal responses to questions three, six, seven, nine and either four or eight or both. Twenty-four persons fell within the activist group, eight whites and 16 Negroes. The factors which contributed to their "activism," including education and background as well as actual experience with lawyers and legal problems, are given considerable attention throughout the study.

A local leader of the NAACP reported that all of the desegregation efforts of his organization in the county have thus far been in the federal courts rather than through demonstration or other means. Although the membership of the poverty group in the NAACP is very low, and none of the sample group reported membership, the organization's local leadership indicated that the black community placed considerable confidence in the Justice Department and the federal courts. 
In the questions involving the denial of social security benefits (question one), the rental property in need of repair (question two) and the inability to pay off a loan when due (question five), a very low number of persons, five or less, suggested the aid of a lawyer. With questions one and two those recommending a lawyer were among the most legally active. With question five none of those suggesting legal help were activists, but all had had some experience with refinancing a loan. The sample group's failure to think in terms of legal assistance for questions two and five probably results from an accurate observation of the situation. The absence of any housing code applicable to the rural areas surveyed forecloses most legal remedies in this area. The rental housing problem could probably best be handled by the self help method of stopping rental payments, as many subjects suggested. The inability to pay a debt on time could probably best be resolved by the informal extension which most subjects recommended and which in fact was almost universally utilized. Thus, in questions two and five, as in question four, it appeared that the sample group did quite well in identifying a self help remedy when a viable one was available.

Question seven, involving the will, presented a unique situation and demonstrated the effectiveness of a "legal education" program conducted by the local bar in cooperation with a frequently utilized state agency, in this case the agricultural extension service. Over 75 percent of the subjects were able to suggest an appropriate resolution, and a good number were even able to identify the handwritten will by the technical term "holographic." The apparent success in this area certainly suggests that future educational programs directed toward creating an awareness of legal remedies would be worthwhile.

\section{Knowledge and Use of Resources}

The second part of the questionnaire sought to test the knowledge and use of resources such as private attorneys, courtappointed counsel, the county welfare and health departments, the Agricultural Extension Service, the Farmers Home Administration, and the Office of Economic Opportunity. Knowledge of the availability of public housing through a regional housing authority was also tested. The degree of the subject's knowledge of a particular program, his reactions to any contact with it, and where he learned about it were among the inquiries made. 
Free Legal Services. When asked whether there was a place in the county where free legal services were available, almost 75 percent of the sample group responded negatively and another 20 percent indicated that they did not know. Only ten white and two Negro subjects felt that they could get free assistance if needed. Nine of these gave the names of specific lawyers in the county and the other three specified court-appointed counsel. Only two of the 12 were among those considered "legally active" on the hypotheticals and only five were "semi-active." The remaining five suggested a lawyer to one or none of the hypotheticals. ${ }^{.7}$ The belief in the availability of free legal services, therefore, would not appear to be immediately relevant to a subject's propensity to think in legal terms. Education in the use of that service rather than a mere awareness of its availability would seem absolutely essential to a successful legal aid program. Eight of the 12 subjects indicated that they learned of free services from friends; one did so from actual contact with a lawyer; two learncd of court-appointed counsel from television; and one did so from jury duty.

Although a Committee on Indigent Legal Services ${ }^{88}$ under the auspices of the North Carolina Bar Association theoretically exists in every state judicial district, the committee was not operating in the sample county, and no subject reported knowledge of it. Indeed, even the members of the local bar had never heard of the committee's existence. Although no Iegal aid programs in the usual sense are available in the county, the sample group was nevertheless tested on its concept of "Legal Aid" for purposes of future possible programs. Only 14 persons were able to define "legal aid" as free legal services, the great majority taking the term to mean paid legal assistance. Of the I4 who correctly conceptualized legal aid, all fell into the activist or semi-activist category. The largest number of subjects felt that a Iegal assistance program could be best publicized through a door to door campaign. This was in fact found to be the case in a sanitation campaign conducted by the OEO. Alternative suggestions were television or newspaper publication.

The five who believed free legal service to be available but who generally did not suggest a lawyer on the hypothcticals, scored low in knowledge of community services and educational attainment.

See note 51 supra and text following note 117 infra. Several members of the bar and the superior court judge for the district in which the sample county is located did not report any knowledge or information about the operations of the committee. 
As might be expected, over 90 percent of the sample group favored free legal services. A reason frequently given was that poor persons either cannot or are afraid to help themselves with many problems and cannot afford to pay for a lawyer's aid. Some Negroes expressed the feeling that free legal services were needed because the white lawyers in the county would not assist them. Many of the 14 persons opposed to free services expressed the belief that free lawyers would be inferior to paid attorneys and five indicated oppostition because they felt that only the Negro group would take advantage of the service.

Use of Private Lawyers. In the sample group of 198, a surprisingly large number-39 Negroes and 48 whites-has used the services of an attorney on one or more occasions. All but three of the activist group, ${ }^{89}$ which gave legal responses to at least five hypotheticals, reported using a lawyer at least once. ${ }^{90}$ Forty-three subjects who had dealt with a lawyer were semi-activists, giving legal responses to at least three hypothetical problems. While only five gave legal responses to one hypothetical, nine persons who had had the services of a lawyer in the past suggested legal assistance for none of the hypotheticals. This data suggests a considerable correlation between ability to think in legal terms on the hypotheticals and actual experience with lawyers, but it is difficult to identify the exact nature of that correlation. Experience with a lawyer may have increased a subject's perception of legal remedies, or the fact that he sought a lawyer's aid in the first place may have resulted from his better than average ability to perceive problems as legal. A combination of both these factors was probably operative in most cases.

Of the nine persons who did not suggest a lawyer for any of the hypotheticals, ${ }^{91}$ four of them had been charged over $\$ 100$ for a lawyer's service, and the average fee for the nine was over $\$ 75$. The

There were 24 persons in the activist category. See note 63 supra and accompanying text.

$\$$ Almost all of the group which had been to a lawyer had been to only one. Three of the four who had taken the same problem to more than one attorney indicated that they felt they were "getting the run-around," and one believed he was being discriminated against because of his race. The largest number of persons who had been to a lawyer had seen one since 1960, and a substantial number had secn one for the first time sinee 1960, indicating a general increase in the use of legal services.

" Three of the nine not suggesting a lawyer to any hypothetical had their sole experience 
average fee paid by a member of the activist group was under $\$ 25$. Since eight of the 11 subjects who reported paying fees of over $\$ 100$ were among the most inactive on the hypotheticals, the conclusion is suggested that fee experience has some real effect on the propensity to think in terms of legal help. The majority of fees paid by the sample group were quite low, generally ranging between $\$ 1.50$ and $\$ 50$, and most often falling between $\$ 10$ and $\$ 25$. Twelve persons, all of them white, reported receiving free legal services. Ten of them fell within the activist or semi-activist group which suggests that their experience may have influenced their attitude toward legal assistance. None of the 12, however, responded that they knew where free legal help could be obtained, perhaps demonstrating a belief that their free experience would not be repeated.

The great majority of subjects having the services of a lawyer reported that they benefitted from those services. This satisfactory experience provides one explanation for this group's willingness to suggest legal help on more hypotheticals than did the sample group in general. Only three persons believed that legal assistance had been detrimental, while eight felt they were in about the same situation. The eight without a positive experience nevertheless suggested a lawyer for at least two, and usually more, of the hypotheticals, while all three who reported an unsatisfactory experience suggested a lawyer only for the criminal problem.

The problems most frequently taken to attorneys by the sample group involved wills, deeds and income tax. The tax matters were brought exclusively by whites, probably reflecting the relatively higher income of the white group. ${ }^{92}$ Will problems were brought by a larger number of Negroes, perhaps indicating some hesitancy on their part to do their own drafting. ${ }^{93}$ Automobile accidents, insurance claims, and home construction loans and contracts were also common problems for which legal help was sought. Two murder cases, a few minor criminal problems such as drunken driving and illegal manufacture of liquor, a few divorces, two social

with a lawyer in the criminal context. It has been observed elsewhere that persons with this experience did not demonstrate a propensity to think of other problems in legal terms. See note 165 infra and accompanying text.

"2 The median income for non-white families in the sample county was below $\$ 2000$ while the same for white families was between $\$ 2000$ and $\$ 2999$. See BrooKs, supra note 8, at 66 .

- See text accompanying notes $80 * 81$ supra. 
security claims, one landlord-tenant dispute and one employer problem were reportedly brought to the attention of attorneys. ${ }^{94}$

All of the subjects indicated that they were referred to a particular lawyer by family or friends, or that they had personally known the lawyer or his family. There were no reported referrals from any community agencies. Over 70 percent of the sample group were able to name at least one of the three lawyers practicing in the county. Because of the small size of the community and the location of virtually all services in the county seat, lack of knowledge as to where a lawyer may be found, or who the lawyers are, does not seem to be much of a problem in the utilization of legal service. Anyone driving through the county seat on either of its two intersecting streets would have a difficult time missing one of the three lawyers' offices. For referral purposes, the state and federal agencies need only send persons across the street to allow them to choose an attorney from the entire county bar. This is certainly a significantly different situation from that experienced in urban areas where anonymity often obscures available services. ${ }^{95}$

The major reason given by the sample group for the failure of most people to utilize lawyers in handling problems was the inability to pay. Distrust of lawyers, a desire to keep problems secret and the unavailability of a Negro lawyer were also suggested factors. Thirty-one persons indicated that they had had one or more problems that they would have liked to have taken to a lawyer but did not, mostly for financial reasons. Sixteen of these cases involved accident or insurance claims which probably would have involved a contingent fee. Knowledge among the sample group as well as among the community leadership element of the possibility of contingent fee arrangements was quite low. It would thus appear that an attempt by the local bar to provide some "education" in this area could be profitable for all concerned. The remainder of problems people would have liked to have taken to

\footnotetext{
"s Other sections of the questionnaire revealed some additional problems about which persons had had the advice of an attorney, but which they neglected to report here as problems taken to a lawyer. This is perhaps evidence of the tendency observed by members of the local bar in persons seeking their aid to consider advice, letter writing, and phone calls outside the scope of a lawyer's professional services. The bar reported that only when documents are drafted or an action is filed do persons feel that they have had professional legal services for which they should be charged.

${ }^{2}$ See Peoria Study, supra note 5, at 65.
} 
lawyers included several landlord-tenant disputes, child support cases, and loan overcharges, but were generally not of the type to generate any sizeable fee. ${ }^{96}$

The Welfare Department. The agency with which all 198 subjects were familiar was the county welfare department. Most members of the sample group were able to identify the function of the welfare department in disbursing payments. Far fewer, however, were able to identify the separate benefit programs available. ${ }^{97}$ This absence of information probably resulted not from lack of knowledge that the type of assistance is available, but from a general tendency to look upon welfare aid as a single entity rather than as a variety of programs. About 30 percent of the persons interviewed reported that they were unaware of the relatively new surplus food program. None of these persons, however, had ever received or applied for welfare. Considerable work has been done by the welfare department in cooperation with the OEO community workers to publicize and assist people in taking advantage of surplus foods, ${ }^{98}$ and indeed the fact that 70 percent of the interviewees knew of the program is not discouraging. As might be expected, the persons actually receiving welfare benefits of some kind were best versed on the various programs available. The legal activist group also demonstrated better knowledge of the various benefit programs than did the sample group in general.

While over 35 percent of the Negroes interviewed reported contacting the welfare department, less than 25 percent of the whites did so. These figures to some degree may reflect the attitude of the white population that welfare is for the Negro ${ }^{99}$ and that whites should be too proud to accept it. Of those able to identify the kind of benefits they sought, the largest number who contacted the welfare department did so with regard to old age assistance.

\footnotetext{
i The activities of the local bar in handling problems for the poverty group and in providing free legal service will be treated at some length further in the study.

"Programs administered by the welfare department on which the sample group was tested wcre old age assistance, aid to the disabled, aid to dependent children and surplus food.

" Over 1500 residents of the sample county had rcceived surplus food under the Commodity Distribution Program as of September, 1968. U.S.D.A., Consumer \& Marketing Service; Food Assistance Programs: Number of Persons Participating in Administrative Units 22 (Sept. 1968).

"See Batton, A Cold Shoulder for the Poverty Program. The Reporter May 30, 1968, at 27.
} 
Fewer persons, both white and Negro, reported contacting the department about aid to dependent chldren, and very few indicated a contact in regard to aid to the disabled. ${ }^{100}$ Although knowledge of the surplus food program was about equal among whites and Negroes, no whites reported contacting the welfare department for this assistance, while almost 20 percent of the Negro group did. The study of actual benefits received revealed no whites taking advantage of surplus food. The welfare personnel felt that considerable stigma was attached to the acceptance of this assistance and that many in need of surplus food declined it.

The failure of a larger number of both Negroes and whites to take advantage of welfare also results from a total misconception of the "welfare lien"101 which attaches to the real property of those receiving old age or disability benefits. Most people believe that this lien attaches to all property they own when any benefits are received, ${ }^{102}$ when in fact it attaches only in limited situations. This is perhaps somewhat the result of a tendency to view all welfare benefits as a single program, when in fact some important distinctions exist. ${ }^{103}$ Further education of the population about the actual effect of the welfare lien is definitely necessary in order to relieve the apprehension preventing the full use of welfare benefits.

The. Agricultural Extension Service. Next to the welfare department, the county extension service of the state department of agriculture was the best known public agency, more than two-thirds of both the white and Negro sample groups reporting knowledge of it. Almost all of the knowledgeable persons, including all of the

${ }^{100}$ Study of actual benefits received, however, demonstrated that more people were receiving aid to dependent children than any other benefit. The fact that more inquired about old age assistance but apparently did not receive it may result to a large extent from the application of the welfare lien to this kind of benefit. See N.C. GEN. STat. $\$ 108-30.1$ (1966). It is the elderly people who are most likely to own some rcal property and, therefore, to be discouraged from accepting benefits by the lien.

101 These findings were somewhat affected by the fact that many persons were able to indicate only that they contacted the welfare department "for welfare," and were not able to identify the type of benefit sought.

10: The lien attaches only to real property, and only upon the receipt of old age assistance or aid to the disabled. See note 172 infra. Some subjects indicated a belief that it attached to aid to dependent children and surplus food benefits as well. Furthermore, they did not understand the concept of the lien and believed that eventually their property would be taken away from them, when in fact the lien could not be foreclosed until after death.

100 The income standard for receiving surplus food, for instance, is different than that for receiving aid to dependent children or old age assistance. 
legal activists, were able to identify correctly the county agents' function. ${ }^{104} \mathrm{~A}$ number of those indicating no knowledge of the extension service were women, although cight were men whose actual occupation was farm labor. Thirty-two of the sample group had contacted and received help from the county agent. Tobacco growing advice and soil tests were the most common reasons for contact, although crop and animal disease were also frequent problems. Five persons had contacted the county agent for information on Farmers' Home Administration home improvement or construction loans provided by the federal government. ${ }^{105}$ The county agents have been very active in assisting persons to apply for these loans and in disseminating information about them. The sanitarian provided by the OEO, the county agents and the federal FHA agent have worked in close cooperation in attempting to improve sanitation facilities by utilizing the home improvement loan; and it was somewhat surprising that only five persons reported services in this area through the county extension service. Although the county agents reported being consulted on a number of problems outside the scope of their official duties, including welfare and social security questions, landlord-tenant farmer difficulties, and consumer and insurance problems, no individuals indicated this type of contact with the state extension service. Several persons did, however, report help from the county agents on unofficial matters such as these elsewhere on the questionnaire.

The Farmers' Home Administration. Over 50 percent of the whites but less than 30 percent of the Negroes in the sample group reported knowledge of the Farmers'. Home Administration. Most people were not apprised, however, of the particular programs offered by this agency. ${ }^{106}$ Only about 35 percent of the sample knew about farm loans from the FHA, and about 25 percent had heard of the availability of home improvement or construction loans..$^{107}$ As might be expected, knowledge concerning the FHA, as well as the extension service, was better among those employed in

tof For a discussion of the county agent's function, see textual paragraph at notes $181-82$ injra.

10: See App. A for a discussion of programs available through the HHA.

106 Id.

${ }^{\text {tor }}$ Study of actual loans revealed that persons in the lowest income group resorted most frequently to finance company loans. See note 151 infra and accompanying text. 
agriculture than in the sample group in general. ${ }^{108}$ A substantial number of persons identified the function of the FHA as providing advice on soil, crop and livestock care, apparently confusing it with the state extension service. This confusion may result from the close cooperation between these two agencies, and the county agents' activity in assisting with applications for FHA loans. A large number of those with knowledge of the home loan program also demonstrated knowledge of the sanitation program, perhaps suggesting that information concerning the loans was obtained through the sanitarian who often assisted persons in applying for .FHA loans for the improvement of sanitation facilities.

About half of the entire sample group reported knowledge of the FHA, but only 15 percent indicated that they had ever contacted the agency for aid. The largest number of this group, which was predominantly white, reported seeking farming loans. Only nine persons indicated that they had sought home improvement or construction assistance; five applied through the county agents and three of the other four were probably encouraged to seek loans for improvement of sanitation facilities by the OEO sanitarian. Although the interest rates for FHA loans are low, and a prerequisite for receiving the loans is an inability to obtain private financing, even the minimum financial responsibility required for FHA programs appears to have limited their utilization among the proverty group. ${ }^{109}$

Health Department. Over 80 percent of the sample group reported knowledge of the health department. Only a small number, however, was able to identify the department's various services. About 10 percent, for example, reported knowledge of the availability of prenatal and baby care, and the vast majority was AFDC benefit recipients suggesting that their knowledge came from the welfare department. A much larger number, over 50 percent of the sample, demonstrated knowledge of the free immunization shots provided by the health department clinic. Over 20 percent of the sample were under the impression that free medical treatment could be obtained from the health department, while in fact the

\footnotetext{
tox Matters concerning the FHA and the extension service, however, were the only ones where agricultural workers demonstrated better than average knowledge.

tos See note 151 infra.
} 
department's services are limited to diagnosis. ${ }^{110}$ Health department personnel reported, however, that in emergency situations where the only doctor in the area is the health department physician, medical treatment is rendered without charge. About 45 percent of the interviewees reported actually contacting the health department for services-usually for their children's immunization shots. A substantial number also reported obtaining pre-marriage blood tests from the department. Almost 80 percent of the group receiving health department aid were Negroes, possibly an indication of a reluctance on the part of whites to utilize these publicly-provided services."11

Another important function of the health department is providing free birth control information and materials to low income persons. About 55 percent of the sample group reported knowing about birth control, 56 Negroes and 30 whites being without knowledge in this area. However, only six persons who were on welfare lacked this information, and all six were receiving old age benefits. The welfare department's requirements that all AFDC recipients be given birth control information by the health department no doubt explains their sophistication in this area.

Almost half of the group who indicated that they knew what birth control was apparently did not know where they could go for information on the subject, a situation which was true for equal numbers of blacks and whites. Most of the Negroes who specified a place where the information might be obtained suggested the welfare or health department, whereas most whites indicated a private doctor-again perhaps demonstrating the white population's hesitance to take advantage of health department services. All but two of the persons in the legally active and semiactive groups had birth control information, and the sample group in general was better informed on birth control than on all other publicly-provided assistance except welfare and the state agricultural service.

Office of Economic Opportunity. Slightly under 20 percent of the sample group reported knowledge of the OEO as such. Almost all of these were activists and among the most knowledgeable in the

"No See textual paragraph preceding note 189 infra.

"II Compare text supra at note 99. 
area of community services. Less than ten percent of the sample, however, were able to specifically identify the Head Start or Community Worker programs." ${ }^{112}$ Every individual who did so was among the activist group, although a number of activists and otherwise knowledgeable persons were without information in this area. A noticeable number of ADC mothers were informed on these two programs, probably reflecting the welfare department's role in disseminating OEO information. None of the sample group reported contacting either of these two programs for aid, although five Negroes volunteered that they knew a community worker. Nor did anyone report elsewhere on the questionnaire that they consulted a community worker or the OEO about any problem..

The OEO funded sanitation or "Privy" program, which is operated through the county health department, had come to the attention of 40 percent of those questioned. The greater awareness of this program probably is a result of the sanitarian's systematic inspections in the past year of the sanitation facilities of all homes in the low income bracket and the enforced requirement that facilities meet state law standards. Since the sanitation program took the initiative of personally contacting all persons in substandard housing, and association with the program often involved, either some expenditures to improve conditions or the threat of a fine, the poor were somewhat compelled to "utilize" this service. The other OEO programs operating in the county"13 were either so new or so limited in scope that it was not deemed worthwhile to survey knowledge concerning them.

Public Housing. North Carolina statutes authorize the establishment of a regional housing authority by local county governments to provide public housing in rural areas. ${ }^{114}$ Because there were some reports of attempts to encourage such a program in the sample county, the poverty group was questioned about its knowledge of the housing authority. Only 6 Negroes and 24 whites reported hearing anything about such a program, and all of these were legally active or semi-active on the hypotheticals and were among the most knowledgeable about other areas of community services. A number of legal activists and otherwise well

\footnotetext{
112 See notes 30 \& 32 supra.

${ }^{113}$ Other OEO programs included Youth Corps, summer recreation and swine projects.

II N.C. Gen. Stat. $\$ \$ 157-35,-39.1$ (1964).
} 
informed persons reported that they did not know about such a program, as did some officials of the county government. One county official indicated that the lack of knowledge and interest in the regional housing authority program stemmed from the fact that considerable local financial support is required for the program, ${ }^{115}$ and that since the county commissioners responsible for undertaking such a project would be personally affected by increased tax burdens, their activity in stimulating support for such a plan thad been negligible. In an area where 70 percent of the housing is substandard, ${ }^{116}$ it would seem that greater awareness on the part of an electorate exposed to these living conditions could well result in political pressure being brought to bear to establish some public housing program. Again, however, the tendency to avoid public assistance programs by the poor white group might result in support or opposition along racial lines.

The Better Business Bureau. In view of the fact that no Better Business Bureau operates in the county, a surprising number of persons, almost 25 percent, reported hearing of this organization, and a large number of these were able to identify its function. More than twice as many whites as Negroes were aware of the Better Business Bureau, and all but one of the legal activists reported knowing of the service. There are Better Business Bureaus in the two nearest cities of about 25,000 in adjoining counties, and persons from the sample county sometimes make their larger purchases there. However, only one person reported having contacted the Bureau for assistance with a consumer problem, although a number of such problems existed among people who knew of the service. This no doubt results to a large degree from the fact that most consumer items purchased by the low income group were purchased within the county either from local merchants or traveling salesmen not under the scrutiny of any better business group.

II The Regional Housing Authority Statute, supra note 114. like most urban renewal legislation, see 42 U.S.C. $\$ \$ 1471-85$ (1964), basically envisions the use of federal funds on a matching basis with local contributions. A variety of federal housing plans could conceivably be available to the sample county, including new construction by local housing authorities, low rent programs for the aged and handicapped, rehabilitation projects, combined public and private ownership projects and rent subsidy plans. See U.S. DEPT. OF HousING AND Urban Development, Housing for Low-1ncome Families (1968). See also App. A for FHA programs.

"Is See Brooks, supra note 8, at 41." 
County Bar Association. Since the local bar association operates the Committee on Indigent Lcgal Services within a judicial district, ${ }^{117}$ the sample group's knowledge of the bar association was tested to see what, if any, problems were channeled through it. While over 25 percent of the sample group, including all the legal activists, had heard of the bar association, none had ever had any contact with it and less than ten percent agreed with the suggestion that the bar association would tell them where to find a lawyer. The county bar association exists in conjunction with a neighboring county in which the number of lawyers is also small, and its formal operations are quite limited. This perhaps accounts for the absence of any formal operation of a Committee on Indigent Legal Services or any use of the bar association as an institutional problemsolving resource. The need for improvement in this area if the committee is to be a meaningful legal aid service is self evident.

Appointed Counsel. Appointment of counsel in criminal cases is made by the court on a rotating basis among the three members of the county bar. The clerk of the court reported that counsel was regularly appointed in all felonies and serious misdemeanors, including drunken driving and non-support cases. Over 25 percent of the sample group, again including most of the legal activists, knew of this kind of assistance. Of the eleven people accused of crimes, however, only one had had the aid of appointed counsel, and that was in a murder case. All of the others involved in serious crimes had retained their own counsel, but all of these cases arose prior to the 1963 decision of Gideon $v$. Wainwright. ${ }^{11 \times}$ A substantial number (19) of those reporting knowledge of the availability of appointed defense counsel expressed the belief that appointed counsel was available in both civil and criminal cases. Despite this fact, these individuals did not respond that they knew where free legal services were available, nor were many legally active on the hypotheticals. This perhaps indicates that belief in the availability of a free legal defense does not contribute significantly to a willingness to utilize the legal process, even in handling problems where another party would be the plaintiff such as in consumer and loan difficulties. More realistically, however, those who agreed with the suggestion that appointed counsel would be

"1i See note 51 supra.

ux 372 U.S. 335 (1963). . 
available in civil suits probably did not entertain this belief on their own and for that reason failed to indicate it as a source of free legal services elsewhere on the questionnaire.

Summary of Knowledge and Use of Resources. In summary, a few generalizations about the level of community knowledge of available services can be made. The welfare department is the best known and most utilized service agency, although there was some disparity between white and Negro willingness to use this service. The Agricultural Extension Service is the next best known public agency, the county health department being third. The health department, however, was utilized by a slightly greater number than was the extension service, and apparently was used far more frequently by blacks. Knowledge concerning OEO programs, with the exception of the sanitation project, was at a considerably lower level than that regarding the more established state agencies. Personal visits used to publicize the sanitation program appeared to be the most effective manner of spreading information.

While many subjects were able to identify particular agencies, a far lower level of information existed concerning the specific programs administered by them. Knowledge about aid to dependent children, the health department's prenatal care program, the community workers, and the FHA home improvement loans, was reported by only 50 percent or less of the sample group. With some of these programs, such as AFDC, lack of knowledge concerning the name of the program does not necessarily mean that knowledge about this kind of aid is absent or even that the very person unable to identify a program is not receiving aid through it." ${ }^{119}$ Various programs are known by many only as "welfare." However, a problem does arise when a new program somewhat outside the former scope of operations of the agency is introduced. Birth control from the health department, food from the welfare department, and home construction loans through the Farmers' Home Administration seem to face this difficulty. However, these agencies are in frequent contact with large numbers of the poverty group, and their attempts at education have shown some profitable returns. ${ }^{120}$ With projects where the responsible authority is more

\footnotetext{
11" One mother who reported receiving welfare for herself and young children indicated that she had never heard of aid to dependent children.

120 The knowledge concerning surplus food, for example, while at a lower level than the general informational level of the supervisory agency, was still over 70 percent.
} 
isolated, such as public housing which is under the direction of the county commissioners, the information gap is much greater. One approach to this problem-presently carried out on a limited scale-would be to utilize the more well-known public agencies, such as the welfare department and the extension service, as education centers for programs outside their own ambit.

\section{Community Activity and Knowledge as Related to Personal} Background and Characteristics

Over 65 percent of the Negroes in the sample group reported attending but not completing grammar school. The second largest number, almost 15 percent, reported no formal education at all. With only one exception, however, the Negroes in the activist group graduated from grammar school or attended high school. Few completed four years of high school, but until around 1945 the Negro high school offered only a two-year program. The correlation between level of education and legal activism is apparent, but education does not appear to be the only important factor, as several persons with the same educational attainment as the activist group were inactive. Knowledge of community services was similarly correlated to educational attainment among the Negro group.

Most whites in the sample group had also attended but did not complete grammar school. The second largest number reported attending high school. Again only a few high school graduates were present in the sample group, probably demonstrating the function of education in income level. Again most of the activists had graduated from grammar school or attended high school. The correlation between education and activism, however, was not as high as that found with the Negro group. Several persons who had not completed grammar school fell within the activist group, while some who attended high school did not. This same difference between the racial groups in effect of education was observed to a lesser extent in relation to knowledge of resources. This difference suggests a greater importance of education as a function of activism and community knowledge among the Negro group than among the whites. Perhaps because of unequal treatment of the Negro group in years past, a higher level of education was necessary to dispel their feelings of suspicion and helplessness and 
to create a willingness to seek legal or other help. More practically, this difference may also demonstrate a disparity in the qualities of the Negro and white school systems, i.e., that a higher grade level of attainment in the Negro school was necessary to produce the same education effect.

Employment itself did not appear to have a direct correlation to either activism or knowledge of community services. The type of employment, however, did seem to be significant. Those who reported working as tenant farmers or farm laborers, for instance, were found to be less active and less knowledgeable than other members of the sample group. This can perhaps be attributed to their long hours of labor in isolated areas without contact with other people. Those working as construction laborers, often as state employees, or those working in the pulp wood industry, on the other hand, were more frequently active or semi-active and generally showed better than average community knowledge. Those who were unemployed or were employed less than full time appeared both more active and more knowledgeable than those working full time, but this was probably largely a result of the fact that most of those who reported being employed full time were tenant farmers. The fact that those receiving welfare benefits also fell within the group not fully employed suggests an additional explanation for that group's better performance in knowledge and activity, since the welfare group demonstrated better performance in both of these areas.

Family background also apparently played a part in activism and community knowledge. Almost all white members of the sample group reported being raised by both of their parents, and a substantial majority of the Negro group reported the same background. Most whites indicated that their father had attended grammar school, while the majority of Negroes indicated that their fathers had no formal education. Without exception, however, those Negroes who were activists and rated well in knowledge came from families where the father had received some education. The same correlation was true for the white group, but it did not appear as significant since almost all white parents had at least attended grammar school.

Church attendance was the most frequently reported community activity for the sample group. Almost all subjects reported 
attending church at least once a month. Very few, however, only six Negroes and five whites, reported being active in church activities other than religious services. Only six members of the sample group reported being PTA members, two were lodge members, and two were home demonstration club members. No Negroes reported being members of the NAACP. Almost all of those who had been active in some group program were activists on the hypotheticals, and all scored above average in community knowledge. Forty Negroes and 76 whites reported having voted in a public election at some time in their lives. Over 80 percent of these had voted in the most recent local election. Only two activists had not voted in this election and voting frequency was also higher among the semi-activist group than among the sample in general. The difference in voting participation between the white and Negro groups perhaps reflects past discrimination in voter registration practices, although the leader of the local NAACP did not believe that voter discrimination was still a problem. He did feel, however, that literacy test ${ }^{121}$ requirements had a discouraging effect on some of the Negro group.

Sex also seemed to have some correlation to both activity and community knowledge. Although only about 30 percent of the Negroes, interviewed were women, almost 50 percent of the Negro activists were of the female sex. This possibly reflects the responsibility assumed by the woman family head in the more matriarchial society of the Negro group, ${ }^{122}$ although the number of families headed by women in the sample county was not as high as that frequently experienced in more urban areas. ${ }^{123}$ Many of these female activists were recipients of AFDC, so association with the welfare department was probably a factor in their increased activism and community knowledge. Only about 20 percent of the white sample group were female, but less than 10 percent of the white activists were women. Again, all but one of these women were receiving AFDC, reflecting the strong influence association with the welfare

121 "Every person presenting himself for registration shall be able to read and write any section of the Constitution in the English language." N.C. ConST. art. VI $\S 4$.

122 S. Drake \& H. Cayton, Black Metropolis 582-86 (1945); E. Frazier, The Negro in the United States 316-17 (1949); N. Glazer \& D. Moynihan, Beyond the Melting Pot 50-53 (1963); E. Reuter. The american Race Problem 219-21 (rev. ed. 1938).

iz U.S. Dept. of labor, The Case of National action-The Negro Family 9-12. 30 34 (1965). 
department and role as head of a family has upon activism and knowledge.

\section{Study of Actual Problems}

Part three of the questionnaire attempted to elicit information regarding actual problems experienced by members of the sample group. The methods of problem solving, the channels followed and the ultimate resolutions reached were compared with individuals' suggestions on the hypotheticals and their levels of knowledge concerning available services. An attempt was made to analyze the effect of problems as a learning experience and the factors which combined to make particular individuals more effective problem solvers.

Worknten's Compensation. The first problem investigated was workmen's compensation. Of $4 l$ persons who reported being injured on the job, 11 applied for workmen's compensation ${ }^{124}$ and eight of these were successful in receiving benefits. Only one of the three that were denied benefits took any action or knew why he was turned down; he first enlisted the aid of his employer in dealing with the insurance company and then went to a caseworker at the welfare department, although he was not a recipient of welfare benefits. He was unsuccessful in achieving a favorable resolution because the insurance company maintained that he was able to work. This individual scored high in knowledge of services and was an activist on the hypotheticals, and even suggested the aid of a lawyer in the benefit-denial hypothetical. However, he was not referred to a lawyer nor did he see one on his own or indicate he would have liked to when confronted with the denial of workmen's compensation benefits. He had, however, seen a lawyer once in regard to a deed. His reason given for failure to pursue the compensation problem further was that he decided the insurance company must have been right. The situation encountered here is a recurrent one: Persons, especially those in the Negro group, who recommended legal services did not in fact attempt to utilize them. Aside from the obvious inhibiting effect of the cost of legal help, this may indicate that the legally-oriented responses on the

\footnotetext{
121 The small percentage of injured workers applying for workmen's compensation bencfits probably reflects the fact that agricultural labor is not covered by the act. N.C. Gix. STAT. § 97-13(b) (1965).
} 
hypotheticals resulted from experiencing the lack of success in using other problem-solving means. On the other hand, a number of individuals-primarily whites-who failed to have problems resolved in their favor indicated satisfaction with the methods they used and a belief that all that was possible was done in their behalf. This group was usually not legally active on the hypotheticals but was above average in knowledge of services. This difference in reaction between the white and Negro groups unsuccessful in solving their problems seems to reflect a greater feeling among the Negroes of suspicion and injustice, and a concomitant tendency at least to recommend, if not to actually utilize, legal help.

Wage Collection. Of the 11 persons having difficulty collecting wages, seven were successful in ultimate resolution. Four of the seven had lawyers and three of these were successful in receiving the amounts due. Of the other three who were successful, two had the assistance of family and friends and one of a local schoolteacher. ${ }^{125}$ One of the parties who had legal help was referred to the lawyer by the county agent and actually had to sue in order to collect. Of the four persons who were unable to collect, three did nothing but see the employer; the other saw an attorney but failed to collect because of the employer's insolvency. All of those who success,fully resolved this problem were activists on the hypotheticals, although only those actually seeing a lawyer here suggested one for the hypothetical wage problem. ${ }^{126}$ The other successful parties suggested dealing with the employer on the hypothetical as they had in fact done when confronted with the actual situation. Only one person who suggested a lawyer on the wage hypothetical did not use one when actually confronted with the wage problem, but he was successful through other means. All of the persons here who did nothing about the problem were inactive on the hypotheticals, had never had a lawyer, but were average in knowledge of community services.

lt appears that those who successfully dealt with the wage problem were more adept at suggesting appropriate remedies to the hypotheticals. Again, it is difficult to determine whether this

125 This was the sole report from the sample group of aid being sought from school authorities. School officials themselves, however, reported being consulted quite often on a variety of problems. See textual paragraphs following note 194 infra.

${ }^{128}$ See Problem eight. 
problem experience improved their perception in other problem areas or whether they solved the problem because they had better perception. That those who went through the problem without successful resolution did not appear to be active on the hypotheticals, legally or otherwise, suggests that experiencing the problem itself is not the essential educational factor, but that actual resolution is. The fact that successful parties suggested resolutions to the wage hypothetical similar to the ones they utilized for the real problem at least indicates that actual experience has some educational effect.

Benefit Denials. Of the 32 Negroes and 28 whites receiving nonwelfare benefits, 48 were receiving social security, 7 veterans' benefits, 4 retirement payments, and 1 unemployment assistance. Only three Negroes and three whites in this group reported benefits being held up when they should not have been. Five of these were receiving social security and one unemployment. Only the subject receiving unemployment did anything. He talked to his former employer and accepted the employer's explanation that his benefits were withheld because he was not attempting to find another job. ${ }^{127}$ The greatest number of responses to the social security hypothetical were similar to the responses of the subjects faced with this actual social security problem. The subjects indicated that they did not know what to do, and therefore did nothing. Four out of the six subjects actually having the benelitdelay problem were semi-active on the hypotheticals but none suggested a lawyer for the social security problem. All, however, rated at least average on the knowledge section of the questionnaire. The data produced by this question seems to confirm the hypothetical's indication that the level of proficiency for everyone dealing with social security difficulties is quite low, especially in a matter not having particular urgency such as a delay of benefits.

The proficiency, in dealing with an actual reduction in social security benefits was somewhat better. Of the nine persons reporting this kind of difficulty, five took some kind of action and

12 Compare N.C. Pub. Assistance Reg. § 210 (III)(f): "Any child (between 16 and 21 years of age) or parent required by this section to engage in gainful employment, but for whom no gainful employment is available, shall ... (3) make reasonable and continuous efforts to find gainful employment." 
two succeeded in having the amount of benefits restored. Both of the two successful parties utilized the services of a lawyer ${ }^{128}$ and were successful in restoring their payment. Both of their problems had arisen from their own filing of erroneous information. Two others went to the social security agent visiting in the county seat, ${ }^{129}$ and one wrote a letter to the regional office. These three persons were informed by social security that their benefits were cut because of too much income; they accepted that explanation. The two persons who actually had lawyers here were among the few who had suggested a lawyer on the social security hypothetical and were also among the activist group. None of the unsuccessful parties suggested seeing a lawyer on the hypothetical, although two suggested seeing the social security agent despite the fact that this approach had not been productive for them. Possibly the experience of going through the administrative channels and at least receiving a satisfactory explanation, if not the lost benefits, was a factor encouraging willingness to take this action again. Those who did nothing about this problem had also responded that they did not know what to do with the hypothetical problem, although three were at least semi-active and four were above average in knowledge of community services. With the exception of the subjects who successfully utilized legal services or recommended consultation with the social security office, experiencing this social security problem did not appear to greatly improve the ability to deal with the social security hypothetical.

Where the problem concerned an absolute denial of benefits, the subjects became still more active in seeking a resolution. Of 13 persons faced with this situation, the ten subjects who were denied social security all took some form of action. The three denied unemployment did nothing. All three of the unemployment denials were on the ground that the individual had not accepted available employment and the subjects all accepted this explanation. The social security denials involved failure by the subjects to prove

\footnotetext{
12x Apparently neither individual considered the social security advice obtained from a lawyer to be "legal services." They did not report this problem as "one which they took to a lawyer" on the questionnaire section concerning the kinds of problems confronted; both indicated that they had seen a lawyer only about deeds.

129 There is no social security office in the county, but an agent from a neighboring county makes periodic visits to the sample county's court house to hear complaints.
} 
physical disability or age, or insufficient payment into the program..$^{130}$ Six of the subjects denied benefits went to the social security agent and two of the six, both of whom were involved in disability disputes, were assisted by counsel. ${ }^{131}$ Four others wrote letters to the regional office. None of these persons were successful in getting benefits but their failure did not discourage them from recommending consultation with the social security agency on the social security hypothetical. The two who had legal assistance, however, appeared discouraged by their lack of success, as they did not recommend a lawyer on the social security hypothetical. All of the group who took action here were active or semi-active on the hypotheticals in general, again perhaps suggesting that going through the administrative procedure of. disputing a social security claim is conducive to activity in other problem areas, whether success is experienced or not. Of course the ready explanation exists that only those who demonstrated their inclination toward activity on the hypotheticals could be expected to take action here, and this is somewhat supported by the fact that those who experienced actual social security problems, but were inactive toward resolution, were also inactive on the hypotheticals and in other problem areas. A final observation can be made that although none of the ten parties faced with an absolute benefit denial were successful in asserting their claims, when confronted with a hypothetical positing absolute denial they did not suggest the services of a lawyer, even though many were legally active with other problems, most had actually seen a lawyer at least once, and indeed two had utilized a lawyer with the very problem. These subjects' experience with their actual social security problem did not appear to impress upon them the need for legal assistance, as did some other problem experiences. ${ }^{132}$ Perhaps one can conclude that most subjects, although denied benefits, did not feel unjustly treated by the social security agency. ${ }^{133}$

${ }^{150}$ The amount of time one is required to contribute towards Social Security before receiving benefits is dependent upon the year of birth, sex and the year the individual reaches retirement age. See 20 C.F.R. $\$ \S 404.101,404.108-404.114$.

131 The two assisted by counsel did not, however, report this on other parts of the questionnaire as a problem with which they had legal assistance.

132 See, e.g., textual paragraph following note 126 supra, and textual paragraphs accompanying notes $146-47$ and note 153 .

Is Each of the group which had experienced social security problems made the suggestion 
Welfare Problems. Of the 20 Negroes and 15 whites receiving welfare benefits, ${ }^{134} 20$ were receiving aid to families with dependent children and 15 old age assistance. Twelve Negroes were receiving AFDC and 8 received old age assistance while 8 whites were receiving AFDC and 7 old age assistance. Only three subjects reported having benefits held up, and all of these were receiving AFDC. Both of the Negroes who had their benefits delayed took action by going to the welfare department. Both were informed that a mixup had occurred and succeeded in adjusting the problem. One of these was very active on the hypotheticals, had suggested a lawyer to the benefit hypothetical and indicated that she would have liked to have had a lawyer with this problem. The other successful person was semi-active on the hypotheticals and both were above average in community knowledge. The white subject who did nothing here was not active on the hypotheticals but was also above average in knowledge of community services. Although the number of subjects involved here was too small upon which to base a conclusion, the difference in activity levels between the races appeared in many areas on the questionnaire. ${ }^{13 i}$ Negroes frequently felt the need to take action, and did so when they believed they were being dealt with unfairly. White subjects demonstrated a greater inclination toward letting things take their course and a higher degree of confidence in the authorities with whom they were dealing.

Four Negroes and six whites indicated that their welfare benefits had been reduced when they thought they should not have been. All of the Negroes and two whites reporting this difficulty were receiving aid to dependent children. Those receiving AFDC indicated that these cuts occurred every summer and that the reason given by the welfare department was that their family

to the social security hypothetical, see textual paragraph accompanying note $6 \mathrm{I}$, that consultation be continued with the social security agency.

13: These figures do not include those receiving food under the Surplus Food Commodities Program, see note 98 supra, administered by the welfare department. Almost $20 \%$ of the Negro sample group reported receiving surplus food at one time or another. There were no reports from the sample group of denials of surplus food, perhaps because the minimum income is higher for this program than for welfare benefits. No white members of the sample group reported receiving surplus food.

${ }^{135}$ See, e.g., text generally accompanying note 86 supra. See generally. How NORTH Carolina White and Blacks vieiv: Each Other, Government and Police. Housing. Poverty. Educatio: aNi EuploymeNt (Summary of a 1968 opinion poll conducted by Oliver Quayle \& Company for the North Carolina Fund). 
earnings were too high. The old age benefit cuts also resulted from increases in earnings or social security. All of the subjects receiving AFDC reported that they were told of the cut before it was made and before any members of the family were working. This fact supported the information garnered from other sources about the welfare department's method of cutting or terminating benefits at the beginning of the tobacco season. ${ }^{136}$ The welfare department "investigates" the income of families receiving AFDC by having landlords or farm operators inform the department of what families "will be working" for that employer during the tobacco season. The wages which all the members of that family can earn by working are then computed ${ }^{13 i}$ and the family's benefits will be reduced by that amount or terminated if the maximum level is exceeded. The family must then choose to work for the employer or reapply for benefits. ${ }^{138}$ All of the subjects reporting these cuts during the tobacco season did nothing about it, accepting the explanation of the welfare department that when work was available their benefits would be cut.

Seven subjects indicated that their welfare benefits had been entirely cut off. All of these were receiving AFDC and learned of the termination at the beginning of the tobacco season. The number of children older than 14 in these families who could work was sufficient to raise their total possible wages above the minimum family income level for welfare eligibility. Again, subjects experiencing this difficulty indicated that the reason given them was that the children would be working or that work was available. All but one person accepted this explanation. The lone dissenter went to the director of the welfare department and complained, but was told that her benefits would not be reinstated as long as work was available. Figures revealed that this problem was experienced by an equal portion of whites and blacks although some of each race indicated a belief that they were denied benefits in this situation because of their race.

\footnotetext{
133 The welfare department, the OEO Community Workers and the county commissioners independently reported the same aspects of the tobacco season benefit termination.

is The Director of the welfare department reported that the summer of 1968 would be the first time that the wages of children under 14 years old would not be considered as part of the family's income.

${ }^{12 x}$ If the family actually has no income, it theoretically must be recertified for welfare benefits. However, the welfare department reported few instances of this occuring.
} 
Two important observations might be made about the "tobacco season" termination problem. First, the state welfare regulations ${ }^{139}$ do not stipulate that AFDC benefits should be reduced or cut off when it is "reported that children will be working." Only when the wages of members of the family actually employed cause the income of the family to rise above the minimum level are benefits to be affected. To allow employers to notify the welfare department as to who will be working and to have benefits cut off on this basis permits the employer to select his work force and insure that they will be willing to work since their other means of support will be unavailable. Certainly the welfare department is not the appropriate agency for insuring that the farm operators' manpower needs will be met. Beginning with the summer of 1968 attitudes among the community leadership concerning this proeedure evidenced some change. ${ }^{140}$ Several commissioners who are also large farm operators reported favoring the continuance of welfare benefits while children are employed during the tobacco season. Their explanation here was that people who are willing to work should not be "penalized" and discouraged by the loss of welfare, again demonstrating their interest in insuring a work force. The welfare director expressed similar feelings, adding that she believed the minimum income permitted was too low. During the summer of 1968, income of children under 14 was excluded for the first time in determining the family income. The wages of children over 14 could also be excluded if the family would agree to place the child's wages in a bank account under welfare supervision to be used for educational expenses.

A second observation relates to welfare benefit recipients' unwillingness to take action regarding reduction or termination. Of the 16 persons experiencing this problem, four were activists on the hypotheticals and well over one-half were semi-active. The knowledge of community services among this group was above average, as it was for almost all those receiving welfare benefits. The subjects here who also experienced actual problems in the other areas studied were among the more successful in resolving them.

\footnotetext{
139 "The net income of all children included in the budget must be counted as a family resource except earnings of children under the age of 14 and those amounts being saved for educational purposes. . . ."N.C. Pub. Assistance Reg. \$ 321(3)(a).

${ }^{110}$ See text two paragraphs beyond note 196 infra.
} 
From all the data available, it appeared that those persons who were receiving welfare assistance were better than the sample group in general in recognizing and suggesting resolutions to problems, and were better informed on community services in general; but in dealing with the welfare department itself, they were extremely inactive in raising and pursuing complaints. The fact that all of the recipients of welfare are either women, the elderly or the disabled might be suggested as one explanation for a lower level of activity; but this lower level was not demonstrated by these persons in other areas probed.141 The implication is that although the welfare department appears to be somewhat successful in improving the informational level and ability to perceive and handle problems among its clients, this ability apparently does not carry over to problems owith the welfare department itself. Possibly because of welfare clients' financial and educational dependence on the welfare department, they seem easy to accept and slow to challenge anything that the department tells them is proper.

A group of nine Negroes and four whites reported being totally denied welfare assistance when they applied for benefits. Three of the six Negroes denied AFDC reported that the reason for denial was that the child involved was not related to them, ${ }^{1+2}$ and three indicated denial because of their refusal to swear out a warrant for non-support against the child's father. The welfare department admitted that this tactic is sometimes used to encourage those entitled to child support to enforce the obligation against the father when he is present in the area. The two persons denied aid to the disabled reported being unable to prove their disability, and the five who reported a denial of old age benefits said the reason was their refusal to submit to the welfare lien. ${ }^{1+3}$ Actually this could more properly be called a refusal to accept benefits rather than a denial by the welfare department. Only two of these five subjects, the

\footnotetext{
is See, e.g., textual paragraph following note 149 infra.

"S See N.C. Pub. Assistance Reg. \$210(111)(a): "A child is eligible for AFDC who (A) is living in a place of residence maintained by the father, mother, grandfather, grandmother, brother, sister, stepfather, stepmother. stepbrother. stepsister. uncle, aunt. first cousin. nephew, niece, adoptive father, adoptive mother, grandfather-in-law, great grandfather. grandmother-in-law, great grandmother, brother of the half blood, brother-in-law, adoptive brother, sister of the half blood, sister-in-law, adoptive sister, uncle-in-law, great uncle, auntin-law, and great aunt."

"See note 102 supra.
} 
whites, were actually subject to the lien since the other three were not real property owners. While according to statute the lien only attaches to real property, even the director of the welfare department was unaware that it did not attach to "all property of value." The welfare department's failure to understand the operation of this lien and to make that operation clear to prospective clients results in the deprivation of benefits to persons who otherwise qualify. Misinformation in regard to the lien also leads to other misunderstandings in the community. For instance, three of the six Negroes who were denied AFDC thought the real reason was that they would not accept the welfare lien. They knew of white families who were getting this assistance and whose property was not "taken under the lien," "1.4 and consequently they felt that they were being discriminated against because of their race. Actually the lien would not attach to the property of anyone receiving AFDC, and even if it did, it could not be foreclosed during the lifetime of the recipient. In fact neither the county attorney nor the director of the welfare department could recall one instance of a welfare lien being foreclosed. The welfare director reported that frequently after the death of persons receiving old age benefits the heirs do not consider the property theirs because of the lien and allow the taxes on the property to fall in arrears. The county then forecloses and sells the property for back taxes after the lapse of the welfare lien, ${ }^{1+5}$ resulting in the proceeds of the sale going into the county treasury rather than the state welfare fund.

Only 2 of the 13 people denied welfare took any action, although again over one-half of these persons were activists or semiactivists on the hypotheticals and 5 had had the services of a lawyer at some time in their lives. Members of this group who had actual problems in other areas, such as consumer or housing difficulties, usually had taken some action toward resolution of those problems. When asked why they did nothing about the welfare denial, a common response was that "if the welfare

\footnotetext{
II" Many of the subjects did not understand the concept of the lien at all and apparently believed that they would lose their homes after they had received a certain amount in benefits. See note 102 supra.

in N.C. Gen. Stat. \$108-30.1 to 108-30.3 (1966); N.C. Pub. Assistance Reg. $\$ 430$.

It is interesting to note, however, that 33 Pubt.1c Wici.fari: Niws 10 (March 1969), reports that $\because \ldots \$ 985,695.51$ [was] recovered through the [North Carolina] Lien law during the past two fiscal years."
} 
department refuses assistance, there is no use doing anything about it or bothering to see them again." 145 Both of the persons taking action with this problem were whites denied old age benefits. One consulted his landlord ${ }^{14 i}$ who advised him to forget about it, while the other, with the aid of her daughter, was successful in receiving benefits through discussion with the welfare director. Both of these persons had been semi-active on the hypotheticals, but had no other characteristics distinguishing them from those who did nothing about the welfare problem. The fact that almost all of the persons having a welfare problem were more active on the hypotheticals and other actual problems than the sample in general again suggests some educational or motivational effect of this experience. Figures here are somewhat skewed, however, by the fact that except for those suffering an absolute denial of benefits, those having welfare problems were by hypothesis members of the welfare recipient group which generally evidenced greater activity and knowledge. The fact that most of the twelve who were never welfare recipients but experienced the welfare denial demonstrated similar problem-solving responses to those of the welfare-recipient group adds weight to the suggestion that experience in dealing with welfare may have had some effect on activism. It does, however, somewhat discredit the theory that those receiving welfare benefits are more active and knowledgeable because of services provided them by the welfare department. The best explanation, possibily, is that those who apply for and receive welfare as well as those who apply for and are denied benefits are among the more active, betterinformed group in the first place and therefore provide similar response patterns, regardless of their experience.

Consumer Problems. Nine Negroes and 10 whites reported purchasing something for cash and later finding it to be in poor condition. These items ranged in price from $\$ 15$ for clothing to $\$ 850$ for a tractor. Most of the items were appliances or furniture selling for between $\$ 25$ and $\$ 100$. Although over half of

\footnotetext{
III A much larger percentage of those denied social security benefits than those denicd welfare benefits took some action.

in The word "landlord" is used here to refer to the agricultural landlord having tenant farmers or farm laborers living on his land, and will be so used throughout the study unless otherwise noted. A discussion of the landlords" role as a problem solving resource is contained in Part 11 of the study.
} 
the group experiencing this problem were activists or semi-activists on the hypotheticals and all but five suggested a lawyer to the consumer hypothetical, none of the subjects sought the aid of a lawyer with his actual problem. Five of the nine Negroes took action in going back to the seller and two were successful in having the item repaired. Seven of the whites took such action and all of them were satisfied in some way. Generally, success was better with the more expensive items, although some persons making purchases of over $\$ 200$ did nothing or had the item fixed at their own expense. Only one of the subjects having this problem purchased from a door to door salesman. The rest dealt with local merchants. The greater willingness on the part of white purchasers to complain to sellers and the noticeably more satisfactory treatment they received, together with the fact that a larger number of Negroes suggested legal help, seems to indicate some disparity of treatment between black and white customers by the local businesses. Only one subject sought the aid of anyone other than the seller. ${ }^{148}$ With the aid of his landlord he succeeded in having an $\$ 800$ tractor repaired without cost:

Almost 90 percent of the sample group reported purchasing some item on credit or the installment plan. Of this group nine Negroes and 12 whites reported receiving an item in poor condition. ${ }^{1+9}$ Six were out of county purchasers-four through a catalogue and two from distant merchants; only one was successful in making an adjustment. The remainder of the group purchased from local businesses, and most of the itcms financed were applicances in the $\$ 100$ to $\$ 200$ bracket, but a few automobiles and farm implements selling for as high as $\$ 1600$ were also included. Negro subjects were much more successful in achieving satisfaction after expericncing the installment purchase problem than the cash sale problem. Only one Negro chose to do nothing while eight returned to the -seller to have the item repaired. Six of the eight

\footnotetext{
"1x There is no Better Business Bureau within the county, and only one interviewee suggested resort to a bureau outside of the county.

'1" Misrepresentation of installment obligations or rental arrangements was not a significant problem in the county according to reports of both the rural poor and the community leaders. Only one subject complained of having to pay installments for an item he thought he had rented. The item was a freezer and although the interviewee had suggested a lawyer to the consumer hypothetical and was among the activist group, he did nothing but make the payments.
} 
were successful, five of them after stopping payments. None of those stopping payments had the item repossessed, or had any legal action taken against them. Eight of the white purchasers appealed directly to the seller and five were satisfied. Three other whites repaired the item themselves, and four made payments without doing anything. Two of the five persons who took action here but were unsuccessful and three who did nothing recommended a lawyer on the consumer hypothetical, perhaps suggesting some effect of this problem experience upon their view of the need for assistance. Most of those who successfully adjusted their problem here recommended consultation with the seller on the consumer hypothetical. It is interesting to note that although 13 subjects suggested a lawyer to the consumer hypothetical, none utilized a lawyer when actually confronted with the problem. This probably indicates a recognition on the part of the sample group that for problems involving $\$ 100$ to $\$ 200$ items, the aid of a lawyer would be too expensive to be practical, especially when success was generally gained by negotiating with the seller. About one-half of the persons who successfully adjusted this problem were at least semi-active on the hypotheticals. The legal inactivity of the remainder did not seem to impair their problem-solving ability in this situation where self help was available.

Four of the five welfare recipients who had this consumer problem reached a successful resolution. The better than average performance in problem solving by welfare recipients is somewhat surprising in light of the fact that most of them are by definition elderly or disabled prople or women with young children who might be expected to be less active. None of these welfare recipients, however, indicated that they had any actual assistance from the welfare department in adjusting their problem. Indeed, only two of the subjects having this consumer problem reported seeking any outside assistance. One talked unsuccessfully to another dealer in the same type of merchandise; the other sought the assistance of the sheriff who referred him to the seller where a satisfactory resolution was reached.

Twenty-four subjects reported buying án item or signing up for a service on the time payment plan and later being charged more than they believed they owed. The racial composition of this group was balanced. Again most of the items were home appliances 
but were of a more expensive type than those involved in the consumer problems discussed above. Of those buying from a door to door seller, one person reported being overcharged for insurance and two for home repairs. One-half of the 24 subjects took action with this problem, the remainder voluntarily making their payments. Five stopped payments without any difficulties, two interrupted payment but finally paid under threats, and two terminated payment and had the items, a tractor and a car, repossessed. Three were able to show their receipts and satisfy the seller in that fashion. The group that took action here was composed of nine activists and three semi-active persons. Although the same remedy of stopping payment was available here as it was in the shoddy-goods problem, a noticeably smaller portion of the sample group took action. This probably results from the fact that many persons were not sure exactly how much they actually owed on the item or how much they had already paid. $1 \mathrm{t}$ is interesting to note that of the three persons having this problem who suggested a lawyer to the consumer hypothetical, two had suffered repossessions. Both of these reported that they would have liked legal help with this problem but could not afford it. The repossession experience, at least in this situation, appears to have created an awareness of the value of legal protection.

Forty-one persons reported making an installment purchase and being unable to make the payments. Again, most of these items were home appliances, although eight persons had experienced this difficulty with farm supplies. Except for four cases of insurance, all of these items were purchased from local merchants. Thirty-three persons made arrangements to postpone paying and ultimately paid for the item, one person reported refinancing through the seller after the debt had been sold to a collector, and several requested loans from friends or relatives. Only four persons reported a repossession and two of these were able to redeem the item afterward. The items repossessed included two automobiles, a tractor, a heater and a television. The person losing the heater and television was the only one who had more than one item repossessed after missed payments. This individual reported that he had paid $\$ 500$ of the $\$ 700$ due when the items were repossessed. In general, however, repossessions resulted most frequently when default occurred while less than one-half of the item's price paid. 
Loan and Credit Problems. Five Negroes and 23 whites reported making crop loans ${ }^{150}$ that they were unable to pay when due. Almost all of the white subjects borrowed from a bank, the Farmers Home Administration or Commercial Credit Corporation, while most Negroes borrowed from private finance companies. The public credit program policies which require a somewhat stable financial position for a borrower probably limit their availability to the lower income Negro group. ${ }^{151}$ Again the great majority of persons unable to meet their obligation arranged for an extension of time. Three farm operators having large loans, who happened to be the only individuals who had recommended a lawyer on the loan hypothetical, refinanced through FHA. All of those who refinanced, as well as a few others, also sought advice from the county agent, but no others reported consulting anyone but the creditor. Three foreclosures were reported; two were by finance companies and one by a bank. There were no reports of FHA or Commercial Credit foreclosures. In two the subjects lost farm equipment and in one an automobile. Over one-half of the persons experiencing difficulty in paying a loan were below average in both activity and knowledge of services, although they would have to have been among the more solvent or industrious individuals in the community in order to obtain a farm loan in the first place. Those employed in fulltime farming operations in general, as well as this group which had defaulted on farm loans, however, were not among the more active in problem resolution or the more knowledgeable in community services outside the area of agriculture.

Only four persons reported being told they owed more than they thought they had borrowed on a crop loan. Three who borrowed from their landlords questioned the amount but paid without doing anything else ${ }^{152}$ since they feared being put off the

\footnotetext{
${ }^{150}$ The crop loan mentioned here is not the type generally utilized in the tenant farming situation. Typically, the tenant is given periodic advances by the landlord for the production of the crop and rarely has any problem in paying off unless the crop fails since all of the advances are secured by a lien against the crop. and the crop cannot be sold without the landlord's permission. See note 85 supra.

${ }^{131}$ One of the supposed prerequisities for an FHA loan is the inability to obtain private credit. The figures revealed, however, that the very low income groups resorted to finance company loans at high interest rates rather than the FHA programs, perhaps because the FHA financial responsiblity requirements were greater.

132 The type of loans involved here were the landlord-tenant loans discussed supra in note
} 
land. The one party who took action had borrowed from a farm supplier. Acting on the advice of his father he refused to pay and was not bothered again about the amount.

Sixty-four persons reported that they had more bills than they could possibly pay. Thirty of these persons reported that these bills were in the area of food and medical expenses. Fifteen indicated farm operating expense as the source of the problem, and the remainder found the difficulty with consumer items. Most of the 27 Negroes in this group had debts between $\$ 100$ and $\$ 300$, while most whites ranged between $\$ 200$ and $\$ 1000$ with almost half above $\$ 500$. These figures probably reflect the greater availability of credit to the white group or perhaps that whites owing lower amounts did not consider them to be debts which they could not possibly pay. The small farm operator or farm laborer most frequently reported this difficulty. Very few on welfare, only six, reported being in this condition and most of their debts were in the area of consumer goods.

Five of the persons on welfare reported that they discussed the difficulties with their caseworker and tried to have their payments adjusted to their needs. The caseworkers also suggested seeing the creditor for an extension, and the welfare department reported occasionally intervening with a creditor on a client's behalf. One individual who found himself in this difficulty asked the advice of a lawyer and was referred to the welfare department which arranged for assistance with his medical payments. This individual did not, however, suggest a lawyer on any of the hypothetical problems or report that he had ever had legal help. So far as he was concerned, positive experience with the advice of counsel did not appear to be instructive.

Although the incidence of difficulty in meeting debts was high among the sample group, the number of repossessions and foreclosures was small. The majority of persons reported being able to negotiate some form of extended payment. Only 12 persons reported ever being sued for a debt. Four of these were represented by counsel in the suit and two of those represented reported

150. Generally, the landlord will keep a running account of advances and settle with the tenant at the end of each season. Unless tenants keep their own account of advances, they are, of course, in a difficult position to prove, or indeed to be sure themselves, that they have been overcharged. 
winning the case. Six indicated that a default judgment was entered against them and two others appeared on their own behalf and lost the case. All of the individuals who had the services of a lawyer and those who appeared in court on their own were activists on the hypotheticals. This is quite different from the tendency observed in criminal defendants to be inactive on the hypothetical problems, ${ }^{153}$ and possibly reflects a greater confidence in the possibilities of defense among those with experience as civil defendants. None of these individuals suggested a lawyer for the loan hypothetical but the hypothetical posed the problem of a debt actually owed.

Housing Problems. Thirty-four Negroes reported renting their dwellings, 29 owned the properties, 13 were tenant farming and the remainder lived in a quasi-tenant arrangement..$^{\text {ist }}$ Thirty-five whites were renting, 41 were property owners, 18 were tenant farmers and the rest lived as quasi-tenants. Almost 25 percent of the sample group reported that a landlord had refused to provide repairs or improve living conditions. Specifically, the most frequent problems were with the water supply and plumbing, but leaking roofs and defective heat were also common. Only nine of the persons having problems were actually renting, however, and when they complained or threatened to stop paying rent, at least some repairs or repair materials were provided in all but two cases. Such success was not experienced by the tenant farmers or quasi-tenants living without meaningful rent payments. Since the landlord had only a marginal economic interest in seeing these dwellings occupied, only three persons, all of them actual tenant farmers, ${ }^{15 i}$ were provided with repair materials. Indeed only 12 even complained to the landlord, the remainder more or less assuming that repairs were

is See text accompanying notes 78 \& 79 supra.

is See note 17 supra. Tenunts who paid no rent, or a rent of less than $\$ 10$ per month. and who worked for the land owner were considered "quasi-tenants."

iss The landlords interviewed indicated that they would sometimes provide repair materials for their tenant farmers because responsible tenant farmers were difficult to find. Day laborers who were permitted to live on the land were not so highly regarded by the landlords. and the increased availability of migrant help lessened the landlord's interest in having access to a convenient source of day labor. The landlords expressed the view that as long as the houses were standing, they would permit people to live in them, but they would not make any investment in the houses. One volunteered that he would close his tenant houses if compelled to make repairs.

For a contemporary discussion of landlord-tenant law, and the subject of constructive eviction in particular, see 43 WASH. L. REV. 461 (1968). 
their own responsibility-the point of view expressed by most of the landlords interviewed. The majority of persons not renting for value reported that they tried to make repairs themselves or did nothing. Seven indicated that they moved to better facilities.

The majority of persons who actually experienced repair problems suggested that they would make their own repairs on the rental-property hypothetical. A number also suggested moving out. All of those who were actual renters who had had this problem suggested a stoppage of rent, a remedy that appeared quite effective for them. A few subjects suggested the health department, but none took their problem to that agency..$^{156}$ Only three persons sought assistance from anyone but their landlords, and these were welfare clients who consulted their caseworker. Since two of these were actual rental tenants the caseworkers were able to negotiate with the landlords for repairs. The majority of welfare recipients lived in rental or self-owned dwellings and therefore did not experience the degree of repair problems suffered by the tenant farmers or quasitenant laborers.

Except for those who were actual renters, most of the persons experiencing repair problems were rather inactive on the hypotheticals and ranked below average in community knowledge. This probably results from the fact that most of the problems were experienced by the tenant farmer or farm laborer groups which in general were less active and less knowledgeable.

Only seven persons reported that their landlord attempted to evict them. Four of these were quasi-tenants and three were actual renters. The quasi-tenants were evicted for inability or refusal to work while two of the renters were behind in rent. Six of these persons left voluntarily. One renter whom the landlord attempted to evict because of an argument refused to leave, physically threatened the landlord, and is still living on the premises. Both of the renters who were evicted had suggested a lawyer on the housing hypothetical and one indicated that he would have liked to have had a lawyer with this problem, suggesting some educational effect of the eviction experience.

About 10 percent of the sample, eight Negroes and 14 whites,

${ }_{158}$ This suggestion probably stemmed from the fact that the health department sanitarian has been active in inspecting toilet facilities and requiring that they be made to conform to state standards. 
reported purchasing land or a house for cash. ${ }^{157}$ Another five Negroes and 25 whites reported buying a house or land on an installment arrangement. Ten of these, including three Negroes, had the assistance of a lawyer. While lawyers were most frequently used by the sample group for deeds, only one-fourth of the persons involved in land transactions utilized a lawyer, despite the fact that almost 45 percent of the purchasers rated high in legal perception. This was particularly true among the Negro land purchasers, a large number of whom were among the active group on the hypotheticals. In this area it would seem that far fewer people actually utilize a lawyer than those probably recognizing the utility of legal assistance in the situation. A few persons indicated that they consulted the clerk of the court, and a few others were advised by relatives. The remainder consulted only the seller. Just five persons reported having any problems with meeting the payments on their home or land purchases. All of these managed to arrange postponed payments.

Although no members of the sample group reported such a problem, several of the community service agencies and the local bar indicated that people in the low income group have had difficulty with "dollar-down" houses. Construction companies of questionable repute from outside the county approach landowners offering an arrangement whereby they will construct a small shell house for one dollar down and monthly payments. The purchaser is required to give the seller a mortgage on his land and the house. While the value of these houses is not over three thousand dollars the amount of the mortgage required is often over ten thousand. The construction company then discounts the mortgage to an outof-state concern which works in close cooperation with the builder. This concern collects the monthly payments until the value of construction has been recouped, often permitting the purchaser to fall into arrears. When payments fall so far behind that it appears unprofitable to continue to depend on the mortgagor, the mortgage is foreclosed and the property sold. Because the amount of the mortgage is so far above the actual value of the property there is never any excess left for the mortgagor from the foreclosure sale.

\footnotetext{
${ }_{157}$ While the substantial number of cash purchasers in the low income sample group may seem somewhat surprising, the Farmers Home Administration agent reported that building lots were available for as low as $\$ 100$ and homes sometimes sold for as low as $\$ 500$.
} 
When the Farmers Home Administration finds a home purchaser in this situation, it often attempts to refinance the purchase through a straw man, often a local attorney, purchasing at the foreclosure sale. The original mortgagor then purchases from the straw man financing the purchase at the favorable rates of an FHA loan. ${ }^{158}$ The difficulty frequently encountered here is that the construction of the typical dollar-down house is too shoddy to meet the building specifications for an FHA loan. The FHA and the county agents have sought to warn persons of the dangers of these dollar-down deals and to encourage use of the FHA home construction program. The number of these dollar-down deals, quite popular during the early 1960's, has therefore reportedly declined.

Domestic Problems. Only five percent of the sample group reported never having been married, while 26 were widowers or widows. Eight Negroes and five whites reported being divorced. Six of the eight Negroes, however, were not divorced in court. ${ }^{159}$ it is interesting to note that each of the plaintiffs in these divorce cases were activists on the hypotheticals while the defendants, whether or not they had been represented by counsel, were among the most inactive, regardless of knowledge level or other experiences. The divorce defendant's reaction to legal experience appears similar to that of the criminal defendant.

Only nine persons reported being separated from their spouses. One of these consulted a lawyer but found the cost of a divorce to be prohibitive. Eight of this group reported having the responsibility of caring for the children after the separation, and four women indicated that they were supposed to but did not receive support. Three of the four saw the sheriff about this problem after being referred to him by the mayor of one of the county's municipalities, or by the welfare department. None of

isx See App. A for information concerning FHA loan rates.

I5 The "common law" divorce whereby the spouses simply separate or remarry is a function of the presumption of validity attached to the second marriage. See, e.g., Batts v. United States, 120 F. Supp. 26 (E.D.N.C. 1954): Kearney v. Thomas, 225 N.C. 156. 33 S.E.2d 871 (1945). Also, persons living together as husband and wife but not joined in a ceremonial marriage may terminate the relationship since North Carolina does not recognize common law marriage. See, e.g., Fields v. Hollowell, 238 N.C. 614, 78 S.E.2d 740 (1953); State v. Wilson, 121 N.C. 650,28 S.E. 416 (1897). Finally, until fairly recently, marriages performed by some of the rural clergy were neither licensed by or reported to the state, creating some difficulties of proof. 
these, however, swore out a warrant because they did not want "to put the law on their husbands."

The average Negro family in the sample group had six children while the white families averaged five. Twenty Negroes also indicated that they were supporting grandchildren. Only three persons admitted to having illegitimate children. ${ }^{160}$ Two of these who were receiving AFDC went to their caseworkers in an attempt to get some support from the putative fathers. With the aid of the welfare department both were successful in working out informal arrangements with the father under the threat of bastardy actions.

Fourteen subjects reported that their children had been in trouble with the law. Non-supports, assault and battery, public drunkenness and larcency were among the offenses reported. Two subjects got lawyers for their children and another two indicated that they would have liked to have had legal assistance. Again, however, none of the subjects having this difficulty were activists and only one was semi-active on the hypotheticals, perhaps reflecting the adverse effect of a criminal experience upon perception of legal remedies in other problem areas. Ten of the fourteen gave their sole legal response on the hypotheticals to the juvenile delinquency problem. From this, one might conclude that their criminal experience at least created some awareness of the utility of counsel in the criminal, if not the civil, context. Three white subjects faced with the problem of a child in trouble attempted to intercede with the sheriff, another common response on the hypothetical. Two others did nothing, saying that the child was guilty and got what he deserved.

Crime and Criminal Problems. Since the crime rate in the sample county was quite low, ${ }^{161}$ criminal problems did not present a major area of difficulty for the sample group. Only six persons reported being the victims of a crime. All of the crimes reported were larceny. ${ }^{162}$ Four persons reported the theft to the sheriff and

\footnotetext{
160 The actual illegitimacy rate in the county was quite high however, averaging about 16 illegitimate births for every 100 live births. Brooks, supra note 8 , at 51.

tsi See note 38 supra and accompanying text.

162 The fact that the sole crime reported here was larceny perhaps suggests that people who were victims of assaults and similar offenses did not consider themselves victims of "crime." The sheriff's report to the effect that such crimes against the person are a way of life among the low income group tends to support that hypothesis.

${ }^{163}$ The figures tend to indicate that Negro crimes against other Negroes are not
} 
one of these ultimately had the stolen property recovered. Two others proceeded on their own and recovered the stolen goods. Since the county is a large geographic area with some isolated concentrations of population, the one sheriff and one deputy have some difficulty in covering the entire area. Consequently, as a county commissioner in one of the more remote areas reported, the small criminal matters are frequently "handled by the people in the area themselves."

Only two Negroes and nine whites reported having been accused of a crime. ${ }^{163}$ One Negro was acquitted upon a charge of bastardy while the other was convicted of maliciously damaging property. Neither had the services of counsel but both were tried prior to 1963. The two whites accused of murder had the aid of counsel, privately retained in one case, and were acquitted. Two others prosecuted for the manufacture of liquor were assisted by counsel and were convicted. Three other whites were convicted of drunken driving and two of malicious property damage. None of these were represented by counsel. Three Negroes and one white each reported having a peace warrant ${ }^{164}$ issued against them, three for assault and battery and one for carrying a concealed weapon; all posted a peace bond and did nothing else about it.

As has been observed earlier, no criminal defendant, whether or not represented by counsel or convicted or acquitted, was active or semi-active on the hypotheticals. Indeed, none even suggested the services of a lawyer on the hypothetical involving the criminal problem. It is of course impossible to determine whether criminal trial experiences actually lessened the subjects' propensity to think of the law as a problem-solving device, or whether this group would have been inactive along established channels regardless of their experience. It is clear, however, that the criminal encounter did not seem to increase legal perception as other problems may have done. ${ }^{165}$

prosecuted. But c/. note 38 supra. However. they could also demonstrate less frankness on the part of Negroes in admitting to criminal involvement.

I6I N.C. GE.X. STAT. \$ 15-32 (1965): "Whenever any person complained of on a peace warrant is brought before a justice of the peace, such person may be required to enter into a recognizance, payable to the State of Nortb Carolina, in such sum, not exceeding one thousand dollars, as such justice shall direct, with one or more sufficient sureties, to appear before some justice of the peace within a period not exceeding six months, and not depart the court without leave, and in the meanwhile to keep the peace and be of good behavior towards all the people of the State, and particularly towards the person requiring such security."

165 See notes 78-79 supra and accompanying text. 
Insurance Problems. Two subjects lost their automobile license plates for failure to maintain liability insurance; another lost his because of an accident involving death..$^{166}$ The latter individual, a member of the activist group, saw a lawyer and succeeded in getting his license plates back by proving no fault in the death. The others did nothing about their problem except renewing the insurance when they got the money.

Only one subject reported difficulty in collecting on his own automobile insurance. He saw a lawyer who wrote a letter in his behalf and he was then paid. Several persons indicated elsewhere on the questionnaire that they had some difficulty in collecting insurance benefits. Community leaders reported that fraudulent door-to-door insurance salesmen, especially in the area of burial insurance, have in the past preyed upon the low income group in the county. These salesmen offer insurance at a very low rate and accept a lump sum payment, often between $\$ 10$ and $\$ 25$. They do not explain the period of coverage, if indeed there is any; and if and when someone attempts to collect, the company is often found to be non-existent. Because of the smallness of the community, however, knowledge of this scheme, like that of the home repair and dollar-down house rackets, ${ }^{167}$ seemed to spread quite quickly and the incidence of persons defrauded has declined.

Summary of Actual Problems. As might be expected, the problem facing the largest number of the sample group was the inability to meet debts or make payments on purchases when they become due. While over 50 percent of the sample reported this difficulty, only about five percent were ever sued on a debt and even fewer experienced repossessions. Only a small number of those sued failed to appear in the action. The usual method of dealing with the debt problem was to arrange for an extension as was successfully done by most of the subjects interviewed.

Over 25 percent of the sample reported some type of consumer problem, either with shoddy merchandise or with overcharges.

\footnotetext{
I4 See N.C. GeN. Stat. \$ 20-17 (1965): "The Department shall forthwith revoke the license of any operator or chauffeur upon receiving a record of such operator's or chauffeur's conviction for any of the following offenses when such conviction has become final: (1) Manslaughter (or negligent homicide) resulting from the operation of a motor vehicle.....

${ }^{16 \pi}$ See textual paragraph accompanying note 158.
} 
Success in dealing with these problems was much greater in the time payment situation where payments could be stopped until the difficulty was corrected, and few repossessions resulted from the payment stoppage tactic. A noticeable disparity between the races in success with consumer problems was apparent, suggesting the difficulty Negro purchasers experience in dealing with the merchant group.

About 25 per cent of the sample also reported some problem with benefit-payment delay, reduction or denial. While a greater number of these problems were experienced with social security, success in resolving the difficulty was also better with this type of benefit. In general the proficiency in handling benefit problems was very low, especially in the welfare area, where decisions of the welfare department were accepted almost without question. Misunderstandings concerning the welfare lien and tobacco season termination added to the welfare difficulties.

While 20 percent of the sample reported problems with landlords in the maintenance of housing, a much greater number probably experienced some housing troubles since over 70 percent of the county's houses are substandard. Many persons indicated that they did not expect landlords to make repairs, and the most common resolution of housing problems was for the tenant to undertake repairs himself. Where persons were paying a rent having economic significance to the landlord, much better cooperation from the landlord was experienced. The absence of any building code application and the economic realities of the tenant and quasitenant relationships make it difficult for persons to do anything about housing conditions except to provide their own repairs or to move. The incidence of evictions, both for failure to pay rent and for inability or unwillingness to work the land, was very low-léss than five percent.

Divorce, support, criminal, and wage problems were present to a more limited extent, about five percent of the sample indicating these kinds of difficulties. A prevalence of "out of court divorces," however, was noted in the Negro group. Women demonstrated considerable reluctance in enforcing support obligations, despite the fact that the welfare department attempted to condition benefits upon the application for a non-support warrant. Considerable success was experienced by the sample in 
dealing with wage and employer problems. Finally, although a number of custody problems were revealed in discussions with the service agencies, and the sample demonstrated considerable proficiency in handling the custody hypothetical, no subjects reported any child custody difficulties.

\section{PART II:}

\section{Community Leadership and Service Agency INTER views}

Part II of the study sought, through a series of unstructured interviews, to probe the knowledge and problem-solving ability of the community service agency personnel and other community leaders such as landlords, county commissioners and employers. These individuals' knowledge level concerning existing problems and assistance available from their own and other agencies and their ability and willingness to make appropriate referrals was also tested. Special attention was given to probing the knowledge of those from whom the poor had indicated they would seek aid about particular problems uncovered in the questionnaire study. Evaluation of the survey responses centered on the leaders' perception of various problems, their attitudes toward the availability and utility of legal assistance, and the attitude of service personnel toward their clients and the importance of their work.

The Welfare Department. The county welfare department is the largest service agency in the county, consisting of a director and four caseworkers, none of them Negro. ${ }^{16 x}$ These workers service an average of 375 cases per month. As has been observed earlier in the study, the welfare department frequently serves as an information center for its clients, and knowledge among the welfare personnel of programs provided by other agencies was therefore quite good.

All of the caseworkers reported having applied for social security benefits for welfare clients. The main difficulty experienced here stemmed from the fact that the nearest social security office was some distance outside the county. The welfare department at one time provided transportation for clients to the office, but the

1ax The Director of the Welfare Department volunteered this lact and oflered the explanation that she had had no qualified black applicants. 
director reported being no longer able to budget for this expense. The caseworkers suggested that the OEO community worker group be permitted to transport people out of the county for social security services, but were informed that this was not permissible under OEO regulations. ${ }^{169}$ On a few occasions, the welfare director reported referring a client with social security problems to a local attorney and requesting. his assistance without charge. In two of these cases letters were written on behalf of the individuals and some adjustment from the social security office was obtained.

Welfare department knowledge concerning the surplus food commodity program was excellent since the welfare department plays a major part in distribution of this food. The same was true for the school lunch program. Knowledge of the OEO sanitation project, the community worker group, health department service and FHA building and improvement loans was also excellent among all of the welfare personnel. However, no information concerning the possibilities of public housing was reported by the welfare personnel, although they had had several recent inquiries on this subject.

Because all of the community service agencies are located in two adjacent buildings and the total number of personnel is low and length of service in the particular job substantial, there is a high degree of interagency knowledge and cooperation. Furthermore, most of the service agency personnel had been county residents all their lives and had known each other socially for many years. One individual suggested that the level of information was so high because a "person does not live and work in a town of four hundred for long before most people know what his job is."

The welfare department did not appear as knowledgeable in the details of its own operation, however. The director reported, for instance, that the local department declined to follow the new HEW guidelines on the man-in-the-house rule ${ }^{170}$ until ordered to do

149 Use of Project Automobiles and Other Vehicles. Community Action Memo \# 72 (Sept. 18. 1967), authorizes out of county transportation but forbids purposes serving "the private personal needs of program beneficiaries or staff members." Perhaps this limitation could be interpreted to prohibit the provision of transportation out of the county for social security services, but that would seem an erroneous view.

${ }^{100}$ Before 1968 the HEW man-in-the-house rule was incorporated in N.C. Pub. Assistance Reg. $\$ 440(111)(6)$. However, this rule was revoked on October 11,1968 . 
so by the state board. While both the caseworkers and the director were aware of the misconceptions in the community concerning the welfare lien, none were able to distinguish between the lien's attachment to real and personal property. ${ }^{171}$ The department was aware that the lien did not attach to ADC and could never be foreclosed while a widow or dependent child was living in the home. ${ }^{172}$ The director also pointed out that most aged widows only possess a life estate anyway and would thus lose nothing by accepting old age assistance. ${ }^{173}$

The caseworkers reported many instances of having to convince people that a lien would not attach to their property if they accepted benefits. The welfare department, however, had undertaken. no concerted educational campaign to clear up the lien misconceptions. The caseworkers reported attempting to explain the lien to all those who demonstrated some misunderstanding but, as was observed earlier, even the caseworkers themselves are not sure of all the lien's effects. The welfare director favored repeal of the lien provision, feeling it worked an inequity upon those who had labored to accumulate a small amount of property. She reported a decrease of over 20 percent in benefit receipients since the institution of the lien.

The welfare department volunteered information about its practice of terminating benefits during tobacco season when work was available which would raise a family's income above the minimum level. ${ }^{174}$ The welfare director opposed this practice since she felt it penalized those who were willing to work ${ }^{175}$ but assumed

\footnotetext{
in A lien is created on real property only. N.C. GEN. STAT. \$108-30.1 (1966).

172 " [N]o execution in enforcement of the lien shall be levied upon any real property. so long as such property is occupied as a homesite by the surviving spouse or by any minor dependent child of such recipient, or as a homesite by the recipient, or a dependent adult child of such recipient who is incapable of self-support . . .. ld.

173 See textual paragraph accompanying notes $143-45$ supra for further discussion of welfare department's observations respecting the welfare lien.

1 'See notes 136-140 supra and accompanying text concerning tobacco season terminations, and note 44 concerning poverty guidelines.

iij A similar view was expressed by several of the county commissioners. Neither the commissioners nor the welfare director thought such a view to be inconsistent with the basic welfare philosophy of providing for people unable to do so themselves. To be consistent with that philosophy it would seem appropriate to reduce benefits by the amount people are able to contribute themselves to attaining that level. What the director and commissioners really seemed to be saying is that the minimum income level is too low. In fact, such a view was explicitly stated by the welfare director.
} 
it to be a necessary part of the welfare program. ${ }^{176}$ The director reported a number of recent complaints about this practice and a demonstration by Negro AFDC mothers organized by one of the OEO community workers. She anticipated some appeal to be made to the state board over the matter. Although the state welfare board will provide an impartial official to hear appeals and the welfare department is obligated to assist in their preparation, ${ }^{177}$ only three appeals have been processed by the county department since 1951 .

The personnel of the welfare department, especially its director, demonstrated considerable ability in recognizing the legal implications of problems and in suggesting legal remedies. One difficulty experienced by the department, related to the adoption of children. It is necessary, for instance, that a person legally adopt a child under his supervision in order to qualify that child to share in his social security benefits. ${ }^{178}$ Also, for custody purposes, many people are often interested in legally adopting a child. The welfare director reported that these adoptions have been significantly impeded by the high legal fee involved-often around $\$ 100$. However, she was of the mistaken belief that state law requires that the adopting parents be represented by counsel..$^{179}$ The welfare director.complained of a similar situation in reference to divorce. She believed that it would sometimes be in a client's best interests to obtain a divorce, especially when domestic strife was causing the home to be unfit for children or when the possibility of a remarriage was present. Again, however, she was of the mistaken belief that state law required counsel to participate. ${ }^{1 \times 0}$ None of the

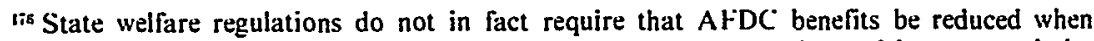
work is available. Benefits are only to be reduced by the amount of actual income made by the family. See note 139 supra and accompanying text. The welfare director reported, however, that the county commissioners, at least in the past, required that benefits be terminated or reduced when tobacco work was available.

1ii "Any individual who wishes to appeal has the right to have his case heard by a representative of the State Board of Allotments and Appeal for the presentation to that board." V.C. Pub. Assistance Reg. $\$ 610$. Sec generally . ..C. Pub. Assistance Reg. $\$ \$ 610$ 619.

17x For Social Security definitions of a child, see Social Security Act, 42 U.S.C. $\$ \$ 402$ (d), 416(e) (1964); 20 C.F.R. \$\$ 404.320, 404.327, 404.1109 (1968).

${ }^{179}$ While counsel may not be required by law, as a practical matter, a petition for adoption could not be drawn without legal assistance.

in Assistance of counsel is a practical necessity lor dralting a complaint in divorce proceedings. The general lee reported lor a divorce in the sample county was $\$ 125$. 
welfare personnel indicated that they thought legal services in these areas would be rendered without charge to a person unable to pay. The welfare director recalled a practice of about 20 years ago by which the local bar association provided free counsel to welfare clients as a public service. The director voiced strong support of the reinstitution of this practice.

Despite the prevalent attitude that a person needed money to seek the aid of a lawyer, referrals to attorneys by the welfare department were reported in adoption, divorce, personal injury, social security, insurance, wage, and real property problems. The welfare director indicated that she suggests a lawyer to people with these problems and sometimes contacts a local attorney in an attempt to persuade him to accept the case on a time payment arrangement or without fee. Neither the welfare director nor the caseworkers evidenced knowledge of the contingent fee possiblity in accident, personal injury or other types of cases.

The caseworkers reported that they would not recommend a lawyer to a client unless they could see that the fee could be fitted into the client's budget. They reported occasions on which they budgeted an extra amount for legal fees for clients and were admonished by the state board. They indicated, however, that they would continue to do so when necessary and would disguise the expense under a permissible expenditure, as was done in a "dollardown" house case where the welfare department supplied the legal fee and reported the expenditure as rental allowance.

The welfare officials apparently saw consumer problems much in the same light as did the sample group. Although they reported knowledge of a variety of consumer problems, they could offer no remedy except consultation with the seller. In welfare clients' problems with overdue payments, the caseworkers reported that they often attempted to intercede on behalf of clients, and that they were sometimes themselves approached by the seller. They reported considerable success in being able to arrange credit extensions. The welfare personnel felt that merchants often took advantage of their clients by selling shoddy merchandise at high prices, and reported that they tried as much as possible to counsel clients before they made consumer purchases.

The attitude of the welfare department personnel toward the people they serve appeared to be basically a sympathetic one. All of 
the personnel of this department are long-time county residents and expressed genuine concern about the increasingly serious plight of the large number of poor in the county and the tendency toward outward migration. While no attitudes of racial discrimination were expressed by the welfare personnel, they did indicate that many whites in need of assistance were too proud to accept welfare aid, but that this problem was not generally experienced with the Negro group. Although they felt this pride factor to be unfortunate, they evidenced a certain amount of esteem for people with this attitude. The welfare personnel also demonstrated some resentment toward any challenge to their manner of administrating the welfare program. They were particularly hostile to what they considered "agitation" over the tobacco season termination of benefits. Also, although their success in providing educational information to their clients in many areas appeared quite good, the failure to become better informed themselves and to provide an accurate picture of the welfare lien certainly inhibited full utilization of welfare services.

Agricultural Extension Service. The Agricultural Extension Service headed by the county agent was the public agency with which the second largest number of the sample group reported contact. The official function of the service is to provide advice and assistance with agricultural problems such as plant and livestock disease, soil tests and animal husbandry. A female member of the service also operates home demonstration clubs through which various home economics subjects are discussed with housewives in the community. The club meetings in the homes often serve as a focal point for distributing community information and were utilized in campaigns to publicize the need for a will, ${ }^{181}$ the surplus food program, and the availability of FHA home improvement loans. ${ }^{1 \mathrm{~K} 2}$

The county agent, a white, and the assistant county agent and home demonstration agent, both Negro, all evidenced a high level

\footnotetext{
IxI See note 80 supra and accompanying text.

tx: One of the recent projects in which the extension service and the FHA cooperated was the "waterboy project." The home demonstration agent, the county agents and the OEO sanitarian sought to interest people in the low income group in installing a "waterboy" unit in their home. This unit, designed through the extension service, provided hot and cold running water to a home for around $\$ 200$. Low income families meeting the FHA credit requirements were encouraged to make a $\$ 200$ home improvement loan for this installation. Quite a number were installed.
} 
of community knowledge. They were well aware of the various FHA loans available for home improvement and often assisted persons in applying for this financial aid. They were also aware of the OEO's community worker and sanitation programs and of the services provided by the health department. The county extension service personnel reported being frequently consulted on welfare matters both by persons who felt entitled to benefits and landlords interested in getting benefits for their employees-one agent believed that the landlords' interest stemmed from a desire to pay these workers less. The extension service reported referring all of these matters to the welfare department. All three of the extension service personnel volunteered the fact that the welfare lien was a great inhibition upon utilization of welfare services by the poverty group. They too, however, were not sure of its operation, or to what benefits and which kind of property it applied. The two Negro extension service members also reported the welfare department's practice of terminating benefits during the tobacco season. They were aware of the availability of an appeal procedure, but did not feel that the individuals deprived were competent enough to utilize it. Although they did not think in terms of utilizing legal help in the welfare area, they did suggest that the OEO community workers should be useful in asserting the right to these benefits.

All three of the extension service personnel indicated that they were often asked for advice outside the area of their official capacities. Both county agents reported that they were sometimes consulted on matters involving landlord-tenant farmer disputes. They usually suggested consultation with the landlord as a first step, and on occasion sought to mediate difficulties, although they deemed this somewhat beyond the scope of their proper duties. Both reported that if they felt a tenant was being dishonestly treated in an accounting, they would refer him to a lawyer but could recall no instances in which they had done so. However, one agent mentioned that he felt the honesty of accounting frequently varied with the price level of the farm commodities market.

Both agents reported being consulted on several occasions by small farm operators or tenants regarding crop damage from insecticides. All of these cases arose incident to aerial spraying of adjoining farms, for which the spraying companies generally carry crop damage insurance. In cases where the injured party had 
difficulty in collecting, the county agents provided him with a letter to send to the insurance company indicating the nature and extent of his damages and recommended that he see an attorney if he had any further difficulties. In some of these cases it was neccessary to involve a lawyer in writing the letter, but in no known instance was a crop damage claim litigated. The county agents also reported a number of requests for advice on social security matters. While they would sometimes assist in the preparation of forms, they reported referring all actual problems to the social security office outside the county, except for a few occasions on which they recommended legal assistance. The extension service personnel also recalled being consulted on occasion about consumer problems, especially in the area of farm machinery. Their advice here usually was to consult with the seller, although in the "dollar down" home situation they referred the persons involved to an attorney and the FHA for possible refinancing. They expressed the view about consumer purchases that was prevalent among most persons interviewed: if you sign the contract, there is nothing you can do. ${ }^{183}$

Both county agents indicated a willingness to refer an individual to a lawyer, regardless of his financial situation, especially in cases involving a small problem such as crop damage insurance. They indicated a belief that in most of these cases a letter or a phone call by an attorney would be all that would be required and that services of this kind are rendered by the local attorneys at little or no charge. Because of their agency's involvement in the program to publicize the need for a will, the extension service personnel reported many referrals to lawyers in will matters and occasions on which they themselves explained the material in the extension service pamphlet describing the intestate laws and procedures to be followed in preparing a holographic will. . $^{\text {st }}$

The attitude of the extension service personnel was public spirited. They recognized the plight of the county's large population of poor and were in favor of means, such as the OEO

\footnotetext{
18 The conspicuous absence of $\$ 2-302$, the unconscionability provision, from North Carolina's version of the Uniform Commercial Code lends some validity to this view. However, this idea is no doubt less than an accurate perception of contract law. See. e.g., Hester, Decuptise Sales Practices and Form Contracts-Does the Consumer Have a Private Remed!\%, 1968 DURE L.J. 831.

txs See note 80 supra and accompanying text.
} 
community worker program, of assisting these people to take advantage of all available programs. One of the county agents was also on the board of directors of the local OEO operation. He felt that while some improvements had resulted from the OEO programs, the power structure of the county government had impeded progress. He expressed an attitude, also observed in others among the community leadership group, that the officials of county government, most of whom were large farm operators, had opposed efforts to attract industry to the county because of their desire to insure the availability of cheap seasonal labor necessary to their own farming enterprises.

The Farmers Home Administration. The Farmers Home Administration (FHA) is a federal agency which makes available a variety of low interest loans and some grants to individual farmers or organizations in rural communities. ${ }^{\text {Ix; }}$ The sample county's branch office employed one agent and one secretary. The FHA agent stated the belief that his agency, if fully utilized, could perhaps do more to improve the living conditions of the rural poor than any other organization. Through the FHA, long-term low interest loans were available to finance farming operations, improvements of tenant houses and other farm buildings, home construction and repairs, sanitation and water supply facilities, and rural recreation programs. The FHA agent felt that his agencys' services were not being fully utilized for several reasons. He recognized that many persons were not aware of the services available and described an "outreach" program which would seek to publicize FHA benefits through the existing community service agencies including the welfare department, health department, school system, OEO and the state extension service. He reported that at present only the extension service was an effective referral agency. The FHA agent also believed that his agency was grossly understaffed. He felt that a single agent would have extreme difficulty in carrying out his administrative responsibilities with existing loans while at the same time greatly increasing the utilization of FHA services.

The agent reported a present caseload of 110 home construction or improvement loans, with a yearly addition of from 20 to 30 new

\footnotetext{
${ }^{\mathrm{ix}}$ For a detailed discussion of programs available through the FHA see Appendix A infra.
} 
cases. He deplored the fact that the yearly increases were so small. The agent's supervisory responsibilities with home construction loans are considerable. He reported that he often has to undertake the entire application himself where low income persons are involved. For construction loans, ownership of the property is essential and a title abstract is required. A mortgage on the land securing construction costs is also necessary. The services of one of the local attorneys is therefore requircd for this type of application, and the FHA agent reported budgeting the legal fees into the amount of the loan so that the attorney could be paid immediately, while the borrower could pay off the legal fees along with the rest of the loan at low interest rates.

After a construction loan is obtained the FHA provides a variety of home plans and the agent attempts to select one most suitable to the needs of a particular family. When the plan is selected the agent. must approve all construction contracts. He then supervises the construction itself to insure that contract standards are met. Through this careful program the difficulties of shoddy construction and extreme overcharges to which the poor are often subjected can be completely avoided. A number of FHA homes built for persons in the low or low-moderate income bracket were apparent in the community and one was inspected by the intcrviewers. It was an all brick, three bedroom, one story structure with modern kitchen and two baths and oil heat, certainly comparable to middle-class housing anywhere in the country. In order to build one of these homes, the agent reported that a family needs a lot and has to be able to allocate about $\$ 500$ of its yearly living expenses to housing. The monthly payments on such a home can be as low as $\$ 42$ on 33-year financing. The agent did not feel that obtaining property was a significant financial difficulty and reported that building lots in the county could be acquired for between $\$ 100$ and $\$ 500$. He did feel, however, that a $\$ 500$ per year housing expense was more than many persons in the $\$ 3000$ income bracket could afford, and expressed the view that his superiors required him to be quite conservative in estimating a family's ability to meet this burden. He favored more flexible credit policies since he reported few difficulties with present loans and believed that the high quality of the homes constructed would always result in a fair resale price.in case of default. 
The FHA agent also reported difficulty in stimulating interest in the grants and loans available to community organizations. He felt that often leadership figures in the community werc unwilling to take the responsibility for getting such programs started. $\mathrm{He}$ cited, for example, the availability of a $\$ 4500$ grant for the installation of a deep well water supply facility adequate to serve a small community. The only manner in which he has been successful in getting such facilities installed has been to solicit persons living in the community, make the application and supervise construction himself. He reported the same difficulty with recreation loans. While one such loan of $\$ 250,000$ has been made to a private group in the community for the construction of an 18 hole golf course, swimming pool and country club, the membership in this facility is entirely middle class. The agent reported considerable activity in trying to persuade organizations interested in the lower income group, or the county government to undertake a recreation loan but as yet has not found the leadership willing.

The agent reported that very few persons who were not FHA benefit recipients sought his advice about anything but loans and "dollar-down" house or repair problems. The agent indicated that the "dollar-down" house racket was once a real problem in the community and that even now 20 percent of the home loan applicants are attempting to refinance "dollar-down" purchases. The agent reported the same "refinancing after foreclosure" scheme discussed by the local bar, ${ }^{186}$ but indicated that the inferior quality of the "dollar-down" dwellings often precluded FHA refinancing because construction standards could not possibly be met. He thought it more advisable to let the "dollar-down" purchase go entirely and begin new construction with an FHA house.

Persons having FHA loans sought advice from the agent on a number of matters. The agent reported that some of the recipients of special home improvement loans of under $\$ 1500$ were welfare or social security benefit recipients and that they sought his advice on these matters. He reported making applications for social security benefits and contacting the welfare department to attempt to have home repair expenses budgeted into benefit payments. The agent

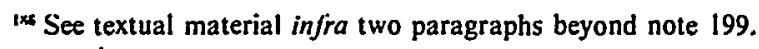


indicated that he would and did refer serious consumer problems to an attorney although he thought that minor problems would not be worth the expense. While he did not believe that free legal services were available from the local bar, he suggested that legal costs could always be financed if necessary in FHA programs and that time payment or contingent fee arrangements could often be worked out.

The FHA agent was also aware of the welfare lien and its inhibitory effect upon benefits. He reported encountering this lien on some of the property against which FHA loans were sought to be secured, and indicated that the presence of the lien would sometimes prevent a loan from being approved. He did not feel that this was necessary, however, since he knew of no instances of welfare lien foreclosures.

The FHA agent was very active in the community outside of the scope of his official duties. He was a member of an organization called the Technical Action Panel (TAP) which has representatives from the extension service, U.S. Department of Agriculture, the county commissioners, the health and welfare departments, the schools and the OEO. This panel undertook studies of the need for, and the practicality of, publicly supplied water and sewage facilities and recreation projects. A labor study was also presently being conducted with a view toward demonstrating to industry the availability of labor within the county. The FHA agent reported unsuccessfully attempting to interest the county government in establishing a Rural Industrialization Corporation ${ }^{187}$ for which federal matching funds were available to attract industry to the county. He expressed the view that the county leadership's personal interest in having cheap farm labor available may have affected their attitude toward encouraging industrialization. The same lack of interest was reportedly encountered in reference to loans for low rental housing projects available through the FHA and recreation project loans.

The FHA agent was one of the most dynamic individuals encountered among the community leadership. His awareness of the variety of federal programs available as well as his knowledge of

15i The Public Works and Economic Development Act of 1965, 42 U.S.C.A. $\$ \$ 3121$ 3226 (Supp. 1968). 
other agencies in the community was excellent. His perception of legal problems was also quite good, as was his ability to suggest some manner in which legal services could be financed. This familiarity no doubt resulted from his contact with real estate and loan transactions. The agent's own faith in the great utility of the FHA programs to the rural poor population, as well as tangible evidences of success such as the quality of the existing FHA-built homes, contributes to a hypothesis that expansion in size and personnel and some liberalization of the credit policies of the Farmers Home Administration Programs could be an important step toward significantly improving the living conditions of the rural poverty group.

OEO Programs. A local economic development corporation operates the Office of Economic Opportunity programs in the county. The operation includes the Community Worker, Rural Sanitation and Summer Recreation programs. Headstart and Job Corps programs are operated on a limited basis within the county but are controlled by a multi-county OEO corporation having its headquarters in another county.

The community worker program ${ }^{188}$ consists of three Negro and two white employees, all natives of the county, who visit low income homes in the community in an effort to assist families to identify their needs and problems and to take advantage of available assistance programs. The workers stressed that it was not their function to get services for people, but rather to provide motivation and information. The community workers did not, however, evidence the knowledge of service programs observed among the state agency personnel. While they were generally aware of the services available from the health and welfare departments, they had little information on the specifics of the programs and evidenced very little information about aid available through the extension service and the FHA. Only one, for instance, was aware of FHA home loans. Both the workers and the OEO director expressed all of the common misconceptions about the welfare lien generally prevalent among the sample group. One worker in fact reported advising a client that to accept AFDC could result in a lien 
attaching to her property. The OEO director also reported knowledge of the welfare terminations during the tobacco season but expressed the view that if work was available, nothing could be done. All but one of the workers agreed with this view. The dissenter, who organized the AFDC Mothers' demonstration against the welfare department, expressed a desire to appeal the procedure to the state board and complained that the local welfare office would only go through the motions of aiding with the appeal while actually providing no assistance. When asked about the possibility of legal help, however, she stated that under no circumstances would she seek the aid of an attorney with this matter, nor would she ever refer anyone to an attorney for any reason. This OEO community adviser stated unequivocally that legal assistance could never be of value to any poor person. While the other workers did not agree with this view, they also reported that they would not refer a person in the low income group to an attorney because of his inability to pay the fee. None of the workers believed that legal services would ever be provided without charge, no matter how desperate the case, and also evidenced no knowledge of the possibilities of a contingent fee, time payment arrangement, or even the availability of appointed counsel in indigent criminal cases.

The. community workers, when questioned on consumer problems, reported knowledge of a variety of difficulties including the home repair and "dollar-down" house rackets, insurance fraud, and a new scheme related to the OEO sanitation program. During the time when the OEO sanitarian was making inspections, two men circulated in the more remote areas of the county informing individuals that the sanitation inspector would be coming to inspect their privies. These individuals warned their victims that their privies did not conform with the state sanitation law and that they would be fined a large amount, unless of course, they wished to pay to have their privies put in order. Requesting $\$ 25$ for the service, they accepted almost any amount offered, sprinkled some lime around the privies and were on their way. This fraud was reported to one of the community workers who immediately notified the sheriff and began to publicize the scheme. No future incidents were reported but the "privy inspectors" escaped apprehension. The community workers expressed the prevalent attitude about consumer difficulties that nothing could be done so long as a 
contract had been signed. The OEO director was more perceptive of legal remedies available for consumer frauds but reported that he would only recommend legal help in the cases involving large amounts.

None of the community workers were able to suggest any remedies for landlord-tenant difficulties, recognizing the unwillingness of landlords to make repairs when receiving little or no rent. While the workers had no concept of the availability of public housing, the OEO director reported several inquiries on this subject. He and the county agent serving on the OEO board of directors had attended several meetings in the state capital on the subject of public housing but reported great difficulty in finding support from the county government in getting such projects started.

Both the OEO director and the community workers reported dissatisfaction with the OEO program. The workers felt that their training was poor, consisting only of a one-hour visit to each of the agencies about which they were supposed to provide information. They thought that the concept of the community worker as one to organize community action groups was suited to an urban rather than a rural environment. They complained that rural distances were too great, and that it was extremely difficult to get any kind of group together because of transportation problems. The director reported that the Negro population was much easier to organize into group activities. He felt that for reasons of racial prejudice, many white persons would not involve themselves in community action groups because of the Negro membership. Indeed, he felt that the OEO program was somewhat stigmatized among the white community as being "something for the Negroes" and saw considerable difficulty in getting white participation, absent some kind of segregated program. The director also doubted the utility of the community worker program. He felt that its emphasis on "stirring up" community action could lead to racial strife and feared a setback in the OEO program's progress in becoming accepted in the community. The director reported that the OEO was treated with considerable suspicion at first, but that acceptance had grown and that cooperation from the other community agencies was excellent.

One of the major complaints of both the director and the 
community workers was the lack of local control over OEO programs. While the local economic development corporation was theoretically in control of local programs, the director expressed the feeling that local suggestions were often ignored. Both he and the community workers had long recommended mobile services or some type of transportation into the county seat as being an essential part of the rural poverty program, but to date these recommendations have gone unheeded. The director also complained that highly organized programs drafted in Washington were not realistically adaptable to the remote rural area, and that many programs were of such short duration that they never got underway. He expressed the view that often a project was set up, well publicized for political advantage, and then phased out before it could have any real effect other than to add to frustration and disappointment.

Health Department. The county health department is staffed by a part-time physician and two registered nurses. Medical services provided by the department are limited to diagnosis and immunization. Except in emergencies, no medical treatment is given and patients generally are referred to a private physician or a hospital in one of the adjoining counties. Among the free services provided by the health department are infant growth tests and child care advice, immunization shots, pre-natal care, birth control advice and materials, and blood tests for marriage licenses. On occasion the health department also provided medical examinations for welfaredisability benefit claimants. Occasional referrals to the welfare department for surplus food in cases of nutritional problems and a few referrals for disability benefits were also indicated. For the most part, however, the health department medical personnel reported being consulted only on medical matters, and had very few inquiries about other problem areas.

The health department sanitarian, on the other hand, reported being consulted on a variety of problems. Although the sanitarian was an official of the county health department, his salary was being paid by OEO. As sanitarian he directed a campaign to improve sanitation facilities by seeing that privies were brought into conformity with state law. ${ }^{189}$ Further, even though it was not part

ixg See N.C. GeN. StaT. \$ .130-160 (1964). 
of the official program, he encouraged installation of indoor plumbing facilities wherever possible. A new privy conforming with state regulations could be purchased and installed for $\$ 30$. Job Corps labor, when available, was used for both construction and installation of the privies. The sanitarian often assisted in obtaining advancements from the welfare department or FHA home improvement loans for sanitation improvements. Wherever possible he encouraged those with sufficient credit to make an FHA home improvement loan in the amount of $\$ 200$ for the installation of a "waterboy unit" which could provide hot and cold running water to a house. ${ }^{190}$ The sanitarian reported personally visiting and inspecting over 1000 dwellings in the county. Most people were cooperative with his efforts to convince them to improve their facilities. On only one occasion did he have to prosecute an individual for non-compliance, and that individual was given a suspended sentence and immediately purchased a conforming privy. The sanitarian reported on occasion attempting to persuade landlords to underwrite the cost of privy installation for their tenants. Since many of these situations involved quasi-tenants not paying rent, however, many landlords refused. Those having actual tenant farmers on the land were more cooperative, usually providing the advance and adding it to the tenants' yearly debt. The sanitarian was well versed on the various assistance available through the extension service, the welfare department, and OEO. $\mathrm{He}$ also volunteered the fact that many needy persons were not taking advantage of welfare benefits because of the welfare lien. Like so many others, however, he did not understand the operation of the lien.

The sanitarian was often consulted on home improvement matters and on many occasions assisted with applications for FHA loans for a variety of projects including new home construction. He reported knowledge of a number of consumer problems in home repairs and the same of mobile homes. While he also expressed the view that nothing could be done once a contract had been signed, he did indicate that a lawyer would be the appropriate person from whom to seek advice. He stated, however, that he would not send a low income person to a lawyer except in the most

\footnotetext{
${ }^{150}$ See note 182 supra.
} 
desperate situation because of the cost involved. He did not feel that any free services could be obtained from the local attorneys, but suggested that the court would appoint a lawyer for anyone who could not afford one, although he was unsure whether this only applied in criminal cases or in any type of court proceeding. Several days after the interview with the sanitarian he approached the interviewers with the suggestion that some type of free "advising" service that could tell people what to do with their problems, perhaps free legal advice, would be of great benefit to the poor of the county. He felt that the community workers were inadequately trained to perform this function, and that the stigma attached to the welfare department prevented many persons from seeking advice there.

The Clerk of the Court. As indicated in the foregoing, the Questionnaire Survey demonstrated that the clerk of the court was often consulted concerning legal matters. The clerk confirmed these reports in regard to will and deed matters, adoption, divorce; debtorcreditor problems, and especially criminal matters. He reported that he referred all inquirers to lawyers, often giving some indication of the fee a person might expect to pay. The fees he anticipated were quite high, at least $\$ 25$ for any matter, and exceeded many of the fees reported by persons who had actually had a lawyer's services. ${ }^{191}$ The clerk volunteered his opinion that legal fees were too high, and that the poor of the community needed some type of free legal services in both civil and criminal matters. While some of the sample group reported being aided by the clerk in drafting wills and deeds, he emphatically denied such activities, stating that they would constitute unauthorized practice. ${ }^{192}$ The clerk's knowledge of the OEO, welfare and extension service programs did not go much beyond acquaintance with the personnel operating these agencies. He was, however, aware of the welfare lien, that it attached only to real property, and that it lapsed after a certain period.

The clerk was also active in a number of other problem areas. He reported being consulted occasionally on consumer problems and indicated that he would refer these to a lawyer unless some

פI See textual paragraph accompanying note 91 supra.

to: The clerk of the court is not required to be, nor was he, an attorney. S'c N.C. (ik:x. STAT. \$ 2-2 (1953). 
criminal charge could be made out, in which case he would assist in obtaining a warrant. In consumer debt situations the criminal warrant was sometimes used to compel payment, especially where a check had been dishonored. Warrants were also sometimes utilized to compel the return of payments to purchasers where consumer frauds could be characterized as criminal violations. The clerk reported the greatest use of warrants in the child support area. He indicated that before the welfare department would provide AFDC benefits, mothers would be required to swear out a non-support warrant, at least if the father was present in the area. The clerk exercised considerable authority in child custody matters, making preliminary rulings as the juvenile judicial officer while the court was not in session. ${ }^{193}$

The clerk also served as an officer of both the local magistrate's and the state superior court. He reported that the number of civil cases involving less than $\$ 300$ which can be tried before a magistrate ${ }^{194}$ was quite low, and that in most of such cases the defendants appeared, although they were rarely represented by counsel. This report was corroborated by the low incidence of small claims actions and the even lower incidence of default judgments discovered among the sample group. The clerk indicated that counsel was appointed in all criminal cases in the superior court except the most minor misdemeanors and stated a belief that fees allowed counsel were quite generous. He showed the interviewers his record of fees in appointed cases, which included appointments in non-support, drunken driving, and assault and battery cases as well as more serious offenses. Fees ranged between $\$ 50$ and $\$ 150$. One figure which cast some doubt upon the clerk's belief in the generosity of appointed counsel fees was $\$ 100$ for a murder defense. The clerk volunteered that he favored the establishment of a public defender service for the county and stated that a similar service in civil matters was also needed.

School Officials and the $N A A C P$. The principals of both of the county's high schools, the teachers association, and the past superintendent of schools have been active in the desegregation movement. The principal of the Negro high school was also a leader in

\footnotetext{
$10 \mathrm{See}$ note 72 supra and accompanying text.

'\$ N.C. GE:X. STAT. § 7A-210 (Supp. 1967).
} 
other NAACP and welfare rights activities. A freedom of choice plan had been originally instituted to achieve desegregation. When it was learned that it did not satisfy HEW integration guidelines, the teachers association and the superintendent of schools opposed the continuation of the non-conforming program. However, the board of education, acting on the advice of its attorney, refused to alter its position. Suit was filed in federal district court to enjoin the continuation of this token desegregation program. The superintendent resigned his position as a result of the controversy and was strongly supported by most of his teaching personnel.

The principal of the black high school reported that he was frequently consulted on matters outside the scope of his school responsibilities and attributed this fact both to his school position and to his leadership of the local NAACP. On many occasions he assisted with social security applications. He suggested the aid of an attorney for social security difficulties, indicating that a percentage fee arrangement could be worked out in this and other areas, such as accident cases. He reported referring will inquiries to the clerk of the court for the drafting of a free will. While he also suggested a lawyer for consumer difficulties, he felt that the amounts usually involved would not justify the fees. He believed that on no occasion could one expect to be assisted by a lawyer without charge. While he was sensitive to the absence of a Negro attorney in the county, he did not believe that free assistance would be provided by any of the Negro attorneys he knew from outside the county. He did, however, place great confidence in the NAACP and Justice Department lawyers who had been active in desegregation efforts and seemed proud of the fact that all of the local civil rights progress had been made in the courts rather than through demonstration.

While the Negro principal believed that blacks were somewhat inhibited in the use of legal services by the absence of a lawyer of their own race, he reported that most Negroes took their problems to the very attorney who had advised the school board against compliance with HEW school desegregation guidelines. The principal felt that this attorney's involvement in local politics made him more inclined than others toward doing favors and charging lower legal fees in order to court political support among both the black and white communities. 
The principal was keenly aware of the potential voting power available to a cohesive black population composing almost one-half of the county electorate. He indicated, however, that considerable difficulty had been experienced in motivating the very low income group of Negroes to political activity and expressed the view that many feared association with the NAACP, although he could not point to specific instances of intimidation. He also indicated that while all past NAACP activities had been in suits to desegregate the schools and public facilities, future activities were planned in the area of welfare rights.

The Negro principal also reported knowledge of the welfare lien and its inhibiting effect upon utilization of benefits. He was not, however, aware of the specifics of its application. He was better informed on the problem of AFDC termination during tobacco season and indicated that complaints would soon be made to HEW by a rather loosely organized Citizens Welfare Group, in which he was active. The principal was only vaguely familiar with the activities of OEO and viewed the community workers as a welfare rights group.

The principal of the white high school was not as frequent a source of advice as the Negro principal. He did, however, report considerable activity in referring needy families, whose children were in school, to the welfare or health departments. The white principal did not report being aware of any welfare difficulties and expressed the view that the welfare department would do all within its power to provide available benefits. While this educator did not report referring any problems to an attorney, he expressed the firm conviction that free legal services would be provided by any local attorney for a person in genuine need, and indicated that he would not hesitate to seek such assistance for any poor person in real trouble.

Ministers. Although no one in the sample group indicated the use of their minister as a problem-solving resource, a group of the local ministry was interviewed to determine the extent of their involvement in community problems. A mong the white ministers, activity was very low. The county has for many years been served by a rather transient ministerial group, the average stay being less than two years. For this reason the white ministers reported a great hesitancy on the part of their congregations to seek their advice and reveal 
problems. No involvement on the part of the white ministers, other than occasional charitable works for the needy, was reported.

The Negro clergy appeared significantly more active in community matters. All of the three ministers interviewed, who were long time county residents, reported being consulted on a variety of matters including consumer, insurance and welfare problems, divorce and child-support. These individuals suggested legal advice as the best method of handling all of these problems. Recognizing the financial realities, however, they suggested that an elected official such as the clerk of the court could often provide advice or assistance, especially in areas where informal intersession was useful. While they did not expect free assistance from any of the local bar, they indicated that in serious matters the advice of counsel was worth the expense.

The Negro ministers were well informed on the community service agencies, including the OEO. One had contacted the OEO director for information about the possibilities of establishing public housing for the elderly and was told that the director would get him some information. All of the Negro ministers were also aware of the welfare lien and pointed out its inhibitive effect upon utilization of benefits. They also were aware of the tobacco season terminations, and one reported that he had advised persons with this problem to seek the aid of a Negro lawyer from outside the county because he anticipated some hesitancy on the part of local counsel to oppose the county commissioner's stand on the matter.

County Commissioners. The county is governed by a commission form of government consisting of five elected officials. The commissioners are responsible for the operation of all agencies such as the health, welfare and sheriff's departments on the county level. They are also the local political body which must approve initiation of OEO programs within the county. ${ }^{195}$ They likewise are responsible for the initiation of such projects as the Regional Housing Authority public housing, for which exists state implementing legislation..$^{196}$ The position of county commissioner was reported to be highly sought after politically, despite the fact that it is by no means a fulltime job. The commissioners are all large landowners or businessmen.

${ }^{105} 42$ U.S.C.A. \& 2790(e) (Supp. 1968).

${ }^{195}$ See note 114 supra. 
The three commissioners interviewed expressed the feeling that control of situations within the county had largely passed out of their hands. They cited the presence of federal money in many county programs as the reason. Federal money in the schools and in the welfare program meant the HEW guidelines had to be followed. In addition, the state welfare board overruled local policy determinations. The commissioners particularly objected to the operation of the OEO agency in the county. They indicated that while their approval was sought before the agency was established, they were no longer consulted on any of its programs. They complained that while they gave their approval for the Job Corps program on the condition that its operations be suspended during the tobacco season, it in fact was operated throughout the summer period. They reported that the past board of commissioners had attempted to remove the OEO program from the county, but had learned that their disapproval could not result in its termination. None of the commissioners demonstrated any knowledge about present OEO operations, and expressed the view that OEO had accomplished nothing except providing a few high paying jobs to its own administrators.

The commissioners were vaguely aware of the welfare lien, but were not sure of its operation or of what effect it had upon utilization of benefits. They were much better informed on the problems of tobacco season benefit termination. They admitted that the past board has approved such cutoffs on the theory that it would better insure a farm labor work force. The present board, however, was not sure of the wisdom of that position. They had been made aware by the state welfare board that people who were not actually working could not have their benefits terminated, and that consequently welfare recipients could refuse work if they were intent upon receiving benefits. The commissioners indicated a belief that it was somewhat unfair to penalize those who were ambitious enough to work by cutting off their welfare, while the lazy could continue to receive benefits. They also felt that when benefit recipients become aware of their rights, termination of the benefits of those working will decrease rather than increase the availability of farm labor. Of course this position, viewing welfare as a reward, overlooks the philosophy of providing only for those who lack the means to support themselves. It would seem that a higher 
permissible minimum income for welfare benefit recipients such as that suggested by the welfare director would better satisfy the commissioners' interest in assuring the availability of farm labor.

The county commissioners reported that they had never heard of a regional housing authority and they knew of no way of obtaining public housing for the county. One admitted that he had had a few inquiries in this area but knew nothing about what could be done. The commissioners indicated that they would not be interested in any tax-supported housing because taxes were already too high. They observed that many landowners were already providing a form of "public housing" by allowing people to live for little or no rent in their tenant houses. The commissioners did demonstrate some knowlege of loan funds available through FHA and indicated that they would prefer this type of individual housing assistance to any public projects.

The commissioners reported that few persons in the low income group consulted them in their official capacities. One indicated that he was occasionally consulted on social security and insurance matters and that he would give what advice he could and refer the people to a lawyer. All of the commissioners demonstrated a belief that free services could be expected from members of the local bar for anyone in serious trouble, and indicated that while the cost of legal help might prevent them from referring somc persons to lawyers, if the difficulty was sufficiently serious they would not hesitate to send anyone.

Landlords and Employers. Three farm operators who employed tenant farmers, as well as day laborers, a large farm operator who maintained a regular work force, and the operator of the county's sole industrial plant-a small tire recapping service-were interviewed. ${ }^{197}$ The landlords reported that the number of persons working in the tenant relationship had declined steadily. Mechanization has enabled large landowners to farm their entire holdings with only the aid of some seasonal day labor. The agricultural employers felt that the federal minimum wage for farm labor will no doubt re-

197 Neither a foreman of a highway crew nor one of a pulpwood cutting operation, two areas of employment associated with better than average community knowledge, see textual section on "Community Activity and Knowledge", text following note 120 supra, was available to be interviewed. 
duce the number of day laborers an operator can employ and create special difficulty for the more substantial tenants who themselves have to hire field hands for tobacco work. Since the amount of advance capital needed to employ this labor will be increased by the federal minimum wage, those not on firm financial footing will have to attempt to borrow for labor expenses or cease operations. As could be expected, the federal minimum wage was very much resented by the operators interviewed. They indicated that they would try to comply with it as far as their means allowed, but would attempt to keep the number of employee man hours below the minimum for application of the wage standards. ${ }^{198}$

The landlords and the employers reported being most frequently consulted about money problems by employees requesting loans. They reported making small loans as a regular proposition, collecting the debt out of wages or adding it to the tenant's bill. None reported being consulted on consumer problems and they demonstrated the belief that most people who were really "defrauded" would and should be too ashamed to admit it. Most of the landlords and employers reported that their employees or tenants occasionally sought their assistance in minor criminal matters. They reported providing bail, ${ }^{199}$ fines and sometimes retaining a lawyer if the matter was sufficiently serious. They expected to be reimbursed for these expenditures in the same manner as with other loans. While neither the landlords nor the employers appreciated being involved in these problems, the landlords took somewhat of a paternalistic attitude, reasoning that if the tenant was a good worker, they would do what they could to take care of him.

The agricultural employers did not display the degree of knowledge about community services found among others in the community leadership group; considerably more knowledge was demonstrated by the tire plant operator. ${ }^{200}$ They were best informed concerning the extension service's operations, and although they were aware of farm loans available through the FHA, they did not think of these as being available to the low income group for home

\footnotetext{
12x Fair Labor Standards Act, 29 U.S.C. \$§ 201, 207 (1964). See note 15 supra.

im Tenants in criminal difficulty were frequently released in the custody of landlords.

200 Compare "Community Activity and Knowledge" section of the text following note 120 supra.
} 
construction. While some of the older tenants received old age assistance, none of the farm employers reported any contact with the welfare department other than providing information as to who would be working during the tobacco season. For the most part they disapproved of welfare support while work was available; however, one employer reported that he would not volunteer employment information to the welfare department because he did not want to see his elderly employees' benefits cut or terminated. None of the agricultural employers reported any knowledge of OEO other than the fact that it existed.

The Local Bar. There are three attorneys practicing in the county, all having their offices in the county seat. All considered that they spent at least 20 percent of their working hours in providing free legal services. A substantial portion of these services, however, were not provided to those in the very low income group, but rather involved problems experienced by persons who on occasion were paying clients, but who did not expect to pay for the service on that particular occasion. Their interest in providing these services was to generate future fees and, to some extent, cultivate political goodwill since all of the three attorneys were extremely active in local politics.

The local bar reported being consulted by low income persons most often on social security, veterans' benefits, and domestic and criminal-problems. Tenant farmer difficulties and welfare, insurance and consumer problems were less frequently brought to their attention. Two of the attorneys indicated that they would sometimes take social security matters on a contingent basis. ${ }^{201}$ The third lawyer reported that he referred all such problems to the regional social security office. All three members of the local bar reported that they would and did take veterans' benefit problems without charge. The local bar reported considerable consultations by the low income group on divorce matters. The usual practice here was to allow time payments until the fee of $\$ 125$ had been

\footnotetext{
${ }_{201}$ It is provided in 42 U.S.C. $\$ 406$ (a) (Supp. 1968) that the Secretary may prescribe the maximum fee that may be charged for legal services rendered in connection with a social security claim. These regulations are contained in 20 C.F.R. $\$ \S 404.975-76$, as amended, 32 Fed. Reg. 7750 (1967). Generally a 25 percent limitation is placed upon the contingent fec. See White \& Carver, Representing Your Client Before the Social Security Administration, 14 Prac. Law. 59, 71 (1968).
} 
paid. Not until that time would papers be filed in the suit. The lawyers indicated that past experiences proved this to be the only means of assuring payment in domestic cases. All three attorneys also reported serving as appointed counsel in criminal cases on numerous occasions. One indicated that he avoided this service as much as possible because of distaste for criminal work. The others complained that appointed counsel fees were quite low but served whenever appointed.

Two of the three lawyers reported considerable hesitancy in getting involved in landlord-tenant farmer disputes. While both indicated that when they encountered such problems they attempted to mediate the difficulties, neither demonstrated a willingness to take a tenant's case against a landlord because of the loss of business that might result. ${ }^{202}$ This problem was especially acute when a tenant with a complaint came to the lawyer who usually represented the tenant's landlord. Only one lawyer reported that he would not hesitate to take a tenant's case against a landlord. He felt that no individual client made up so substantial a part of his practice that he could not afford to lose the business. The two attorneys who favored the role of mediators reported that this was one of the areas in which they never received compensation for their services.

Two members of the local bar also reported that they avoided involvement in welfare problems as much as possible. They generally referred people to the welfare department with the assurance that they would receive fair treatment there. The third lawyer indicated that he would occasionally assist a welfare client by calling or visiting the welfare office, but that such services never received any compensation. The lawyer who was also the county attorney was fully aware of the application of the welfare lien, and had the impression that it did sometimes discourage the utilization of welfare benefits.

Insurance and consumer problems were occasionally brought to members of the local bar by low income persons. Unless the insurance problem involved a contingent fee, the usual step taken by the attorneys was to write a letter to the company, often without

\footnotetext{
202 See A BA Canons of Professional. Ethics No. 31. A proposal for the new canons in regard to this question is that a case "may not lightly be declined."
} 
charge. The same practice was employed in consumer difficulties involving out-of-county sellers. The local attorneys reported the most serious consumer fraud problems to be in the area of home repairs and the "dollar-down" houses. Where a problem in this area arose, the purchaser had usually secured the transaction by subjecting his property to a mortgage around three times the value of the purchase. The lawyers indicated that they would attempt to work out a refinancing through FHA or would advise the client to stop paying and would themselves buy at the foreclosure sale and then resell to the client on some prearranged local financing.

The local bar reported few referrals from the welfare department and extension service, although the lawyers recognized a considerable increase in their will business after the extension service's will publication program. Two reported few referrals from the clerk of the court and felt that the clerk would often attempt to provide legal advice himself. The third lawyer indicated that he had many referrals from the clerk and the sheriff's department.

The local bar was well aware of the services provided by the various state and county agencies. This was probably somewhat the result of each lawyer's involvement at one time or another in county politics and government. While not thoroughly informed on OEO operations, two of the attorneys were generally aware of the OEO programs. The third attorney was on the OEO board of directors and was one of the most active members of that board.

One of the three attorneys volunteered his belief that some type of free legal service program should be established in the county. He felt that such a program would relieve him of the many nonpaying problems that were brought to him by the low income group. He also believed that because of the local attorneys' dependence on their paying clientele, they could not always take the cases of groups or persons unpopular in the community. He did not feel, however, that sufficient work would be provided for a full time attorney. While the other two lawyers agreed that they were often burdened by providing free services, they preferred to continue handling problems for the poor on a voluntary basis. They did not believe a sufficient number of problems existed to warrant the establishment of any full time legal service operation. On the other hand, they did not oppose state-furnished financial assistance similar to that given in appointed criminal cases since such a program 
would be profitable for both themselves and the clients, whereas an independent legal service operation might pose some financial competition. All of the members of the local bar felt that they did their share in providing free services, and that while they could not do so in every situation where their aid would have been helpful, they nevertheless generally provided the poor community with adequate legal representation. They did, however, believe that there was sufficient business in the county to support additional lawyers and felt that they turned down a considerable amount of paying as well as non-paying business because of a lack of time.

Summary of Leadership and Agency Interviews. The personnel of the established services agencies in the county, such as the welfare department and the agricultural extension service, were well versed on most of the benefit programs available to the rural poor. Considerable ability in recognizing and referring legal problems was also observed in these agencies. Knowledge concerning the availability of publicly-supported housing was the prime area of deficiency-only the FHA agent demonstrated expertise concerning housing programs. The cooperation and interaction between agencies was excellent and probably can be attributed to the small total number of service personnel and their associations both professionally and socially as members of a small educated elite in the community. The attitude of the service agency personnel could generally be typified as a public-spirited one, as they had for the most part served for many years in their positions and considered their work very important to an extremely poor community.

The welfare department, while serving as an important information source in the community, lacked some expertise regarding its own programs, and its personnel demonstrated some hostility to challenges of their methods of operation. On the other hand, welfare personnel were generally in favor of paying as much in benefits as their budget would allow and stated opposition to both the welfare lien and tobacco-season terminations which interfered with the full utilization of benefits. Problems in welfare benefit utilization, therefore, seemed to stem from misunderstanding among both the welfare workers and the community about the specifics of benefit programs rather than from any reluctance to provide benefits to the fullest extent. 
The Farmers Home Administration was the agency best versed on the variety of federal aid programs available to the rural poor and this expertise included programs outside the FHA's own scope of operations. The FHA was particularly well-informed on housing problems and the availability of grant or loan assistance, but was also active in planning for industrialization, recreation and community development. It would seem that expansion of the operations of this agency would be well worth the effort, especially since the stigma attached to some community services did not appear to exist with the farm-related services such as the extension service and the FHA:

In terms of community knowledge and leadership the OEO program was the least effective of all agencies. Knowledge about other services and the ability to make appropriate referrals, especially in the area of legal problems, was poor. Furthermore, some community hostility and considerable stigma surrounded OEO programs. Persons were not anxious to be viewed as the subjects of the "war on poverty." It would seem that the same kind of assistance provided through an established agency with greater experience and expertise and lacking the stigma attached to a "poverty" program would be considerably more effective. Present use of the OEO community worker program as a problemsolving resource was extremely low, as was the apparent effectiveness of that group in problem solving.

The clerk of the court served a somewhat unique function in the rural community, apparently often being viewed as a source of free legal advice. Use of the clerk in this fashion suggests a willingness to utilize free legal services and an ability to identify the courthouse as a possible source for legal help. Apparently because the clerk's position was politically sought after, people expected him to be willing to do favors in the legal area. It would seem that people would be at least equally as willing to utilize a legal service office in the county courthouse where they would be assured that free assistance would be eagerly provided. It would seem important, however, to keep that office separate from the welfare department and the OEO because of the stigma attached to those programs.

A noticeable difference existed in the use of school authorities and ministers by the black and white populations. A transient white ministerial group was somewhat responsible for this difference. It 
might also be suggested that blacks felt a greater need in seeking advice of these leaders because of educational inadequacies. Negro ministers and school authorities were also more active in community affairs and demonstrated more awareness of both problems and services than their white counterparts, perhaps accounting for their increased prominence as a problem-solving resource. The ability of these leaders in making appropriate referrals, especially in the area of legal problems, was quite good. The county commissioners, landlords and employers were a much less effective problem-solving resource than the community service agencies. The county commissioners demonstrated feelings of impotency in directing the county government and had to some extent abdicated their power to federal and state standards imposed on welfare and educational programs. The commissioners were unaware of any role they might play in housing improvements and expressed particular dislike for the OEO operations in the county. They reported no contact with the poverty group in their official capacities. Landlords and employers, almost all of whom are primarily engaged in agricultural operations, demonstrated the lowest level of community knowledge. They were most frequently merely a source for loans or assistance in occasional criminal problems. Their ability to recognize and refer legal problems outside of the criminal area was quite low. While demonstrating a somewhat paternalistic attitude toward their tenants and employees, they nevertheless were not particularly sympathetic toward the plight of the poor and were most concerned with the continued availability of low-cost agricultural labor.

The local bar, while admitting that attorneys would be inhibited in handling cases against landlords and expressing the desire to avoid involvement in welfare problems, nevertheless demonstrated the view that the poor of the county were being adequately represented. The local attorneys did not, however, oppose free legal services, but preferred a system similar to court-appointed counsel whereby local lawyers would provide services for indigents and be paid by the state. Lawyers in the county reported spending about 25 percent of their working hours rendering free services-a substantial amount of this aid being given to persons who were prospective paying clients rather than members of the very low income groups. Housing, consumer and benefit problems, the areas 
in which the most numerous difficulties faced the sample group, did not receive significant attention from the local bar because no adequate fees were involved.

\section{CONCLUSION}

None of the problems of the rural poor revealed by the study are particularly startling. As is the case with any poverty group, debts, consumer problems such as overcharges and shoddy merchandise, benefit payment difficulties and grossly inadequate housing are the major trouble areas. The fact that debt extension would be easily arranged and that the number of repossessions, default judgments and evictions was very low is a noteworthy contrast to the common urban situation..$^{203}$ Study of both hypothetical and actual problems revealed that persons were most inactive and least successful, and therefore probably most in need of assistance, in dealing with housing problems and benefit denials. The current absence of any housing code regulation of the vast majority of areas inhabited by the rural poor, in addition to the landlord's lack of economic interest in having dwellings occupied, aggravates the housing difficulty. Lack of information and interest in housing publicly supported by either federal grants or loans was the informational area in which the greatest deficiency was shown by both the sample group and all of the community leadership except the FHA agent. Although housing was a significant problem, very few of the sample, less than five percent, suggested any form of legal assistance for this difficulty. In fact, in the absence of a housing code, and where tenants pay no meaningful rent, there is probably little an attorney could do.

Problems with social security benefits were heightened by the lack of any office of that agency in the county and the significant transportation problem facing the poor. The value of simple assistance in the benefit denial area was demonstrated by the much better success experienced by welfare clients with their social security difficulties. Some similar type of external assistance would also seem necessary to cope with welfare benefit problems, as the wefare department evidenced a less than flexible attitude toward those who differed with its position on benefit matters. Again,

\footnotetext{
- See Peoria Study, supra note 5, at 31, 34, 46 \& 48.
} 
although a substantial number of persons experienced welfare or other benefit denials, this was an area for which less than five percent of the sample suggested legal help.

While the sample group demonstrated considerable activity and success with both the hypothetical and real consumer problems in the installment sale situation, where the self help remedy of stopping payments was available, no such success was seen in cash sale cases. Furthermore, both the sample and the community leadership demonstrated the attitude that once a contract had been signed or an item paid for, nothing could be done, and the fairly low cost of the items involved in most of the difficulties made private legal assistance economically unfeasible. As a practical matter, only some type of legislative or administrative consumer protection, ${ }^{204}$ or free legal services could remedy the troubles experienced with most consumer purchases. The willingness among the sample group to resort to legal help with consumer difficulties was not significant, although the serious problems were more often brought to attorneys.

The problems most frequently thought of by the sample as requiring the attention of a lawyer were child custody and criminal difficulties, both of which were experienced by very few of the sample group. Landlord/tenant-farmer and wage disputes were recognized as having legal overtones by about 20 percent of the sample, but again the incidence of both of these problems was quite low. Study of actual cases revealed that the poverty group most frequently consulted attorneys for deeds, wills, income tax, insurance and personal injury claims, and loan applications. All of these matters, of course, at least involved some small fee.

The local bar itself evidenced some hesitancy to become involved in welfare or social security benefit claims or in problems with landlords which could arise from housing or crop loan disputes. The bar also reported few incidents of handling consumer problems for the low income group because the amounts involved were too small to warrant an expenditure of legal fees. Thus, it would seem that the areas most in need of attention-housing, consumer, and benefit problems-are those receiving the least attention of the local attorneys, are most infrequently thought of as

\footnotetext{
2n See Lefkowitz, Consumer Protection, 204 CaSe \& Comment Mar. 1969, at 10.
} 
legal problems, and are least suitably handled by private lawyers since the opportunity for a reasonable fee is small while the chance for arousing the ire of the community power figures such as landlords, merchants and county governmental officials is great.

The conclusion suggested is the need for some type of free legal or quasi-legal advisory service ${ }^{205}$ to assist in the resolution of these problems. Some type of legislative action in the housing and consumer areas is probably a prerequisite to any resolution, and could possibly include some type of public enforcement procedure obviating the necessity for private enforcement through legal help. Benefit denials, on the other hand, could probably best be alleviated through some type of legal assistance, but it would be essential to assure that any type of advice in this area could be obtained independently of the benefit agency involved. ${ }^{206}$ The local bar, while

Since neither benefit, housing or consumer difficulties present highly technical legal problems, it is quite possible that non-lawyers well trained in the specific area could provide adequate services. In fact, the consumer and benefit problem areas have becn recommended as suitable for paraprofessional services. See Office of Economic OPportunity, Paraprofessionals in Legal Service Programs: A Feasibility Study 90 (1968). Through the use of checklists and forms these paraprofessionals could compile the information necessary to determine the merits of a claim, allowing an attorney to scrutinize the record before him and determine the action to be taken in a minimum amount of time. While paraprofessional personnel are generally envisioned as assisting in a legal services office, they could conceivably operate independently in a rural community under the parttime supervision of a member of the local bar. The services of trained non-lawyers have also been deemed sufficient in the adoption and divorce areas, id. at 65 , where special problems were reported in the study. It would be extremely important in any paraprofessional service project to use highly trained personnel. While it is admirable to attempt to utilize persons from the poverty group in OEO programs, the inadequacies demonstrated by the community workers in the instant study point up the need for personnel with an education equal to the needs of the job.

$20 \times$ The recent HEW plan to provide free legal services in the civil area to recipients of Aid to Dependent Children, see 3 LAW IN ACTION 3 (1968), creates some question of the need for independence from welfare authorities. The plan envisions the federal government contributing 85 percent of the funding and the state contributing the remainder, probably through the welfare structure. Legal services are to be "bought" from existing legal aid projects or from private attorneys by the welfare agency serving the client. It would not appear likely that welfare agencies would be anxious to refer clients to counsel and to pay legal fees for actions to be brought against the agency for benefit denials. Also, counsel working in close cooperation with the welfare department in other civil matters might be hesitant to undertake actions against the department. This problem would be particularly acute in areas such as the sample county, where private counsel would be relied upon to provide the welfare funded services because of the absence of any legal aid agencies. To the extent that counsel found themselves on the welfare department payroll, a genuine conflict of interest could result. 
not indicating any opposition to free legal services in these areas, showed some preference for providing services for the poor through private attorneys who would be paid similar to the procedure used with appointed counsel. ${ }^{20 t}$ This approach would not, however, lessen the difficulty in the areas in which members of the local bar indicated a hesitancy to become involved for political or business reasons.

Thus, it would appear that some type of independent legal service agency or paraprofessional service, ${ }^{20 x}$ preferably providing some type of mobile service as well as an office in the county seat, could best handle the immediate problems facing the rural poor. No doubt some efforts would be necessary to educate the population to the availability of legal help in the three main problem areas where a low level of legal perception was demonstrated. Cooperation on the part of the community service agencies would be vital to any educational campaign and, as experience has indicated, use of the existing agencies for referrals and as a source of information could be quite successful.

As has been observed in several situations, ${ }^{209}$ the news of particular services travels quickly in the rural community if properly disseminated, and if free legal services could avoid the stigma attached to some other benefit programs by remaining an independent entity, utilization of such services could be quite high. Indeed, even at the present educational level, over ten percent of the sample fell within the "legal activist" category, recommending legal help for. at least five of nine legal problems posed. If the same degree of activism is attributed to the poor population in general, a base of about 600 legally aware and otherwise active persons could

\footnotetext{
$m$ A federal program. commonly referred to as "Judicare," is being tested under OEO auspices in several locations in the United States. Judicare is a legal aid system whereby eligible clients select their own private lawyers who are in turn compensated by the system. See Schlossberg \& Weinberg. The Role of Judicare in the American Legal Si'stem, 54 A.B.A.J. 1000 (1968). The first such system was instituted in 26 rural Wisconsin counties. Id. at 1001. Others have been tried in Montana and Connecticut, id. at 1002-03, and rcportedly in Delaware. Interview with Mrs. K. Rinella, May 1, 1969, Duke University Legal Aid. Schlossberg and Weinberg have concluded "that the principal utility of the judicare system is in sparsely settled rural areas that present physical difficulties of transportation for both clients and attorneys in a staff attorney system." Schlossberg \& Weinberg, supra, at 1003.

See note 205 supra.

20 See text accompanying note 167 supra.
} 
be relied upon to encourage others to take advantage of legal services.

Furthermore, the ability of most of the community service personnel, particularly in the highly utilized community services such as the welfare department and extension service to make referrals of legal problems was quite good. These agencies would no doubt serve as a fertile source for legal aid clients, with the exception, of course, that few welfare benefit denial problems could be expected to be referred to legal aid through the welfare office. The agency least effective in making appropriate referrals was the $O E O$, and the OEO community workers who were charged with the responsibility of assisting the poor in problem solving were the most inept of all in the area of legal problems. Certainly if the OEO community education plan is to have any value, the training and qualifications of its personnel must be improved significantly.

While the local bar indicated a doubt that a full time attorney would be kept busy by the problems of the county poor, if the incidence of legal problems among the poor population in general is similar to that in the random sample, there would be approximately 1500 housing problems, 1500 benefit denial difficulties and 1200 consumer problems to be handled. While certainly. all of these would not come to the attention of a legal service lawyer, the case load would no doubt increase as familiarity with legal remedies grew. Although the rural areas are perhaps not those in the most dire need of legal service efforts when compared to the more urban concentrations, ${ }^{210}$ they should not be overlooked, for even a limited program with a small expenditure could provide a highly utilized public service.

\footnotetext{
210 Sete generall! Peoria Study, supra note 5.
} 


\section{A PPENDIX A-FEDERAL PROGRAMS}

Low and moderate income families living in rural areas benefit from a wide variety of federal programs. Many of these are general assistance programs, while others are tailored especially to satisfy rural needs. It would be impractical in a work of this kind to describe every federal program which in any way affects rural citizens. Thus, only the most important programs which directly serve the rural community are discussed. These programs may be divided into two main groups: (1) programs designed to provide employment opportunities and stimulate economic development in rural areas and small communities, and (2) programs to provide food and housing to needy rural citizens.

The Public Works and Economic Development Act of 1965, 42 U.S.C.A. $\S 3121-3226$ (Supp. 1968), which is adminstered by the Department of Commerce, authorizes a program which is designed to foster economic development in distressed areas. Local citizens initiate participation in the program by submitting a detailed, comprehensive plan for the economic development of their area. Upon approval of such a plan the area will be formally designated as a Redevelopment Area, an Economic Development District, or an Economic Development Region, depending upon its size. Such areas are eligible for a wide range of assistance: technical aid, federal planning grants, EDA business loans, and federal public works grants. Technical assistance is supplied, at a cost of up to $100 \%$ to the federal government, by federal personnel or by federally employed private consultants who assist the development areas in planning overall programs. If the area prefers to do its own planning, grants of up to $75 \%$ of total planning costs may be provided. Furthermore, to encourage private investment, low-interest long-term loans may be made to help businesses expand or establish plants in development areas. If an area is in serious distress it may be entitled to a grant ranging from 50 to 80 percent of the project cost to help finance public works of an economic development nature. The sample area was assigned a maximum grant rate of $50 \%$ and was both a redevelopment area and part of an economic development district.

The Department of Labor, Bureau of Employment Security, operates a "Smaller Communities Program," 29 U.S.C. $\$ \$ 49-49$ K (1964), which was developed when it was discovered that regular employment security services were not reaching the unemployed in rural areas. In the sample area, a mobile team of interviewers, counselors, and test administrators spend three months conducting a comprehensive labor supply survey which 
included, among other things, information on the potential skills of the work force. Such surveys are of great help to development groups, both in attracting employers and in establishing vocational training programs under the Area Redevelopment Act or the Manpower Development and Training Act. Rural residents are provided, often for the first time, with the counseling, testing, and placement services of a regular local employment office.

In addition to programs encouraging general economic development, the Department of Agriculture, Farmers Home Administration, operates a number of projects which enable the individual to create his own means of employment. Under the Economic Opportunity Act of 1964, 42 U.S.C. $\$ \S 2841-61$ (Supp. 1968), the Farmers Home Administration provides direct "opportunity loans" to Jow-income farm and non-farm rura] families who need capital to finance small businesses, trades or services such as carpentry or trucking, and other income-producing activities. The maximum loan of this type is $\$ 3,500$, with an interest rate of $41 / 8^{\circ}$ r and a maximum term of 15 years. Loans are accompanied by technical and management assistance.

Tenant farmers may increase their earning capacity by purchasing a farm with a loan available through the FHA, under the Consolidated Farmers Home Administration Act of 1961, 7 U.S.C. $\$ \S 1921-29$ (1964), at a $5 \%{ }^{\circ}$ interest rate and 40-year maximum term to operators of not larger than family size farms. The FHA county agent provides any loan recipient with extensive supervision and counseling in planning an efficient farm enterprise, scheduling the repayment of debts, and managing farm production.

FHA farm operating loans, authorized by the same act, are available at a $5 \%$ interest rate but usually for a maximum term of from five to seven years. These loans are used for such purposes as buying livestock and equipment, improving real estate, and buying membership in local cooperatives. Emphasis is placed on the farm background and experience and potential ability of the applicant to operate the farm successfully. All loans are adequately secured by the farm property or machinery. Loans on the same terms as operating loans may be made for water development and soil conservation purposes-drilling wells, constructing irrigation ditches, leveling land, and fertilizing soil. Operating loans may be made at a special $3 \%$ interest rate when they are used for forestry purposes such as planting timber on unused farm land. 
The Consolidated Farmers Home Administration Act of 1961 also provides for FHA loans for recreational enterprises. 7 U.S.C. $\$ 1923$ (1964). Individuals and groups may use these loans to purchase and improve land and water resources, acquire recreational equipment, and construct building and recreational facilities. Loans to groups are made for a maximum term of 40 years at $5 \mathrm{c}_{\mathrm{c}}$ interest and to individuals at a rate of from $5 \%$ to $51 / 2 \%$ with a maximum term of 40 years for loans secured by real estate and seven years for loans secured by chattels. A private country club in the sample county was constructed under this program.

All of these programs provide rural residents and farmers with the initial capital to turn otherwise unproductive resources into incomeproducing assets, thus contributing to the livelihood of the individual and to the economic development of the region. However, loans to individuals represent only a part of the federal programs designed to stimulate economic development; many programs assist group enterprises as well. $A$ familiar example is the Department of Agriculture's Rural Electrification Administration, but a variety of lesser known services exists as well.

A community, for example, cannot prosper without an adequate water and sewer system: farms and homes will be primitive, health conditions poor, and the area will not attract outside capital. To meet this need the Farmers Home Administration, by authority of the Consolidated Farmers Home Administration Act of 1961, 7 U.S.C. $\S 1926$ (1964), administers a comprehensive water and sewer program for rural areas and towns of less than 5,500. States, political subdivisions, and regional and local planning commissions may receive assistance. Planning grants are available to pay for technical, professional and clerical services needed to develop comprehensive area plans and to make necessary test wells and soil and water investigations. Development grants may finance up to $50 \%$ of the development cost of the system when needed to reduce user charges to a reasonable level. Forty-year, $5 \%$ development loans not exceeding $\$ 4$ million and secured by bonds or notes pledging taxes may be made to cover other costs of development. Department of Agriculture publication PA 653 reports that between January 1, 1961, and December 31, 1964, the Farmers Home Administration had made or insured more than $\$ 72$ million in loans to finance some 558 associations in 37 states. There have been no losses on loans. Sewage facility improvements in each of the sample county's three towns are being planned under this program. 
Another community service vital to many rural areas is the establishment of farmers cooperatives. FHA, by authority of the Economic Opportunity Act of 1964, 42 U.S.C. $\$ 2852$ (1964) el seq., makes 30-year, $41 / 8 \%$ loans to cooperatives that furnish essential processing, purchasing, or marketing services, supplies, or facilities to lowincome rural families. In addition, the Department of Agriculture operates a Farmers Co-operative Service created by the authority of the Agricultural Marketing Act of July 2, 1926, 7 U.S.C. $\$ \$ 451-57$ (1964). A staff of specialists conducts research and acquires information about farmers cooperatives, their operations, costs, processing, and membership relations. As well as publishing extensive quantities of such information, the service provides teehnical assistance to cooperatives upon their request and to groups wishing to form cooperatives. No such cooperative was yet operative in the sample county, however.

The Bureau of Federal Credit Unions, a division of the Department of Health, Education and Welfare, administers by authority of the Federal Credit Union Act, 12 U.S.C. $\$ \S 1751-75$ (1964), a program called "Project Moneywise" designed to help low-income people to learn credit practices and to develop consumer knowledge and habits of thrift. To accomplish this the Bureau, presently funded by the Office of Economic Opportunity, helps set up federal credit unions which work very much like savings and loan organizations. The Bureau sends selected low-income community leaders to an intensive four week course where they are instructed in consumer education, family financial counseling; and credit union operations and management. These leaders are expected to return to their local communities, establish credit unions, and share their knowledge with their friends and neighbors. The Bureau also makes available a limited number of specialists to assist low-income credit unions in their day-to-day operations. Although there was no credit union in the sample area, a spokesman at the Bureau reported that there are approximately 700 federal credit unions nationwide classified as low-income-about $2 / 3$ in urban areas. However, a state organized non-profit credit association, the Commercial Credit Corporation, did provide credit services to the county.

The aforementioned economic development programs are aimed at stimulating the economy in certain areas so that needy rural residents will eventually become self-supporting. On the other hand, many of these citizens have urgent present needs for such basic commodities as housing 
and food. Again, a plethora of federal programs has made inroads in this area.

The Farmers Home Administration administers most of the housing programs which are tailored specifically to fit the needs of rural residents. Title $V$ of the Housing Act of 1949, 42 U.S.C. $\S \S 1471-90$ (Supp. 1967), as amended, provides rural housing loans to farmers, rural residents, and residents of communities of up to 5,500. The loans have a maximum term of 33 years and may be used to finance the cost of a building site, or to construct, improve, or repair rural houses or farm service buildings, and, under some circumstances, to refinance existing housing debts. Depending upon its size and income, a family may not be able to meet payments on a loan at a usual rate of interest. Such families may qualify for an interest credit, however, which cannot result in an interest rate of less than $1 \%$. Furthermore, under this rural housing program, 50-year loans up to $\$ 200,000$ are made to private non-profit corporations and cooperatives for constructing housing for low-income senior citizens. Catalog of Federal Assistance Programs 182 (OEO; June 1, 1967). Forty-year loans up to $\$ 300,000$ can be made to individuals and organizations to construct housing for the elderly. Id.

The FHA also operates a self-help housing program under the same act for low-income rural families who cannot afford to build a modest house by customary methods. A group of from six to ten families under the supervision of an FHA county agent and with the assistance of a construction expert pools its labor to build minimum adequate housing for the group. The Farmers Home Administration determines the eligibility of each family, provides the plans, conducts preconstruction meetings, and, if necessary, hires a construction expert. The families pay for all materials and must agree to provide the work necessary to complete all the houses, except for such things as plumbing and wiring which may be contracted for by the group.

Still another Housing Act program administered by the FHA provides direct and insured loans for construction of rental and cooperative housing in rural areas for low and moderate-income families, including senior citizens of 62 years or older. Fifty-year, 3\% direct loans are made to private non-profit corporations and consumer cooperatives to build rental housing for low-income rural families in all age groups. Forty-year, 5 $3 / 4 \%$ insured loans are made to associations, partnerships, corporations, trusts and individuals to build rental housing for moderate-income families in all age groups. Funds may be used to construct apartments, 
duplex units, or individual detached houses, as well as to provide appropriate recreational and service facilities and to improve the land upon which the buildings are located.

The housing problems of rural areas become even more acute during harvest season when large numbers of migratory workers are present. To alleviate this problem the Farmers Home Administration, again under the Housing Act, provides grants and insured loans to finance construction of housing for domestic farm laborers. Loans are made to farm owners, associations of farmers, or to the state or its political subdivisions at $5 \%$ for 33 years or the useful life of the security. Funds may be used to construct, improve, or repair farm-labor housing, including kitchens, dining halls, health centers, and water, sewage, heat and light systems. Grants to cover up to $50 \%$ of the cost of the land for such a project may be made to the state or a political subdivision or to a broadly-based nonprofit organization. Migrant labor was not a significant problem in the sample county at the time of the study; however, the trend toward eliminating tenant farming may aggravate this problem in the future.

Sufficient food is an even more immediate need than adequate housing to many low-income rural families. The Department of Agriculture, Consumer and Marketing Service, administers a comprehensive range of food programs providing assistance directly to families and indirectly through the school system.

The most direct means of providing low-income families with food is through the Commodity Distribution Program authorized by the Agricultural Adjustment Act of 1949, 7 U.S.C. $\$ \S 1301,130 \mathrm{lb}, 1330$, 1334 note, 1340, 1342-48, 1358, 1362, 1374 (1964). The Consumer and Marketing Service offers available foods to state agencies which in turn distribute it to needy citizens, usually through the local welfare machinery. The federal government purchases some of these foods under section 6 of the National School Lunch Act, 42 U.S.C. \$ 1755 (1964), buys others under surplus-removal programs, as originally authorized by the Act of August 24, 1935, ch. $641, \S 32,49$ Stat. 744, acquires still more through price-support obligations and donates them according to section 416 of the Agricultural Act of 1949,63 Stat. 1058, as amended, 7 U.S.C. $\$ 1341$ (1964). The Consumer and Marketing Service provides the recipients with current reports on available foods as well as information on storing, handling, and preparation. The Commodity Distribution Program also provides food for victims of disasters, Indians on reservations, campers, and children and adults in charitable institutions 
and other nations. The government is, however, in all instances trying to replace direct food donation to the needy with the food stamp program.

The Food Stamp Act of 1964, 7 U.S.C. $\$ \S 2011-25$ (1964), authorizes the Consumer and Marketing Service to issue stamps which are purchased at less than face value by low-income families through local welfare officials. The stamps may be used at retail storcs authorized by the Consumer and Marketing Service to purchase any domestic food marked for human consumption. Retailers redeem the coupons at face value at local banks or authorized wholesalers; the federal government pays the difference. To be eligible to receive food stamps, families must be found by local welfare officials to be in need of food assistance, unemployed or working for low wages, and receiving some sort of welfare. On the other hand, families not receiving welfare may also be eligible to receive food stamps depending upon family size and income. The Commodity Distribution Program rather than food stamps, however, was operative in the sample county.

The Department of Agriculture began administering school food services with the passage of the National School Lunch Act of 1946, 42 U.S.C. $\$ \S 1751-60$ (1964). Federal grants which pay up to $25 \%$ of food costs are distributed among the states on the basis of the school lunch participation and per capita income of the state. Approximately $75 \%$ of the food used in the program is purchased by the schools on the local market. However, the Department of Agriculture is authorized to buy food for participating schools, as well as to donate food available from surplus-removal and price-support programs. All public and non-profit private schools are eligible if they agree to operate the lunch program on a non-profit basis, serve U.S.D.A. Type A lunches, and provide lunches free or at a reduced rate to children who are unable to pay the full price. This program was fully operative in the sample county.

The Child Nutrition Act of 1966, 42 U.S.C. $\$ \S ~ 1771-85$ (Supp. 1967), provides for a pilot school breakfast program. In severe cases, federal funds will pay for up to $80 \%$ of the breakfast program cost. The program is presently very limited, preference being given to schools in low-income areas and schools where attending children travel long distances, factors frequently present in rural areas. Since 1954 the Department of Agriculture has operated a special milk program to benefit children attending public and non-profit private schools of high school grade and under, as well as non-profit child-care institutions such as nursery schools, child-care centers, settlement houses and summer camps. Participating 
schools are reimbursed at a maximum rate of from 3 cents to 4 cents per half pint sold.

A 1968 amendment to the National School Lunch Act authorizes a three-year pilot "Special Food Service Program for Children." Eligible for the program are public and non-profit private institutions such as centers that provide day-care for children from low-income areas or from areas with many working mothers. Summer day camps and similar recreational summer programs may also be eligible. In addition to receiving food donated by the Department of Agriculture, the institutions may receive reimbursement for the cost of food served up to a maximum rate of 15 cents for each breakfast, 30 cents for each lunch or supper and 10 cents for supplemental food served between meals. Technical assistance needed to establish and operate the program is provided by the federal government as well as financial grants of up to $75 \%$ of the cost of buying or renting the equipment. Use of this program was being planned incident to the OEO summer recreation project in the sample county.

Many schools in needy areas were unable to take advantage of the school lunch program because they could not afford adequate cafeteria equipment. The non-food assistance program, created by the Child Nutrition Act of 1966, alleviates this problem by providing grants-in-aid to schools in low-income areas of up to $75 \%$ of the cost of equipment for storing, preparing, transporting, and serving food to school children. To be eligible schools must agree to participate in the school lunch and/or school breakfast program and must have little or none of the equipment needed to carry on a school food program.

A majority of the federal programs here discussed are operative to some degree in the sample county. While the school authorities, the FHA, the extension service and the welfare department were well versed on the particular programs related to their agencies, and on some of the others as well, the OEO group demonstrated knowledge only as to the food programs. The form of assistance noticeably absent from the sample county was the food stamp program. While welfare and extension service personnel felt that surplus food was not fully utilized because of the difficulty in preparation, they believed that many persons could not afford the individual contribution required by the food stamp program and preferred continuation of the Commodities program. 


\section{APPENDIX B-QUESTIONNAIRE*}

\section{Part I - Hypothetical Problems}

1. Imagine you are in this situation: You believe that you ought to get social security benefits. You go to the social security people and they turn you down. You try again and they still will not give you benefits. You need money. What would you do?

2. Imagine yourself in this situation: You are renting this house. The plumbing in the house will not work. You have complained to the landlord several times; he says that he docsn't have to make repairs and absolutely won't do anything at all. You are almost sure you can't find anywhere else to live. If you were in this situation, what would you do?

3. Your husband/wife has left you and has taken your child with him/her and refuses to bring him/her back. You are very fond of the child, think that the taking of the child was very unfair, and want the child back to live with you. If you were in this situation, what would you do?

4. You have bought a refrigerator froin a store and are paying for it on time. After the refrigerator has been used for six months but while you are still paying for it, it stops working. The store owner absolutely refuses to take it back or to repair it. What would you do?

5. You are unable to work and cannot pay off a loan when you are supposed to. What would you do?

6. Your teenage son/daughter has been picked up by the police while riding in a stolen car. The case has been sent to juvenile court. What would you do?

7. You own something, such as a house or car, or you have saved some money, and you want to make sure that a particular person receives it after you die. What would you do?

8. You have found $\$ 25.00$ missing from your paycheck. Your employer said he did not owe you anymore and he refused to pay. You are sure you have inore money coming. What would you do?

9. You are tenant farming and have a chance to sell your crop for a good price, but your landlord refuses to let you sell. What would you do?

*The categories for pre-coded responses, instructions to the interviewers about the order in which to proceed, and some probes for responses have been omitted for purposes of length. The original questionnaire was 80 pages. 


\section{Part II - KNowledge OF Resources}

1. (a) Are there any places around here where a person can get a lawyer's services for free?

(b) Where are they located?

2. How did you first find out that there was a place where a person could get free legal services?

3. (a) Have you ever heard of the Committee on Indigent Legal Services?

(b) How did you first find out about this service?

4. Have you ever asked for help from the Committee on Indigent Legal Services?

5. What is Legal Aid or Legal Services; in other words, if someone asked you about it, what would you tell him?

6. What do you think would be the best way to let people know about free Legal Aid programs?

7. (a) Do you think that free legal services should be provided for people who cannot afford a lawyer?

(b) Why do you think that?

8. Have you ever gone to a private lawyer about a problem that you had? By private lawyer, I mean a lawyer who usually charges a fee and is not attached to legal services or any other public agency like that.

9. (a) , How many different private lawyers have you ever gone to in your life for help?

(b) How many problems have you taken to him/each of these lawyers?

(c) How inany problems did you take to more than one of the lawyers?

(d) What reasons did you have for not going to the same lawyer every time?

10. (a) When was the first time you ever went to a lawyer for help with a problem?

(b) When was the last time?

(c) Are you seeing a lawyer now about a/that problein?

11. (a) What were-the problems that you took to a lawyer?

(b) How did you find out about the lawyer you went to that time?

(c) Did he take your case, that is, did he do solnething for you or say he would do soinething?

(d) What reason did he give for not taking your case?

(e) Do you think that he did everything that he could do to help you or could he have done more? 
(f) Do you think that you were better off or worse off after going to the lawyer, or do you think you were about the same?

12. How much did the lawyer charge for this problem?

13. (a) Have you or any member of your family ever had any problems you would have liked to have taken to a lawyer?

(b) How many problems like this have you had?

(c) What were these problems?

(d) Why didn't you take these problems to a lawyer?

14. (a) Have you ever heard of the Welfare Department?

(1) Have you ever contacted them for help?

(2) At the Welfare Department do you

(i) decide who can get welfare?

(ii) give advice to people about their families?

(iii) give advice to public officials?

(b) Have you ever heard of the Better Business Bureau?

(1) Have you ever contacted them for help?

(2) At the Better Business Bureau, do they

(i) give advice to people who want to start business?

(ii) give information to people who want to make sure they buy froin honest sellers?

(iii) listen to complaints by people who think they were cheated when they bought something?

(c) Have you ever heard about Planned Parenthood or Birth Control?

(1) Where can you get informatiour about it?

(d) Have you ever heard of public housing or a Regional Housing Authority?

(1) Have you ever tried to get this kind of help?

(e) Have you ever heard of Aid to Dependent Children?

(1) Have you ever tried to get this aid?

(2) Does Aid to Dependent Children give medical care to sick children?

Does it give people money to pay for medical care for children if they cannot pay themselves?

Place abandoned children in foster hownes?

(f) Have you ever heard of counsel for indigent defendants or appointed counsel?

(1) Have you ever tried to get this kind of help?

(2) Do appoiuted counsel or counsel for indigent defendants help people accused of crimes?

Provide lawyers for people accused of crimes who can't afford to pay a lawyer? 
(g) Have you ever heard of the County Bar Association?

(1) Have you ever contacted them for help?

(2) Will the County Bar Association

(i) tell people where they can get a lawyer?

(ii) give people legal advice?

(iii) help lawyers look up the law?

(h) Have you ever heard of the County Extension Chairman or County Agent?

(1) Have you ever contacted him?

(2) Does he

(i) advise farmers on good ways to farm?

(ii) sell farm equipment?

(iii) buy crops?

(i) Have you ever heard of surplus food?

(1) Have you ever tried to get this aid?

a. Did you receive aid?

b. Why were you demied aid?

(2) Is surplus food

(i) free food for people who need it?

(ii) left over food the farmers sell to people?

(iii) food for farm animals?

(j) Have you ever heard of the Health Department?

(1) Have you ever gone there for aid?

a. Did you receive aid?

b. Why were you denied aid?

(2) At the Health Department do they

(i) give free shots?

(ii) give free care to babies?

(iii) have free doctors for sick people?

(k) Have you ever heard of the Farmers' Home Administration (FHA)?

(1) Have you ever gone there for aid?

a. Did you receive aid?

b. Why were you turned down?

(2) Does the FHA

(i) loan money to build or fix up homes?

(ii) give advice on crops?

(iii) buy crops from farmers?

(1) Have you ever heard of the OEO?

(1) Have you ever gone to them for aid?

a. Did you receive it? 

b. Why not?
(2) Does the OEO
i. Send young children to school?
ii. Help you to get benefits?
iii. Give jobs to young people?

(m) Have you ever heard of Community Workers?

(1) Have you ever gone to them for aid?

a. Did you receive it?

b. Why not?

\section{Part III - Concrete Problems}

1. Are you actively employed full time now?
(a) Have you ever been employed?
(b) What do (did) you do for a living?
(c) How long have you been (or were you) doing that?
(d) What else have you done for a living?

2. Have you ever been injured while working?

(a) Did you apply for workmen's compensation?

(b) Were you turned down for compensation when you thought you shouldn't have been?

(c) How many times has this happened, i.e., how many times have you been turned down for compensation for injury on the job?

(d) When did this (these) happen?

(e) Why were you turned down?

(f) Did you try to do anything about it or did you decide to accept what happened?

(1) Briefly, what did you do?

(g) Did you speak to anyone at all for advice or help?

(h) Why didn't you do anything about this?

3. Have you ever had trouble collecting your pay froin an employer? (In answering this question, don't count any time your employer had to hold up your wages because they were garnished or attached for a creditor.)
(a) How many times lias this happened?
(b) When did this (these) happen?
(c) Why did you have trouble collecting your pay?
(d) Did you try to do anything about it or did you decide to accept what happened?
(e) Did you speak to anyone at all for advice or help?
(f) Why didn't you do anything about this? 
4. (a) Are you presently receiving any unemployment, retirement, veterans benefits or social security benefits?

(1) Which kind of benefits?

(b) Have you ever received any (other) unemployment, retirement, veterans benefits or social security benefits in the past?

(1) Which kind of benefits?

(c) Have you ever applied for any unemployment, retirement; veterans benefits or social security benefits?

5. Was your benefit check ever held up when you thought it shouldn't have been?

(a) How many times has this happened?

(b) When did this (these) happen?

(c) What were the reasons why your benefit check was held up?

(1) How did you find out why your benefits were held up?

(d) Did you try to do anything about it or did you decide to accept what happened?

(1) Briefly, what did you do?

(e) Did you speak to anyone at all for advice or help?

(f) Why didn't you do anything about this?

6. Was the amount of your benefits ever cut to a lower amount when you thought it shouldn't have been?

(a) How many times has this happened?

(b) When did this (these) happen? Ask subject to specify type of benefit and year and month when amount cut, for each.

(c) What were the reasons why the amount of your benefits was cut? (1) How did you find out?

(d) Did you try to do anything about it or did you decide to accept what happened?

(1) Briefly, what did you do?

(e) Did you speak to anyone at all for advice or help?

(f) Why didn't you do anything about this?

7. Were your benefits ever completely cut off when you thought they shouldn't have been?

(a) How many times has this happened?

(b) When did this (these) happen?

(c) What were the reasons why your benefits were cut off?

(1) How did you find this out?

(d) Did you try to do anything about it or did you decide to accept what happened?

(1) Briefly, what did you do?

(e) Did you speak to anyone at all for advice or help? 
(f) Why didn't you do anything about this?

8. Were you ever turned down when you applied for unemployment, retirement, veterans benefits or social security benefits when you thought you shouldn't have been?

(a) How many times has this happened?

(b) When did this (these) happen?

(c) What were the reasons why you were turned down?

(1) How did you find this out?

(d) Did you try to do anything about it or did you decide to accept what happened?

(1) Briefly, what did you do?

(e) Did you speak to anyone at all for advice or help?

(f) Why did you do nothing about this?

9. (a) Are you presently receiving any kind of public welfare assistance, that is, anything like Old Age Assistance, Aid to Disabled, or AFDC (Aid to Families with Dependent Children)?

(1) What kind of welfare?

(b) (1) Have you ever received any (other) kind of public welfare in the past; that is, anything like Aid to Disabled, Old Age Assistance, or AFDC (Aid to Families with Dependent Children)?

(2) What kind of welfare?

(c) Have you ever applied for any kind of public welfare?

10. Was your welfare check ever held up when you thought it shouldn't have been? (The following series of probes were repeated after questions marked (1.), but are deleted from this appendix because of length.)

(a) How unany times has this happened?

(b) When did this (these) happen?

(c) Were you told why the welfare check was being held back?

(1) Were you told what the reasons were before or after the the check was held up?

(2) What reasons were given to you?

(3) Why do you think the check was being held up?

(d) Did you try to do anything at all about this or did you decide to accept what happened (and what they said)?

(e) What did you do?

(f) Did you speak to anyone at all for advice or help?

(1) Why did you talk to

(2) What did ? do or tell you to do?

(g) Why didn't you do anything about this? 
11. Was the amount of your welfare ever cut to a lower amount when you thought it shouldn't have been? (1.)

12. Have you ever been turned down when you applied for welfare when you thought you shouldn't have been turned down? (1.)

13. Have you ever bought something which you paid for in cash or on the lay-away plan, and when you got it, you found that it was not the same item you saw or it was in bad condition?

(a) How many times has this happened?

(b) When did this (these) happen?

(c) What did you buy?

(1) What was the price?

(2) Who did you buy it from?

(d) Did you try to do anything at all about this or did you decide to accept the thing as it was and not do anything?

(e) What did you do?

(f) Did you speak to anyone at all for advice or help?

14. Have you ever bought anything on credit and agreed to pay for it in installments?

15. Have you ever borrowed money from anyone or anywhere, such as a bank, finance company, or credit union, and agreed to pay it back in installments?

16. Have you ever bought soniething on the installnient plan, that is, paying for it on time, and, when you got it, found that it was not the same iten you saw or it was in bad condition? (The following series of probes were repeated after questions inarked (2.), but are deleted from this appendix because of length.)

(a) How many times has this happened?

(b) When did this (these) happen?

(c) What did you buy?

(1) How much was the price?

(2) Whon did you buy it from?

(d) Did you try to do anything at all about this or did you decide to accept the thing as it was and make the payments?

(e) What did you do?

(1) Was the item repossessed?

(2) Was anything else you owned taken away?

(3) Were any of your wages held back?

(i) Did you taik to your employer (that is; your immediate boss, your supervisor, or the payinaster) when your wages were held back?

(ii) Did you see anyone else at work about this problem? 
(4) Did the seller or sales finance company take the case to court?

(f) Did you speak to anyone at all for advice or help?

(g) Why didn't you do anything about this?

17. Did you ever think you were renting an item, such as a freezer or tractor, or using it on a trial basis and found out later that you actually had signed a contract to buy the item on time? (2.)

18. Did you ever buy anything on time or sign up for something like insurance, training school, home repairs, dental work or any other services on an installment plan and you couldn't make the payments as they became due? (2.)

19. Did you ever make a crop loan or borrow money from a bank, loan company, finance company, landlord or someone like that and then were unable to repay it as you had agreed? (The following series of probes were repeated after questions marked (3.) but are deleted from this appendix because of length.)

(a) How many times has this happened?

(b) When did this (these) happen?

(c) What did you borrow the money for?

(1) How inuch did you borrow?

(2) How much did you have left to pay?

(3) Who did you borrow the money from; e.g., bank, finance company?

(d) What, if anything, did you do?

(e) What happened then?

(1) Was any item(s) you owned taken away?

(2) Were any of your wages held back?

(i) Did you see anyone else at work for help?

(3) Did the people you owed the money to take the case to court?

(f) Did you speak to anyone at all for advice or help?

(1) Why did you talk to ?

(2) What did tell you to do?

(g) Why didn't you do anything about this?

20. Did you ever inake a crop loan or borrow money from a bank, loan company, finance company, landlord, or someone like that, and, after you started to pay, you were told you owed more money than you believed you did? (3.)

21. Have you ever lad inore bills, imcluding your rent and installment payments, than you could possibly ever pay, and you kept falling further behind? 
(a) Did you ever do anything about it?

(b) How many times did you do anything?

(c) When was this?

(d) Generally, what kind of bills and debts were they; that is, what were they for? For example, I mean things like rent, inedical bills, autoinobile repair, crop loan, etc.

(1) Approximately how inuch did these bills add up to?

(e) What did you do about this?

(f) Did you speak to anyone at all for advice or help?

(1) Why did you talk to

(2) What did ? do or tell you to do?

(g) Why didn't you ever do anything about this?

22. (a) Have you ever been in small claims court?

(1) Did you have a lawyer?

(2) Was a judgment entered against you; that is, did you loose the case?

(3) Did you understand what was going on?

(b) Have you ever had a judgment entered against you; that is, have you ever lost a court case when you did not personally go to court or have a lawyer go for you?

23. (a) Code whether area is racially integrated.

(b) How long have you lived in this area of the country?

(c). Where did you live before you came here?

(d) How many times have you moved in the past two years?

(e) Where did you live most of the time while you were growing up?

(f) Where were you born?

(1) Where were your parents born?

(g) When were you born?

24. (a) How long have you lived in this house/apartment?

(b) Before you came to live in this apartment/house, did you ever live in public housing?

25. (a) Is there any way people could get public housing around here if they want it?

(b) Have you ever applied for public housing?

(c) Have you ever been turned down for public housing when you thought you should not have been?

(There was no pubhic housing in the county, but some projects did exist in adjoining counties, so information regarding them was probed.)

26. Are you renting this place? Under what circumstances?

27. Before you moved here, did you ever rent any place you lived in? 
28. Has a landlord ever refused to provide a service, fix something, or do anything he was supposed to in a house, apartment, or flat you were renting? Suggest as examples, if necessary, broken plumbing, no heat, rats, dirty conditions, etc.

(a) How many times has this happened?

(b) When did this (these) happen?

(c) What was the problem the last time this happened?

(d) What, if anything, did you do?

(e) Did you speak to anyone at all for advice or help?

(1) Why did you talk to ?

(2) What did do or tell you to do?

(f) Why didn't you do anything about this?

29. Has the landlord of any house, apartment or flat you were renting ever tried to evict you; that is, did he try to put you out?

(a) How many times has this happened?

(b) When did this (these) happen?

(c) What kind of rental arrangement did you have; that is, no lease at all, a month to month lease, a year's lease, or soine other kind of lease?

(d) Why did he want to evict you?

(e) Did you owe him any back rent at the time he wanted to evict you?

(f) Did you try to do anything at all about being evicted?

(g) What did you do?

(h) Did the landlord try to keep any of your things?

(1) Were any of your wages held back?

(2) Did you talk to your employer (that is, your immediate boss, your supervisor, or the paynaster) when your wages were held back?

(3) Did you see anyone else at work for help?

(i) Did you speak to anyone at all for advice or help?

(1) Why did you talk to

(2) What did do or tell you to do?

(j) Why didn't you do anything about this?

30. (a) Did you ever buy a house or land and pay cash for it?

(1) How many houses have you bought for cash?

(2) When did you buy that house (those houses)?

(3) Did you speak to anyone at all for advice or help when you were arranging to buy the house (in

(i) Why did you talk to ?

(ii) What did do or tell you to do? 
(b) Have you ever arranged to buy a house or land by obtaining a mortgage or by agreeing to pay for it in installments, such as monthly payments?

(1) How many houses or land have you arranged to purchase in this way; that is, with a mortgage or installment payment arrangement?

(2) When did you make the arrangement to purchase that house (those houses) or land?

(3) Did you speak to anyone at all for advice or help when you were arranging the purchase, the mortgage, or the installment payments?

(i) Why did you talk to ?

(ii) What did do or tell you to do?

(c) Were you ever unable to make mortgage or installment payments on that (any) house as they became due?

(1) How many times did this happen?

(2) When did this (these) happen?

(3) What, if anything, did you do?

(4) What happened then?

(5) Did you speak to anyone at all for advice or help?

(i) Why did you talk to ?

(ii) What did do or tell you to do?

. (6) Why didn't you do anything about this?

(d) Were you ever unable to repay a crop loan when it was due?

(1) How many times did this happen?

(2) When did this (these) happen?

(3) What, if anything, did you do?

31. Have you ever been married?

(a) How many times have you been married?

(b) What is your present marital status?

(c) Were you ever divorced?

(1) Was this divorce in court or not?

(d) How many times have you been divorced?

(e) When were you divorced?

(f) Did you get the divorce; that is, did you sue for divorce or did your husband/wife sue?

(1) Did you have a lawyer representing you in the divorce suit?

(2) Did your husband/wife have a lawyer representing him/ her in the divorce suit?

32. How many children do you have?

(a) Starting with the oldest, what is each child's age? 
(b) How many of your children are presently living with you?

33. Besides your husband/wife and your children, are there any (other) persons presently living with you that you help to support?

34. (a) How long have you and your husband/wife been separated?

(b) Have you tried to do anything at all about this separation or have you done nothing?

(c) What did you do?

(d) Did you speak to anyone at all for advice or help?

(e) Why liaven't you done anything about this?

35. Did you ever have the responsibility of taking care of any of your children after you were divorced from their father?

(a) Did the court order their father to pay support for your children?

(b) What, if anything, have you done to get your former lusband to pay support for your children?

(c) Did you speak to anyone at all for advice or help about getting support?

(d) Why didn't you do anything about this?

(e) Have you ever had any difficulty collecting the support payments?

(1) When after getting the divorce did the problem of receiving support begin?

(2) What, if anything, did you do about this?

(3) What happened then?

(4) Did you speak to anyone at all for advice or help?

(5) Why didn't you do anything about this?

36. Have you had the responsibility of taking care of your children at any time since you were separated from their father?

(a) Do you receive or were you ever supposed to receive money from your husband to support those children?

(b) What, if anything, have you done to get him to pay support?

(c) Did you speak to anyone for advice or help about getting support?

(d) Why didn't you do anything about this?

(e) What kind of arrangeinent do you or did you have? For example, what the arrangement an informal agreement that you and he had, was it a court order, or was there no arrangement and he just paid you on his own, etc.?

(f) How did it coine about that this was the support arrangement you and he had?

(g) Did you speak to anyone for advice or help in making this arrangment?

(h) Have you ever had difficulty collecting the support payments with this arrangement? 
(1) When did the problem of receiving support begin?

(2) What, if anything, did you do about this?

(3) What happened then?

(4) Did you speak to anyone at all for advice or help?

(5) Why didn't you do anything about this?

37. Do you have any children other than those by your present husband or any previous husband?

38. Do you receive or are you supposed to receive support payment (a) for your youngest child, (b) for the youngest of these children from his/her father. (Probes from Question 36 were repeated here.)

39. Question 39 apphies to all males.

Did a court ever order you to pay support for any child?

(a) How many times have you been ordered by a court to pay support?

(b) Were you always able to make the payments ordered?

(c) How many times were you unable to make payments?

(d) When was the last time this happened?

(e) What, if anything, did you do about this?

(f) What happened then?

(g) Did you speak to anyone at all for advice or help?

(h) Why didn't you do anything about this?

40. Have any of your children ever been in any kind of trouble with the school authorities or with the law?

(a) How many of your children has this ever happened to?

(b) How many times did it happen for each of them?

(c) When did this happen most recently?

(d) What kind of trouble was it and with whom?

(e) What, if anything, did you do about it?

(f) Did you speak to anyone at all for advice or help?

(g) Why didn't you do anything about this?

(h) Is there anytime during the regular school year when the school allows your children to stay home?

41. Have any of your children ever been taken away from you?

(a) How many times has this happened?

(b) Who took the child away?

(c) What, if anything, did you do about it?

(d) Did you speak to anyone at all for advice or help?

42. Have you ever been the victim of a crime, for example, someone robbing you?

(a) How many times has this happened?

(b) What happened to you? 
(c) What, if anything, did you do about it?

(d) Did you speak to anyone at all for advice or help?

43. Have you ever been accused of a crime?

(a) How many times has this happened?

(b) When did this (these) happen?

(c) What was the crime you were accused of?

(d) What happened to you?

(e) What, if anything, did you do about it?

(f) Did you speak to anyone at all for advice or help?

(g) Why didn't you do anything about this?

44. Have you ever been required to post a peace bond?

(a) What were you accused of?

(b) What happened to you?

(c) What, if anything, did you do about it?

(d) Did you speak to anyone at all for advice or help?

(e) Why didn't you do anything about this?

45. Were you ever told you would lose your driver's license or license plates because of an accident or because you didn't have insurance?

(a) How many times has this happened?

(b) When did this (these) happen?

(c) What happened to you?

(d) What, if anything, did you do about it?

(e) Did you speak to anyone at all for advice or help?

(f) Why didn't you do anything about this?

46. Did an insurance company ever refuse to pay you when your car had wrecked?

(a) How many times has this happened?

(b) When did this (these) happen?

Part IV-Background

1. Sex: (by observation only)

2. Race: (by observation only)

3. How far did you get in school?

4. How far did your husband/wife get in school?

5. What does he/she do for a living?

6. Is he/she actively employed full time now?

7. Whom did you live with most of the time while you were growing up, that is, until you were 18 ?

8. How far did your father get in school?

9. What did your father do for a living?

10. What is your religion? 
(a) How often do you attend church services?

(b) How far do you have to go to get to church?

(c) Do you attend any other activities at your church, besides services, on a regular basis?

(1) What are these activities?

11. When was the last time you voted in a public election?

12. What organizations do you belong to?

(a) What do you do in this (these) organizations(s)?

(b) How active are you in this (these) organization(s)?

13. (a) Are inany members of your family (including sisters, brothers, cousins, aunts, uncles, etc.) living in this area, that is, within 20 miles of here?

(b) Do you see them often?

Personality and attitude probes are also omitted. 